\title{
Anxiety and depression in Parkinson's disease
}

Citation for published version (APA):

Broen, M. M. P. G. (2016). Anxiety and depression in Parkinson's disease. [Doctoral Thesis, Maastricht University]. Datawyse / Universitaire Pers Maastricht. https://doi.org/10.26481/dis.20161202mb

Document status and date:

Published: 01/01/2016

DOI:

10.26481/dis.20161202mb

Document Version:

Publisher's PDF, also known as Version of record

\section{Please check the document version of this publication:}

- A submitted manuscript is the version of the article upon submission and before peer-review. There can be important differences between the submitted version and the official published version of record.

People interested in the research are advised to contact the author for the final version of the publication, or visit the DOI to the publisher's website.

- The final author version and the galley proof are versions of the publication after peer review.

- The final published version features the final layout of the paper including the volume, issue and page numbers.

Link to publication

\footnotetext{
General rights rights.

- You may freely distribute the URL identifying the publication in the public portal. please follow below link for the End User Agreement:

www.umlib.nl/taverne-license

Take down policy

If you believe that this document breaches copyright please contact us at:

repository@maastrichtuniversity.nl

providing details and we will investigate your claim.
}

Copyright and moral rights for the publications made accessible in the public portal are retained by the authors and/or other copyright owners and it is a condition of accessing publications that users recognise and abide by the legal requirements associated with these

- Users may download and print one copy of any publication from the public portal for the purpose of private study or research.

- You may not further distribute the material or use it for any profit-making activity or commercial gain

If the publication is distributed under the terms of Article $25 \mathrm{fa}$ of the Dutch Copyright Act, indicated by the "Taverne" license above, 


$$
\begin{gathered}
\text { ANXIETY } \\
\text { AND } \\
\text { DEPRESSION } \\
\text { IN }
\end{gathered}
$$

PARKINSON'S DISEASE

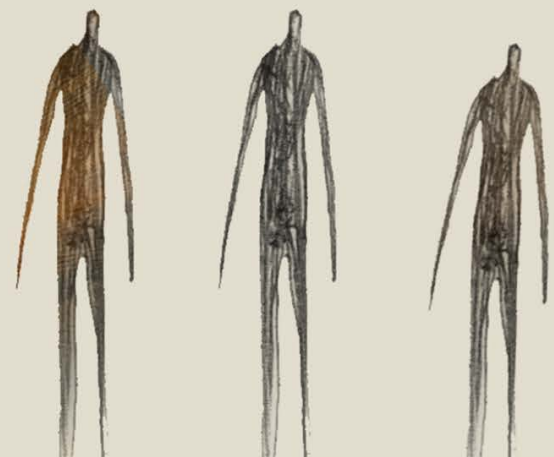

Martijn P. G. Broen 
ISBN nr: 9789461596192

Print: Datawyse | Universitaire Pers Maastricht

Copyright: M. Broen, Maastricht 2016

The publication of this thesis was kindly supported by Abbvie and the Parkinson Vereniging. 


\section{ANXIETY AND DEPRESSION IN PARKINSON'S DISEASE}

\section{PROEFSCHRIFT}

ter verkrijging van de graad van doctor aan de Universiteit Maastricht, op gezag van de Rector Magnificus, prof. dr. Rianne M. Letschert volgens het besluit van het College van Decanen,

in het openbaar te verdedigen op vrijdag 2 december 2016 om 14.00 uur

door

Martinus Petrus Gertrudis Broen 


\section{Promotor}

Prof. dr. R.J. van Oostenbrugge

\section{Co-promotor}

Dr. A.F.G. Leentjens

Dr. M.L. Kuijf

\section{Beoordelingscommissie}

Prof. dr. F.R.J. Verhey (Voorzitter)

Prof. dr. H.W. Berendse (VUmc, Amsterdam)

Dr. P.H.M.F. van Domburg (Zuyderland MC)

Prof. dr. F.P.M.L. Peeters

Dr. M.E. de Vugt 
Aan mijn moeder... 



\section{Table of contents}

Chapter $1 \quad$ General introduction 9

Chapter 2 Prevalence of anxiety in Parkinson's disease:

A systematic review and meta-analysis.

(Movement Disorders, 2016)

Chapter 3 Modeling anxiety in Parkinson's disease.

(Movement Disorders, 2016)

Chapter 4 Factor analysis of the Hamilton Depression Rating Scale in Parkinson's disease.

(Parkinsonism and Related Disorders, 2015)

Chapter 5 Trajectories of recovery in depressed Parkinson's disease patients treated with paroxetine or venlafaxine.

(Parkinsonism and Related Disorders, 2016)

Chapter 6 Unraveling the Relationship between Motor Symptoms,

Affective States and Contextual Factors in Parkinson's Disease:

A Feasibility Study of the Experience Sampling Method.

(PLoS One, 2016)

Chapter 7 General Discussion

Nederlandse samenvatting

Knowledge valorisation

Additional files

- List of publications

- Dankwoord/ Acknowledgments

- Curriculum vitae 



\section{Chapter 1}

GENERAL INTRODUCTION 


\subsection{PARKINSON'S DISEASE}

\subsubsection{History}

The first formal description of "Parkinson's disease" dates back to 1817 (1) when James Parkinson published his monograph "An Essay on the Shaking Palsy" in which he described six patients with an insidious onset of progressive symptoms, including a tremulous motion and a shuffling gait, propensity to bend the trunk forward, general slowness, soft speech and "saliva trickling from the mouth". However, he also acknowledged that there were notifications of a similar tremulous disease a long time before his observations. For example, ancient medical documents with descriptions resembling the shaking palsy's symptoms dates back as far as the Neosumerian period (2012-2004 BC). Galen of Pergamon (129-200 AD) wrote a book called "De Tremore, Palpitatione, Convulsione et Rigore" in which he seem to distinguish resting ("palpitatione") from intentional tremor ("tremore") (2). Although James Parkinson described mostly motor features of the disease, he did mention some non-motor features like disturbed sleep and "torpid bowels" but stated that the senses and intellects were not affected (1). Rigidity was later described by Charcot in 1872 and he proposed to call this disease Parkinson's disease (3). For a long time, research mainly focused on the complexity of motor symptoms in $\mathrm{PD}$, but the last two to three decades there is increasing awareness of the importance of non-motor symptoms, like anxiety and depression, and their impact on the quality of life of PD patients $(4,5)$.

\subsubsection{Epidemiology}

At present, Parkinson's disease is the second most common neurodegenerative disease, after Alzheimer disease (6). The prevalence of PD in industrialized countries is estimated at $0.3 \%$ of the entire population and about $1 \%$ in people over 60 years of age. Incidence rises steeply with age; 17.4 in 100000 persons years between 50 and 59 to 93.1 in 100 000 person years between 70 and 79 years (6-8). Mean age at onset is approximately 60 years. Importantly, it is expected that due to the ageing population prevalence and incidence will increase, together with its social and economic burden.

\subsubsection{Etiology and pathogenesis}

Although the exact cause of PD is still not known, it is generally accepted that it has a multifactorial origin in which environmental $(9,10)$ and genetic factors $(11,12)$ eventually lead to mitochondrial dysfunction, disturbance of proteolysis, protein aggregation and neuro-inflammation, which are all important pathogenic factors for PD $(13,14)$. The pathological hallmark is the selective loss of dopaminergic neurons from the pars compacta of the substantia nigra, an anatomical structure located in the midbrain. It is estimated that at time of appearance of motor signs about $30 \%$ of total substantia nigra neurons is already lost (15). The cell loss is accompanied by intraneural inclusi- 
ons, mainly Lewy bodies that are composed principally of $\alpha$-synuclein aggregates. In addition to the dopaminergic neuronal cell loss, there is also loss of the serotonergic, noradrenergic and acetylcholinergic neurons, which may explain the variation of motor and non-motor symptoms in PD $(8,15)$.

\subsubsection{Symptomatology}

The four cardinal motor features, upon which the diagnosis of PD is currently based, include bradykinesia, muscle rigidity, resting tremor and postural instability (16). However, PD also encompasses a wide range of non-motor symptoms: neuropsychiatric disturbances, such as depression, anxiety, and hallucinations), autonomic disturbances, such as constipation, orthostatic hypotension, and bladder disturbances), sensory disturbances, such as pain, olfactory loss, sleep disorders including vivid dreaming and REM-sleep disorders, and cognitive disturbances such as executive dysfunction and dementia $(5,17,18)$. These Non-motor symptoms can develop at all stages of PD, although some symptoms such as olfactory dysfunction and constipation are considered prodromal signs of PD (19). Non-motor symptoms are increasingly recognized as an important part of the clinical spectrum of PD, and a significant cause of disability and poor quality of life in PD patients (4).

\subsubsection{Treatment}

There are currently no treatments that cure PD nor treatments with a proven neuroprotective effect which can slow down or stop progression of the disease (20). However, there are a number of symptomatic therapeutic options, mainly targeting motor symptoms that work by correcting the central dopaminergic deficit. Levodopa, a precursor of dopamine, is the most effective and currently the gold standard for treating motor symptoms in PD, followed by dopamine agonists. Catechol-O-methyltransferase (COMT) inhibitors and monoamine oxidase B (MAO-B) inhibitors have been developed to provide more continuous oral delivery of dopaminergic stimulation, especially in patients with motor fluctuations. In some cases, the anti-NMDA receptor antagonist amantadine can be useful in targeting motor symptoms (20-22). In more advanced cases, neurosurgical interventions such as deep brain stimulation (DBS) and continuous dopamine replacement pump therapies such as subcutaneous apomorphine or levodo$\mathrm{pa} /$ carbidopa intestinal gel can be indicated to alleviate disabling motor symptoms (23, 24). Despite their importance for patients' quality of life, evidence based treatment is sparse for non-motor symptoms (25). Although non-motor symptoms can be dopamine responsive by replacement therapy to some extent, for several indications, like anxiety disorders, orthostatic hypotension or urinary dysfunction there is a lack of suitable interventions at the moment $(19,26)$. In addition to pharmacologic treatment, patients can benefit from physical therapy, speech therapy, occupational therapy or cognitive behavioral therapy (27-31). 


\section{$1.2 \quad$ ANXIETY AND DEPRESSION IN PARKINSON'S DISEASE}

\subsubsection{Neuropsychiatric disturbances in PD}

Neuropsychiatric symptoms are the most frequent non-motor symptoms and occur in up to $67 \%$ of PD patients (4). The most common and most important non-motor features are depression, anxiety, apathy, fatigue, impulse control disorders, dopamine dysregulation syndrome and psychosis, which all have a negative effect on quality of life (4, 32-34). Among those, mood and anxiety disorders are both frequent and disabling (35). Mood disorders encompasses a group of symptoms in which the person's mood is the underlying feature, including major depressive disorder, dysthymic disorder and bipolar disorders (36). Together with disturbances in affect, e.g. anxiety disorders, they have a detrimental influence on patient's life, contributing to motor symptoms, motor complications, gait difficulties, cognitive impairment, poor self-perceived health status and even increased mortality (37-40). In addition, anxiety and depression commonly co-occur in PD (41-43).

\subsubsection{Depression in Parkinson's disease}

It is thought that depressive symptoms are the most common neuropsychiatric feature associated with Parkinson's disease (44). A thorough systematic review found a weighted prevalence of $17 \%$ major depressive disorder in PD patients, $22 \%$ minor depression and $13 \%$ dysthymia, according to DSM criteria. Up to $35 \%$ have clinically relevant depressive symptoms (45). It is a syndrome characterized by persistent sadness or anhedonia, with a range of cognitive and vital (physical) symptoms (36). Despite extensive research, there is still discussion about the optimal treatment strategy of depression in PD (46), but a large randomized, placebo controlled clinical trial found that both paroxetine and venlafaxine were more effective than placebo for the treatment of depressive symptoms in PD (47). Additionally, there is some evidence for the use of nortriptyline, citalopram and cognitive-behavioral therapy in depressed PD patients (48-50). Depressive disorders in PD develop in the context of multiple interacting risk and protective factors and are believed to affect dopaminergic, serotonergic and noradrenergic systems (51). A recent model of depression in PD showed that nonspecific factors (female sex, history of anxiety and/or depression, family history of depression, worse functioning on activity of daily living and worse cognitive status) might be more prominent markers of depression than PD-specific factors (increased disease duration, more severe motor symptoms and the use of levodopa) (52). It may be that PD patients that become depressed are those that already have a number of general risk factors for depression, that are not related to PD.

Currently, depression is most commonly defined by the criteria of the DSM. A wide range of rating scales are available for screening or quantification of symptoms, among 
which the Beck Depression Inventory (BDI), Hamilton Depression Scale (HAMD), Hospital Anxiety and Depression Scale (HADS), Zung Self-Rating Depression Scale (SDS), Geriatric Depression scale (GDS) and Montgomery-Asberg Depression Rating Scale (MADRS) (53). However, up to $65 \%$ of depressive disorders remain undetected and untreated in PD (54). A possible explanation is the symptom overlap between PD and depression, for example fatigue, agitation, impaired concentration and insomnia are seen in both depression and PD. In addition, reliability and validity differ between rating scales (53) and some question the use of DSM criteria in depressed PD patients (55). As previously stated, depression has a negative impact on disability and quality of life but also negatively influence medication adherence (56). Improving detection and, when antidepressant treatment is initiated, improving treatment compliance could possibly increase quality of life and alleviate functional impairment in PD patients.

\subsubsection{Anxiety in Parkinson's disease}

Non-motor symptom research in PD has predominantly focused on depressive disorders. Although anxiety syndromes seem to be common in PD, they have not been extensively studied (57). Prevalence rates of anxiety vary widely between 25 to $65 \%$ (38, 40,42 ). Next to clinically relevant anxiety symptoms assessed by rating scales, anxiety disorders are classified by the DSM criteria. They include generalized anxiety disorder (GAD), panic disorder, agoraphobia, obsessive-compulsive disorder (OCD), social or specific phobia, posttraumatic stress disorder (PTSS), and anxiety not otherwise specified (NOS) (36). The latter category is often used to describe significant anxiety that do not meet criteria for a standard DSM anxiety disorder. Anxiety disorders contribute to cognitive impairment and increased severity of motor symptoms such as on/off fluctuations or freezing episodes $(38,40,41,58)$. Anxiety also has a negative impact on quality of life, some state even more so than depression $(39,40)$. Currently, there is a paucity of treatment data for anxiety in PD and treatments include benzodiazepines, SSRI's or cognitive and behavioral therapies (59). The relationship between anxiety and PD is not well understood but likely involves dopaminergic, noradrenergic and serotonergic neurotransmitter systems (57). As for depression and anxiety in the general population, anxiety disorders in PD develop in the context of multiple interacting risk and protective factors. Although some PD-specific risk factors for anxiety have been identified in some studies, including younger age of PD motor symptom onset, motor fluctuations, high dose of antiparkinsonian medication, longer disease duration and disease severity (41, 60-62), other studies found no significant associating between these variables and anxiety (42, 63-65). Only a few studies have investigated the role of general risk factors for PD, like female gender, younger age and a history of anxiety or depression $(41,42$, 65). 
As for depression, similar issues exist for anxiety in PD. It is often underdiagnosed and some studies have indicated that over half of the clinically significant anxiety cases are not recognized by clinicians $(66,67)$. In addition, frequent used anxiety rating scales are criticized and somatic symptoms of anxiety show overlap with those of PD, making identification of anxiety in PD difficult (68). Increased awareness and knowledge about the phenomenon of anxiety in PD is required to improve the accuracy of diagnosis, subsequent treatment and ultimately a better quality of life for PD patients.

\subsection{AIM AND OUTLINE OF THIS THESIS}

The main aim of this thesis was to investigate conceptual and clinical aspects of anxiety (Chapter 2 and 3) and depression (Chapter 4 and 5) in Parkinson's disease, alongside testing the feasibility of a new method (Chapter 6) to further unravel the complexity of these non-motor symptoms in the future.

Since there is no agreement on the prevalence of anxiety and anxiety in PD, in Chapter $\mathbf{2}$, we conduct a systematic review and meta-analysis to calculate an average point prevalence of DSM anxiety disorders and clinically relevant anxiety symptoms. In Chapter 3, a clinical model of anxiety in PD is proposed, implementing both non-PD and PD-specific risk factors and their relative contributions to the anxiety outcome.

In Chapter 4, we explored the multidimensionality of the Hamilton Depression Rating Scale (HAMD), the most common used measure of depressive symptoms, by conducting an exploratory factor analysis. Since education of depressed patients when starting antidepressants greatly improves compliance, we explored in Chapter 5 differential response patterns to treatment with venlafaxine or paroxetine in the affective, somatic and cognitive domains of depressed PD patients. Second, we studied the timing of the placebo response during a 12-week study period.

In Chapter $\mathbf{6}$ we investigated the feasibility of a new method to determine non-motor symptoms in daily life in PD: the Experience Sampling Method (ESM). This method assesses motor symptoms, affective states and contextual factors at random moments in the flow of daily life, using an application on a mobile device. ESM holds promises for future research to unravel the complex relationship between non-motor symptoms, like anxiety and depression, with motor symptoms and contextual influences. Finally, in Chapter 7 the most important findings of this thesis are reflected and the conceptual design of anxiety and depression in PD is discussed. 


\section{REFERENCES}

1. Parkinson J. An essay on the shaking palsy. 1817. J Neuropsychiatry Clin Neurosci. 2002;14(2):223-36; discussion 2.

2. Raudino F. The Parkinson disease before James Parkinson. Neurol Sci. 2012;33(4):945-8.

3. Charcot JM. De la paralysie agitante. In: Oeuvres Complètes ( $\mathrm{t}$ 1) Lecons sur les maladies du système nerveux Paris: A Delahaye; 1872 . p. 155-88.

4. Barone P, Antonini A, Colosimo C, Marconi R, Morgante L, Avarello TP, et al. The PRIAMO study: A multicenter assessment of nonmotor symptoms and their impact on quality of life in Parkinson's disease. Mov Disord. 2009;24(11):1641-9.

5. Chaudhuri KR, Healy DG, Schapira AH, National Institute for Clinical E. Non-motor symptoms of Parkinson's disease: diagnosis and management. Lancet Neurol. 2006;5(3):235-45.

6. de Lau LM, Breteler MM. Epidemiology of Parkinson's disease. Lancet Neurol. 2006;5(6):525-35.

7. de Rijk MC, Breteler MM, Graveland GA, Ott A, Grobbee DE, van der Meche FG, et al. Prevalence of Parkinson's disease in the elderly: the Rotterdam Study. Neurology. 1995;45(12):2143-6.

8. Lees AJ, Hardy J, Revesz T. Parkinson's disease. Lancet. 2009;373(9680):2055-66.

9. Burbulla LF, Kruger R. Converging environmental and genetic pathways in the pathogenesis of Parkinson's disease. J Neurol Sci. 2011;306(1-2):1-8.

10. Dick FD, De Palma G, Ahmadi A, Scott NW, Prescott GJ, Bennett J, et al. Environmental risk factors for Parkinson's disease and parkinsonism: the Geoparkinson study. Occup Environ Med. 2007;64(10):666-72.

11. Gasser T. Update on the genetics of Parkinson's disease. Mov Disord. 2007;22 Suppl 17:S343-50.

12. Verstraeten A, Theuns J, Van Broeckhoven C. Progress in unraveling the genetic etiology of Parkinson disease in a genomic era. Trends Genet. 2015;31(3):140-9.

13. Dawson TM, Dawson VL. Molecular pathways of neurodegeneration in Parkinson's disease. Science. 2003;302(5646):819-22.

14. Hirsch EC, Hunot S. Neuroinflammation in Parkinson's disease: a target for neuroprotection? Lancet Neurol. 2009;8(4):38297.

15. Cheng HC, Ulane CM, Burke RE. Clinical progression in Parkinson disease and the neurobiology of axons. Ann Neurol. 2010;67(6):715-25.

16. Jankovic J. Parkinson's disease: clinical features and diagnosis. J Neurol Neurosurg Psychiatry. 2008;79(4):368-76.

17. Lee HM, Koh SB. Many Faces of Parkinson's Disease: Non-Motor Symptoms of Parkinson's Disease. J Mov Disord. 2015;8(2):92-7.

18. Lim SY, Lang AE. The nonmotor symptoms of Parkinson's disease--an overview. Mov Disord. 2010;25 Suppl 1:S123-30.

19. Chaudhuri KR, Schapira AH. Non-motor symptoms of Parkinson's disease: dopaminergic pathophysiology and treatment. Lancet Neurol. 2009;8(5):464-74.

20. Sprenger F, Poewe W. Management of motor and non-motor symptoms in Parkinson's disease. CNS Drugs. 2013;27(4):259-72.

21. Clarke CE. Parkinson's disease. BMJ. 
2007;335(7617):441-5.

22. Rascol O, Lozano A, Stern M, Poewe W. Milestones in Parkinson's disease therapeutics. Mov Disord. 2011;26(6):1072-82.

23. Ossig C, Reichmann H. Treatment of Parkinson's disease in the advanced stage. J Neural Transm (Vienna). 2013;120(4):523-9.

24. Trenkwalder C, Chaudhuri KR, Garcia Ruiz PJ, LeWitt P, Katzenschlager R, Sixel-Doring F, et al. Expert Consensus Group report on the use of apomorphine in the treatment of Parkinson's disease--Clinical practice recommendations. Parkinsonism Relat Disord. 2015;21(9):1023-30.

25. Schrag A, Sauerbier A, Chaudhuri KR. New clinical trials for nonmotor manifestations of Parkinson's disease. Mov Disord. 2015;30(11):1490-504.

26. Seppi K, Weintraub D, Coelho M, Perez-Lloret S, Fox SH, Katzenschlager R, et al. The Movement Disorder Society Evidence-Based Medicine Review Update: Treatments for the non-motor symptoms of Parkinson's disease. Mov Disord. 2011;26 Suppl 3:S42-80.

27. Bloem BR, de Vries NM, Ebersbach G. Nonpharmacological treatments for patients with Parkinson's disease. Mov Disord. 2015;30(11):1504-20.

28. Herd CP, Tomlinson CL, Deane KH, Brady MC, Smith $\mathrm{CH}$, Sackley CM, et al. Speech and language therapy versus placebo or no intervention for speech problems in Parkinson's disease. Cochrane Database Syst Rev. 2012;8:CD002812.

29. Reynolds GO, Otto MW, Ellis TD, Cronin-Golomb A. The Therapeutic Potential of Exercise to Improve Mood, Cognition, and Sleep in Parkinson's Disease. Mov Di- sord. 2016;31(1):23-38.

30. Speelman AD, van de Warrenburg BP, van Nimwegen M, Petzinger GM, Munneke M, Bloem BR. How might physical activity benefit patients with Parkinson disease? Nat Rev Neurol. 2011;7(9):528-34.

31. Sturkenboom IH, Graff MJ, Borm GF, Veenhuizen Y, Bloem BR, Munneke M, et al. The impact of occupational therapy in Parkinson's disease: a randomized controlled feasibility study. Clin Rehabil. 2013;27(2):99-112.

32. Aarsland D, Larsen JP, Lim NG, Janvin C, Karlsen K, Tandberg E, et al. Range of neuropsychiatric disturbances in patients with Parkinson's disease. J Neurol Neurosurg Psychiatry. 1999;67(4):492-6.

33. Aarsland D, Marsh L, Schrag A. Neuropsychiatric symptoms in Parkinson's disease. Mov Disord. 2009;24(15):2175-86.

34. Gallagher DA, Schrag A. Psychosis, apathy, depression and anxiety in Parkinson's disease. Neurobiol Dis. 2012;46(3):581-9.

35. Tan LC. Mood disorders in Parkinson's disease. Parkinsonism Relat Disord. 2012;18 Suppl 1:S74-6.

36. Diagnostic and Statistical Manusal of Mental Disorders. Association AP, editor. Washington, DC: American Psychiatric Association; 1994.

37. Pachana NA, Egan SJ, Laidlaw K, Dissanayaka N, Byrne GJ, Brockman S, et al. Clinical issues in the treatment of anxiety and depression in older adults with Parkinson's disease. Mov Disord. 2013;28(14):1930-4.

38. Pontone GM, Williams JR, Anderson KE, Chase G, Goldstein SA, Grill S, et al. Prevalence of anxiety disorders and anxiety subtypes in patients with Parkinson's disease. Mov Disord. 2009;24(9):1333-8. 
39. Quelhas R, Costa M. Anxiety, depression, and quality of life in Parkinson's disease. J Neuropsychiatry Clin Neurosci. 2009;21(4):413-9.

40. Yamanishi T, Tachibana H, Oguru M, Matsui K, Toda K, Okuda B, et al. Anxiety and depression in patients with Parkinson's disease. Intern Med. 2013;52(5):539-45.

41. Dissanayaka NN, Sellbach A, Matheson S, O'Sullivan JD, Silburn PA, Byrne GJ, et al. Anxiety disorders in Parkinson's disease: prevalence and risk factors. Mov Disord. 2010;25(7):838-45.

42. Leentjens AF, Dujardin K, Marsh L, Martinez-Martin P, Richard IH, Starkstein SE. Symptomatology and markers of anxiety disorders in Parkinson's disease: a cross-sectional study. Mov Disord. 2011;26(3):48492.

43. Sagna A, Gallo JJ, Pontone GM. Systematic review of factors associated with depression and anxiety disorders among older adults with Parkinson's disease. Parkinsonism Relat Disord. 2014;20(7):708-15.

44. Marsh L, McDonald WM, Cummings J, Ravina B, Depression NNWGo, Parkinson's D. Provisional diagnostic criteria for depression in Parkinson's disease: report of an NINDS/NIMH Work Group. Mov Disord. 2006;21(2):148-58.

45. Reijnders JS, Ehrt U, Weber WE, Aarsland D, Leentjens AF. A systematic review of prevalence studies of depression in Parkinson's disease. Mov Disord. 2008;23(2):183-9; quiz 313.

46. Troeung L, Egan SJ, Gasson N. A meta-analysis of randomised placebo-controlled treatment trials for depression and anxiety in Parkinson's disease. PLoS One. 2013;8(11):e79510.
47. Richard IH, McDermott MP, Kurlan R, Lyness JM, Como PG, Pearson N, et al. A randomized, double-blind, placebo-controlled trial of antidepressants in Parkinson disease. Neurology. 2012;78(16):1229-36.

48. Devos D, Dujardin K, Poirot I, Moreau C, Cottencin O, Thomas P, et al. Comparison of desipramine and citalopram treatments for depression in Parkinson's disease: a double-blind, randomized, placebo-controlled study. Mov Disord. 2008;23(6):850-7.

49. Menza M, Dobkin RD, Marin H, Mark MH, Gara M, Buyske S, et al. A controlled trial of antidepressants in patients with Parkinson disease and depression. Neurology. 2009;72(10):886-92.

50. Dobkin RD, Menza M, Allen LA, Gara MA, Mark MH, Tiu J, et al. Cognitive-behavioral therapy for depression in Parkinson's disease: a randomized, controlled trial. Am J Psychiatry. 2011;168(10):106674.

51. Kano O, Ikeda K, Cridebring D, Takazawa T, Yoshii Y, Iwasaki Y. Neurobiology of depression and anxiety in Parkinson's disease. Parkinsons Dis. 2011;2011:143547.

52. Leentjens AF, Moonen AJ, Dujardin K, Marsh L, Martinez-Martin P, Richard IH, et al. Modeling depression in Parkinson disease: disease-specific and nonspecific risk factors. Neurology. 2013;81(12):1036-43.

53. Schrag A, Barone P, Brown RG, Leentjens AF, McDonald WM, Starkstein S, et al. Depression rating scales in Parkinson's disease: critique and recommendations. Mov Disord. 2007;22(8):1077-92.

54. Weintraub D, Moberg PJ, Duda JE, Katz IR, Stern MB. Recognition and treatment of depression in Parkinson's disease. J Geriatr Psychiatry Neurol. 2003;16(3):178-83. 
55. Leentjens AF. Depression in Parkinson's disease: conceptual issues and clinical challenges. J Geriatr Psychiatry Neurol. 2004;17(3):120-6.

56. Daley DJ, Myint PK, Gray RJ, Deane KH. Systematic review on factors associated with medication non-adherence in Parkinson's disease. Parkinsonism Relat Disord. 2012;18(10):1053-61.

57. Dissanayaka NN, White E, O'Sullivan JD, Marsh R, Pachana NA, Byrne GJ. The clinical spectrum of anxiety in Parkinson's disease. Mov Disord. 2014;29(8):967-75.

58. Henderson R, Kurlan R, Kersun JM, Como P. Preliminary examination of the comorbidity of anxiety and depression in Parkinson's disease. J Neuropsychiatry Clin Neurosci. 1992;4(3):257-64.

59. Chen JJ, Marsh L. Anxiety in Parkinson's disease: identification and management. Ther Adv Neurol Disord. 2014;7(1):52-9.

60. Burn DJ, Landau S, Hindle JV, Samuel M, Wilson KC, Hurt CS, et al. Parkinson's disease motor subtypes and mood. Mov Disord. 2012;27(3):379-86.

61. Kulisevsky J, Pagonabarraga J, Pascual-Sedano B, Garcia-Sanchez C, Gironell A, Trapecio Group S. Prevalence and correlates of neuropsychiatric symptoms in Parkinson's disease without dementia. Mov Disord. 2008;23(13):1889-96.

62. Maricle RA, Nutt JG, Carter JH. Mood and anxiety fluctuation in Parkinson's disease associated with levodopa infusion: preliminary findings. Mov Disord. 1995;10(3):329-32.

63. Kummer A, Cardoso F, Teixeira AL. Generalized anxiety disorder and the Hamilton Anxiety Rating Scale in Parkinson's disease. Arq Neuropsiquiatr. 2010;68(4):495-501.

64. Menza MA, Robertson-Hoffman DE,
Bonapace AS. Parkinson's disease and anxiety: comorbidity with depression. Biol Psychiatry. 1993;34(7):465-70.

65. Negre-Pages L, Grandjean H, Lapeyre-Mestre M, Montastruc JL, Fourrier A, Lepine JP, et al. Anxious and depressive symptoms in Parkinson's disease: the French cross-sectionnal DoPaMiP study. Mov Disord. 2010;25(2):157-66.

66. Hu M, Cooper J, Beamish R, Jones E, Butterworth R, Catterall L, et al. How well do we recognise non-motor symptoms in a British Parkinson's disease population? J Neurol. 2011;258(8):1513-7.

67. Shulman LM, Taback RL, Rabinstein AA, Weiner WJ. Non-recognition of depression and other non-motor symptoms in Parkinson's disease. Parkinsonism Relat Disord. 2002;8(3):193-7.

68. Leentjens AF, Dujardin K, Marsh L, Martinez-Martin P, Richard IH, Starkstein SE, et al. Anxiety rating scales in Parkinson's disease: critique and recommendations. Mov Disord. 2008;23(14):2015-25. 



\section{Chapter 2}

Prevalence of anxiety in Parkinson's disease: a systematic review and meta-analysis.

Broen MPG, Narayen NE, Kuijf ML, Dissanayaka NNW, Leentjens AFG. Mov Disord. 2016 Aug;31(8):1125-33. 


\section{ABSTRACT}

\section{Objective:}

Prevalence rates of anxiety disorders in Parkinson's disease vary widely, ranging from 6 up to $55 \%$. The aim of this systematic review was to calculate average point prevalence of anxiety disorders and clinically relevant anxiety symptoms in PD.

\section{Methods:}

Using PubMed, we carried out a systematic literature search for studies reporting DSM defined anxiety disorders or clinically relevant anxiety symptoms assessed by an anxiety rating scale.

\section{Results:}

A total of 49 articles were included and assessed for quality, 45 fulfilled the quality criteria. The average point prevalence of anxiety disorders in PD was 31\%, with non-episodic anxiety being more prevalent than episodic anxiety. Generalized anxiety disorder was the most frequent in $14 \%$, followed by social phobia $(13.8 \%)$, anxiety NOS $(13.3 \%)$ and specific phobia (13.0\%). Panic disorder with or without phobia was present in $6.8 \%$ of PD patients. Thirty-one percent (31\%) of patients fulfilled criteria for current multiple anxiety disorders. Based on anxiety rating scale cutoff scores, clinically significant anxiety symptoms were present in a weighted average of $25.7 \%$.

\section{Conclusion:}

This systematic review confirms that anxiety, although often unrecognized, is very common and highlights the need for efficient identification of anxiety in PD. 


\section{INTRODUCTION}

Parkinson's disease (PD) is a neurodegenerative disorder primarily characterized by motor symptoms; however non-motor symptoms such as anxiety and depression are common in PD. Anxiety disorders include generalized anxiety disorder (GAD), panic disorder, agoraphobia, obsessive-compulsive disorder (OCD), social or specific phobia and anxiety not otherwise specified (NOS)(1). They contribute to cognitive impairment, increased severity of motor symptoms such as on/off fluctuations or freezing episodes (2-4), and also have a negative impact on quality of life and self-perceived health status (5-7).

Although anxiety syndromes are common in PD, they have not been extensively studied. Research on mood disorders in PD has predominantly focused on depressive disorders. Prevalence rates of anxiety in PD that are reported in the literature vary widely. Up to $55 \%$ of PD patients experience substantial anxiety symptoms (8), and up to $40 \%$ have a circumscribed anxiety disorder as defined by the criteria of the Diagnostic and Statistical Manual (DSM) (9). Possible reasons for this variation include the nature of the population studied, the way the diagnosis is established, differences in the number of ascertained DSM diagnoses and the statistical measures used. Against this background, this systematic review aims to calculate an average point prevalence of DSM anxiety disorders and clinically relevant anxiety symptoms in PD.

\section{METHODS}

\section{Search strategy}

A systematic review (Figure 1, PRISMA flow chart) of research-based literature cataloged in PubMed, Medline and Cochrane library was performed. The entire time scale was used up to September $19^{\text {th }} 2015$. In order to include all existing literature on anxiety in PD, we only used the key terms: "anxiety" in combination with "Parkinson*". Articles with an abstract available and written in English, German, French or Dutch were screened. The abstracts of these 1257 articles were read and studies reporting any anxiety disorder or anxiety level using a (validated) anxiety scale were subsequently read in full. Studies reporting anxiety by using a global non-motor scale (such as non-motor symptoms scale, NMSS (10) or the Movement Disorder Society revised Unified Parkinson Disease Rating Scale (MDS-UPDRS)(11)), reviews and studies with only DBS patients were excluded. All articles with potential reference to the prevalence of anxiety were assessed for eligibility. After reading these articles, another 58 articles were excluded because of the following reasons: there was no reference to the actual prevalence of anxiety $(n=28)$, no cut-off score on an anxiety rating scale was reported $(n=8)$, 
the population included only PD patients with dementia, psychosis or mood fluctuations $(n=9)$. In addition, if, during the assessment it became clear that publications stemmed from the same databases $(n=13)$, only one of these publications was included in the meta-analysis to prevent a disproportional influence of these the prevalence rates reported in these publications. If studies were indeed based on the exact same sample, we decided to include only the first publication in the analysis. When studies based on the same sample had varying numbers of patients included (as is the case in cumulative databases), the study with the highest number of patients was included. The remaining 49 studies were included in the qualitative synthesis.

\section{Figure 1.}

PRISMA flow-chart

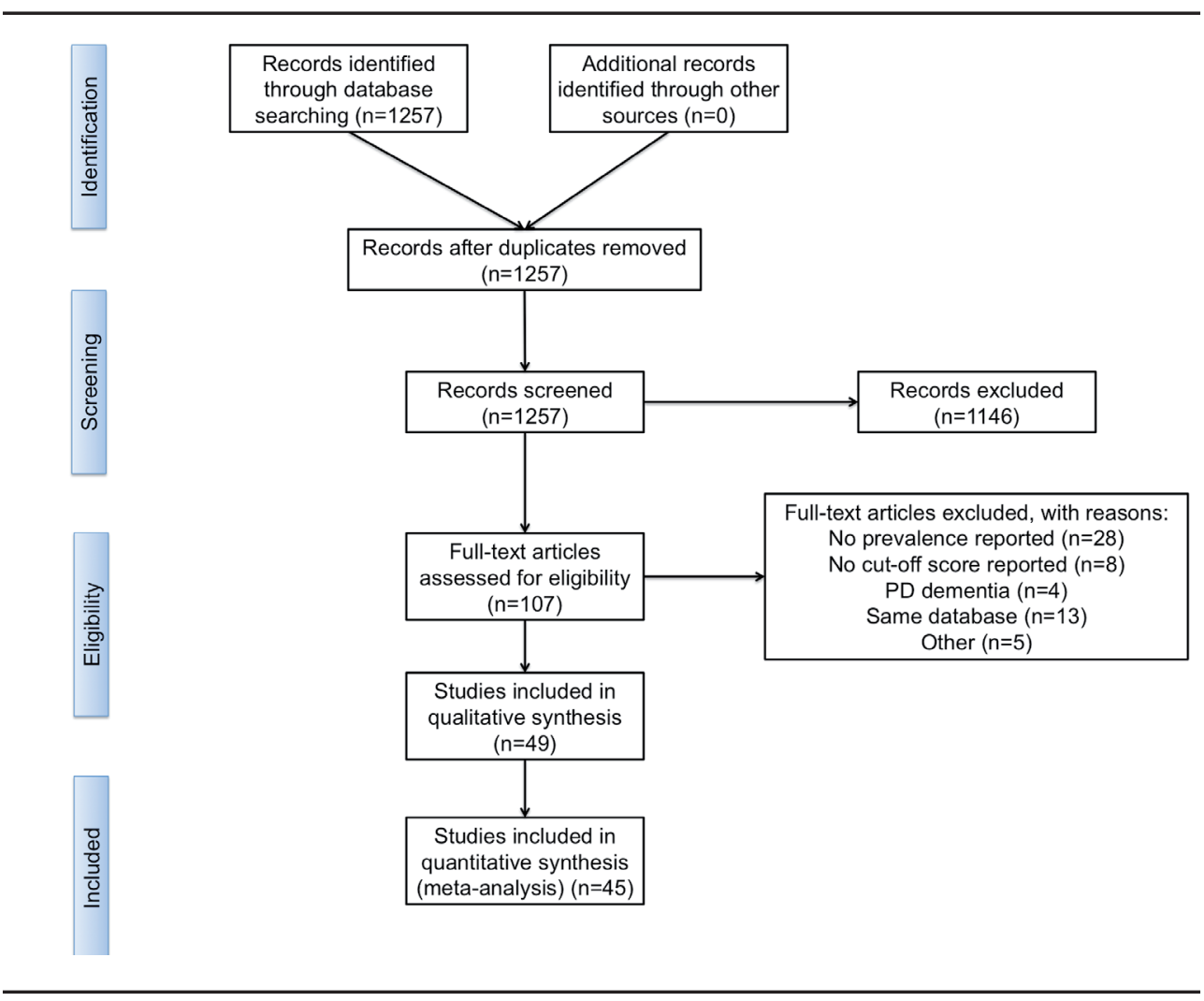




\section{Quality assessment}

With regard to the reported prevalences, the quality of the studies was assessed with epidemiological quality criteria. The modified Quality Assessment of Diagnostic Accuracy Studies (QUADAS) tool is a quality assessment adapted and modified from Leboeuf-Yde et al. $(12,13)$, and previously used to determine the prevalence of pain in PD (14). The modified QUADAS tool includes 10 criteria in which the reliability of the prevalence study is evaluated (Table 1). The score ranges from 0 to 19 points, with a cutoff level for methodological acceptability set at $>13$ points, which is $75 \%$ of the total points that can be achieved. All articles were reviewed independently by 2 researchers (M.B., N.N.) and in case of discrepancies between the raters, consensus was achieved after discussion if possible, or a decision was made after reassessment by the last author (A.L.). The complete list of included studies with their item-by-item quality score is provided as supplementary information.

\section{Table 1.}

Modified QUADAS tool: quality criteria for prevalence studies.

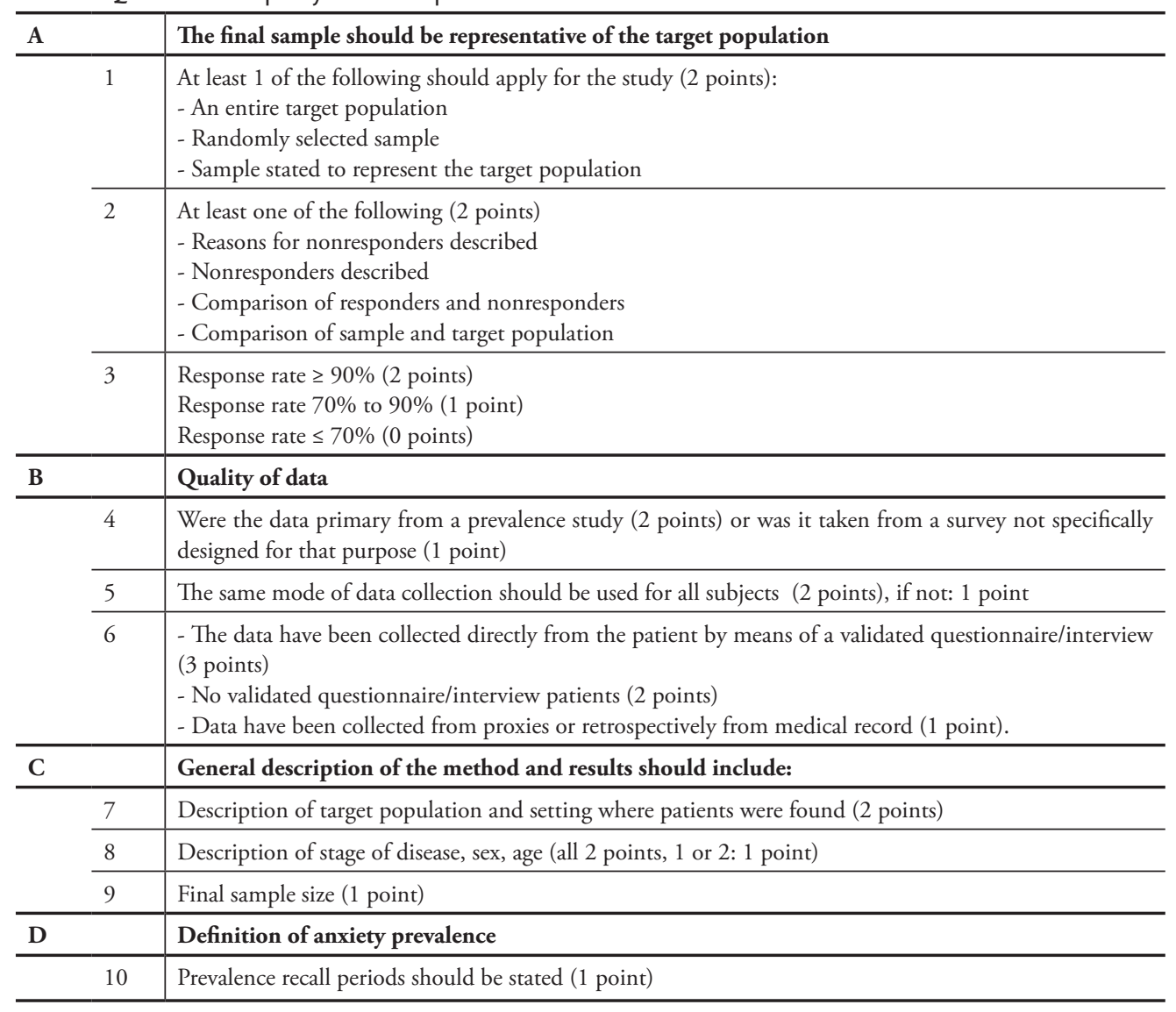




\section{Data extraction and analyses}

For studies assessing specific anxiety disorders, the prevalences were recorded in combination with the clinical setting and sample size. Two studies $(15,16)$ on anxiety disorders only reported a total percentage of anxiety disorders. For these we contacted the first author for information on the percentage of individual anxiety disorders. For one of these studies, this information could be obtained (15). For all studies using cutoff scores on anxiety rating scales, the prevalence percentage represents the presence of anxiety symptoms that was regarded as clinically relevant in these studies. Currently, there is no clear consensus about the best cut-off scores on the anxiety rating scales (17-19). Authors of the included studies chose cut-off scores referencing to other articles or based on own experiences. Since cut-off values vary across studies, we used for the sake of this review the thresholds stated by the authors of the studies. The number of patients scoring above the threshold of an anxiety rating scale was taken as the prevalence of clinically relevant anxiety symptoms. Prevalence rates across studies were calculated as weighted means. The prevalence rate per study was multiplied by the corresponding sample size and divided by the total sample of all studies.

\section{RESULTS}

Of a total of 49 studies, 27 focused on the prevalence of anxiety in PD as a primary objective. Other studies had other primary objectives but also reported the prevalence of anxiety in the study sample as a secondary outcome. Of the 49 studies included in the qualitative synthesis, 45 met the cutoff score of 14 points on the QUADAS tool (92\%). The actual scores ranged from 12-19 points with a mean of 15.45 (see supplementary information). Only 5 out of the 45 studies were conducted before the year 2000, with more than half of the papers published in the last 5 years, which likely reflects the increasing awareness of anxiety in PD in the last decade. Thirty-nine studies were in outpatient settings, often in movement disorder clinics, and 5 were population-based. One study included both inpatients and outpatients. Eighteen studies reported anxiety disorders according to the DSM criteria and 27 reported clinically relevant anxiety symptoms assessed with an anxiety rating scale. Of the eighteen studies examining DSM defined anxiety disorders, one was a population study in the Netherlands (20). Four were multicenter studies $(9,21-23)$, of which 1 was conducted in China, 1 in the USA and 2 as well in the USA, Europe and Australia. Of the 13 single center studies, three included patients from the USA (24-26), 6 from Europe (15, 16, 27-30), 2 from South America $(31,32), 1$ from Australia (7) and 1 from India (33). An overview of studies reporting the prevalence of anxiety disorders is illustrated in Table 2 , and studies reporting clinically relevant anxiety symptoms according to validated rating scales are shown in Table 3. 


\begin{tabular}{|c|c|c|c|c|c|c|c|c|c|c|c|c|}
\hline 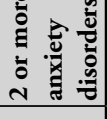 & & & & $\begin{array}{l}\stackrel{0}{\hat{~}} \\
\stackrel{\lambda}{2}\end{array}$ & & & & & & & & $\begin{array}{l}\stackrel{0}{0} \\
\infty \\
\omega^{+} \\
\end{array}$ \\
\hline 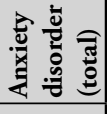 & $\begin{array}{l}\stackrel{0}{n} \\
\stackrel{n}{n}\end{array}$ & $\begin{array}{l}0 \\
\vdots \\
\infty \\
i \\
\text { iे }\end{array}$ & & $\begin{array}{l}\stackrel{0}{ } \\
\stackrel{\sim}{i} \\
\end{array}$ & 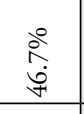 & & $\begin{array}{l}\text { oे } \\
\text { कें } \\
\text { mे }\end{array}$ & $\begin{array}{l}\stackrel{0}{\pi} \\
\stackrel{\lambda}{\pi}\end{array}$ & & 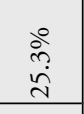 & & $\begin{array}{l}\stackrel{0}{i} \\
\stackrel{n}{n} \\
\end{array}$ \\
\hline 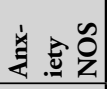 & & $\begin{array}{l}\stackrel{\circ}{\stackrel{0}{+}} \\
\text { ì }\end{array}$ & & & & & & iे & & & & 守 \\
\hline Оి & & & & $\stackrel{0}{\grave{0}}$ & $\begin{array}{l}\stackrel{0}{ } \\
\stackrel{n}{n}\end{array}$ & $\begin{array}{l}\stackrel{0}{2} \\
\stackrel{2}{2}\end{array}$ & $\begin{array}{l}\dot{0} \\
\dot{\theta} \\
\dot{r}\end{array}$ & 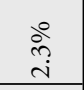 & & $\stackrel{\text { े }}{\text { İ }}$ & $\begin{array}{l}\stackrel{0}{m} \\
\text { nे }\end{array}$ & \\
\hline 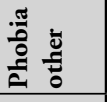 & & $\begin{array}{l}\stackrel{\circ}{i} \\
\stackrel{i}{i}\end{array}$ & & 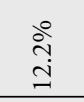 & & & & & & & ف̊ & \\
\hline 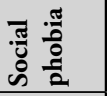 & $\begin{array}{l}\stackrel{0}{2} \\
\stackrel{i}{a}\end{array}$ & & & $\stackrel{\stackrel{0}{i n}}{\stackrel{i}{=}}$ & & 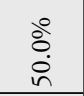 & & $\begin{array}{l}\stackrel{0}{2} \\
\text { के }\end{array}$ & $\begin{array}{l}\circ \\
0 \\
\dot{0}\end{array}$ & $\begin{array}{l}\stackrel{0}{\hat{~}} \\
\stackrel{-}{i}\end{array}$ & $\begin{array}{l}\stackrel{m}{े} \\
\stackrel{\forall}{*}\end{array}$ & $\begin{array}{l}\stackrel{0}{0} \\
\stackrel{0}{-}\end{array}$ \\
\hline હ્ડ & ثे & $\stackrel{\circ}{\stackrel{\Xi}{\Xi}}$ & $\begin{array}{l}\stackrel{0}{i} \\
i \\
i \\
i\end{array}$ & $\begin{array}{l}\stackrel{0}{0} \\
\text { i }\end{array}$ & $\begin{array}{l}\stackrel{0}{\leftrightarrows} \\
\beth\end{array}$ & $\stackrel{\circ}{\stackrel{\circ}{m}}$ & $\begin{array}{l}\stackrel{0}{o} \\
\stackrel{\text { i }}{~} \\
\end{array}$ & 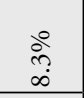 & & $\begin{array}{l}\circ \\
\stackrel{0}{0} \\
\end{array}$ & $\begin{array}{l}\stackrel{0}{\circ} \\
0 \\
\stackrel{+}{+}\end{array}$ & $\begin{array}{l}\dot{0} \\
\dot{0} \\
\dot{i}\end{array}$ \\
\hline 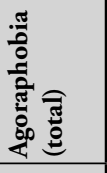 & & & & $\stackrel{\text { ڤे }}{\dot{\forall}}$ & & & $\begin{array}{l}\circ \\
\vdots \\
\end{array}$ & $\begin{array}{l}\stackrel{0}{0} \\
m_{0} \\
\infty\end{array}$ & & 仓̊․․ & & $\begin{array}{l}\stackrel{0}{ }^{\circ} \\
\stackrel{n}{n}\end{array}$ \\
\hline 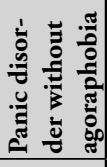 & & & & & & & & & & & & $\stackrel{\circ}{\stackrel{0}{i}}$ \\
\hline 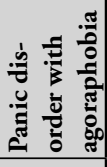 & & & & & & & & & & ڤ̊․ & & $\stackrel{\circ}{\stackrel{0}{+}}$ \\
\hline 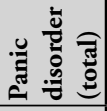 & $\begin{array}{l}\stackrel{0}{0} \\
\infty \\
\infty\end{array}$ & $\stackrel{\circ}{\Xi}$ & & 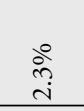 & $\begin{array}{l}\dot{0} \\
\dot{8} \\
\dot{m}\end{array}$ & $\begin{array}{l}\stackrel{0}{\hat{\imath}} \\
\text { b }\end{array}$ & ঐे & ڤે̀ & & ذ̊. & 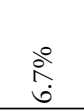 & ڤे \\
\hline 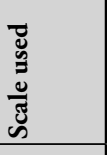 & 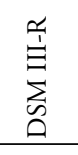 & 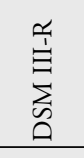 & $\underset{\sum}{\Xi}$ & 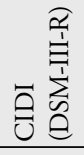 & $\sum_{\substack{n \\
0}}$ & 妾 & 妾 & : & 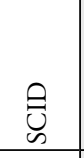 & 点 & $\vec{z}$ & $\vec{z}$ \\
\hline 总 & 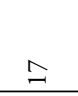 & 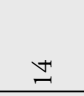 & $\stackrel{\odot}{\smile}$ & $\beth$ & $\cong$ & $\cong$ & 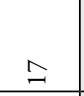 & $\stackrel{\infty}{-}$ & $\cong$ & 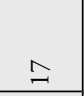 & $\beth$ & $\stackrel{\unlhd}{\beth}$ \\
\hline 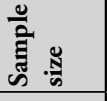 & $\stackrel{\sim}{\sim}$ & $\underset{\forall}{*}$ & 아 & $\begin{array}{l}\text { 仿 } \\
m\end{array}$ & 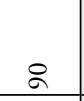 & 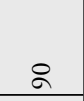 & 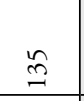 & $\stackrel{m}{-}$ & in & 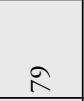 & $\stackrel{m}{m}$ & ָै \\
\hline 䒕 & 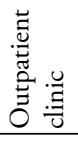 & 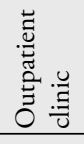 & 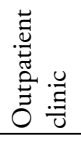 & 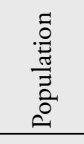 & 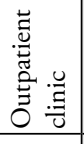 & 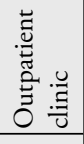 & 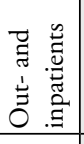 & 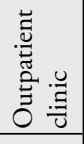 & 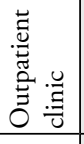 & 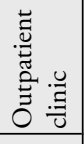 & 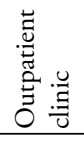 & 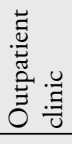 \\
\hline के & 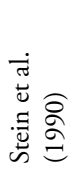 & 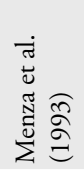 & 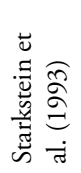 & 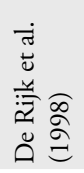 & 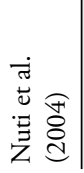 & 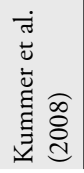 & 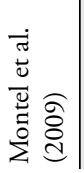 & 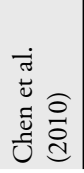 & 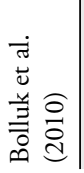 & 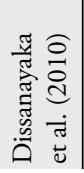 & 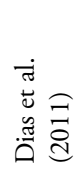 & 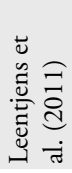 \\
\hline
\end{tabular}




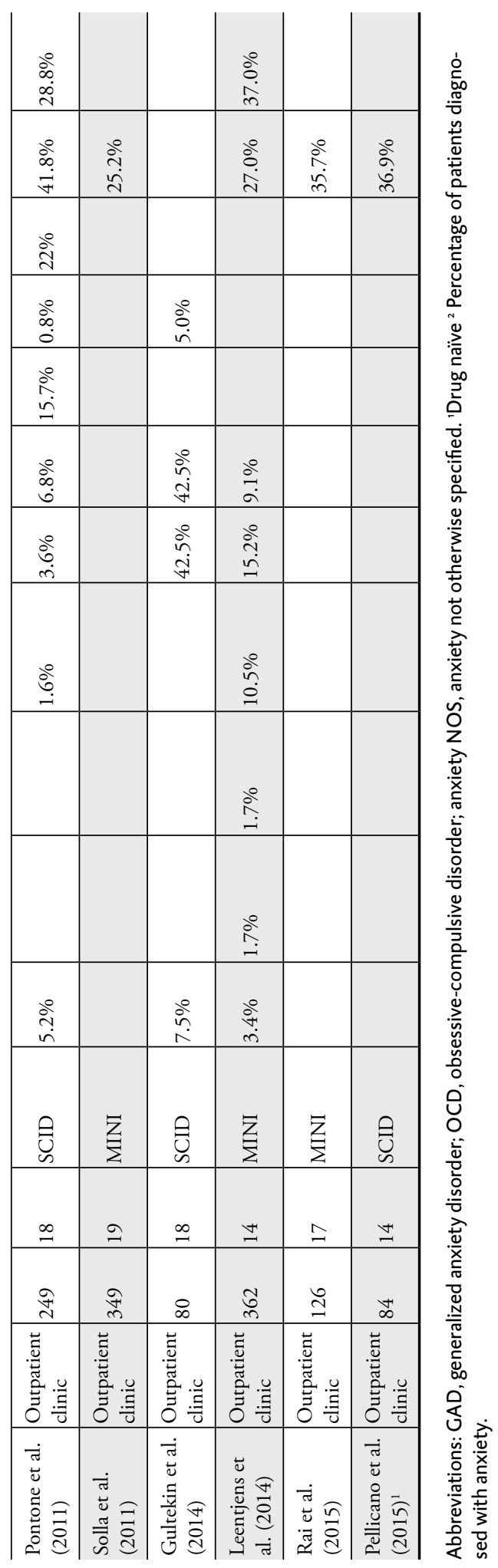


Table 3.

Overview of studies reporting clinically relevant anxiety symptoms in Parkinson's disease according to validated rating scales $(n=27)$.

\begin{tabular}{|c|c|c|c|c|c|c|}
\hline Study & Sample & Sample size & $\begin{array}{l}\text { Quality } \\
\text { score }\end{array}$ & Scale used & \begin{tabular}{|l} 
Cut-off \\
score used
\end{tabular} & $\begin{array}{l}\text { Clinically } \\
\text { relevant anxiety } \\
\text { symptoms }\end{array}$ \\
\hline Marinu et al. (2002) & $\begin{array}{l}\text { Outpatient } \\
\text { clinic }\end{array}$ & 177 & 16 & HADS & $\geq 11$ & $19.8 \%$ \\
\hline $\begin{array}{l}\text { Carod-Artal et al. } \\
(2007)\end{array}$ & $\begin{array}{l}\text { Outpatient } \\
\text { clinic }\end{array}$ & 144 & 14 & HADS & $\geq 11$ & $23.6 \%$ \\
\hline $\begin{array}{l}\text { Mondolo et al. } \\
(2007)\end{array}$ & $\begin{array}{l}\text { Outpatient } \\
\text { clinic }\end{array}$ & 46 & 14 & HADS & $\geq 8$ & $10.8 \%$ \\
\hline $\begin{array}{l}\text { Carod-Artal et al. } \\
(2008)\end{array}$ & $\begin{array}{l}\text { Outpatient } \\
\text { clinic }\end{array}$ & 115 & 14 & HADS & $\geq 11$ & $30.4 \%$ \\
\hline $\begin{array}{l}\text { McKinley et al. } \\
(2008)\end{array}$ & $\begin{array}{l}\text { Outpatient } \\
\text { clinic }\end{array}$ & 42 & 15 & HADS & $\geq 8$ & $16 \%$ \\
\hline $\begin{array}{l}\text { Havlikova et al. } \\
(2008)\end{array}$ & $\begin{array}{l}\text { Outpatient } \\
\text { clinic }\end{array}$ & 150 & 14 & HADS & $\geq 11$ & $30.6 \%$ \\
\hline $\begin{array}{l}\text { Kulisevsky et al. } \\
(2008)\end{array}$ & $\begin{array}{l}\text { Outpatient } \\
\text { clinic }\end{array}$ & 1351 & 19 & HADS & $\geq 11$ & $20.8 \%$ \\
\hline $\begin{array}{l}\text { Rodriquez- } \\
\text { Blastez et al. (2009) }\end{array}$ & $\begin{array}{l}\text { Outpatient } \\
\text { clinic }\end{array}$ & 387 & 14 & HADS & $\geq 11$ & $22 \%$ \\
\hline $\begin{array}{l}\text { Negres-Pages et al. } \\
(2010)\end{array}$ & Population & 422 & 17 & HADS & $\geq 11(\geq 8)$ & $27 \%(51 \%)$ \\
\hline Hu et al. (2011) & Population & 197 & 14 & HADS & $\geq 11$ & $32.0 \%$ \\
\hline Brown et al. (2011) & $\begin{array}{l}\text { Outpatient } \\
\text { clinic }\end{array}$ & 513 & 16 & HADS & $\geq 11$ & $22 \%$ \\
\hline Ozdilek et al. (2012) & $\begin{array}{l}\text { Outpatient } \\
\text { clinic }\end{array}$ & 50 & 14 & HADS & $\geq 10$ & $18 \%$ \\
\hline Quelhas et al. (2014) & $\begin{array}{l}\text { Outpatient } \\
\text { clinic } \\
\end{array}$ & 33 & 14 & HADS & $\geq 11(\geq 8)$ & $18.2 \%(54.5 \%)$ \\
\hline $\begin{array}{l}\text { Fereshtehnejad et al. } \\
(2015)\end{array}$ & $\begin{array}{l}\text { Outpatient } \\
\text { clinic }\end{array}$ & 140 & 14 & HADS & $\geq 8$ & $38.9 \%$ \\
\hline Borek et al. (2006) & $\begin{array}{l}\text { Outpatient } \\
\text { clinic }\end{array}$ & 120 & 16 & HARS & $\geq 14$ & $23.2 \%$ \\
\hline $\begin{array}{l}\text { Stefanova et al. } \\
(2013)\end{array}$ & $\begin{array}{l}\text { Outpatient } \\
\text { clinic }\end{array}$ & 360 & 19 & HARS & $\geq 11$ & $37.8 \%$ \\
\hline Jiang et al. (2015) & $\begin{array}{l}\text { Outpatient } \\
\text { clinic } \\
\end{array}$ & 99 & 14 & HARS & $>11$ & $25.3 \%$ \\
\hline Wu et al. (2015) & $\begin{array}{l}\text { Outpatient } \\
\text { clinic }\end{array}$ & 301 & 15 & HARS & $>14$ & $10.6 \%$ \\
\hline $\begin{array}{l}\text { Schulman et al. } \\
(2001)\end{array}$ & $\begin{array}{l}\text { Outpatient } \\
\text { clinic }\end{array}$ & 101 & 16 & BAI & $\geq 10$ & $39 \%$ \\
\hline Rutten et al. (2015) & $\begin{array}{l}\text { Outpatient } \\
\text { clinic }\end{array}$ & 294 & 16 & BAI & $>12$ & $45 \%$ \\
\hline $\begin{array}{l}\text { Yamanashi et al. } \\
(2013)\end{array}$ & $\begin{array}{l}\text { Outpatient } \\
\text { clinic }\end{array}$ & 117 & 15 & STAI & $41(\mathrm{~m}) 42(\mathrm{f})$ & $55 \%$ \\
\hline
\end{tabular}




\begin{tabular}{l|l|l|l|l|l|l}
\hline $\begin{array}{l}\text { Weintraub et al. } \\
(2015)^{1}\end{array}$ & $\begin{array}{l}\text { Outpatient } \\
\text { clinic }\end{array}$ & 423 & 15 & STAI & $>39$ & $24.6 \%$ \\
\hline Siri et al. (2010) & Population & 486 & 15 & SCL-90 & $>1$ & $46 \%$ \\
\hline Bugalho et al. (2012) & $\begin{array}{l}\text { Outpatient } \\
\text { clinic }\end{array}$ & 36 & 15 & SCL-90-R & $>1$ & $28 \%$ \\
\hline $\begin{array}{l}\text { Henderson et al. } \\
(1992)\end{array}$ & $\begin{array}{l}\text { Outpatient } \\
\text { clinic }\end{array}$ & 164 & 16 & Zung & $>49$ & $15 \%$ \\
\hline $\begin{array}{l}\text { Baig et al. (2015) } \\
\text { Outpatient } \\
\text { clinic }\end{array}$ & 769 & 17 & $\begin{array}{l}\text { Leeds } \\
\text { anxiety score }\end{array}$ & $>7$ & $17.3 \%$ \\
\hline $\begin{array}{l}\text { Aarsland et al. } \\
(2009)^{1}\end{array}$ & Population & 175 & 16 & NPI & $\geq 4$ & $6.9 \%$ \\
\hline
\end{tabular}

${ }^{1}$ Drug naive

Overall, a weighted mean of 31\% (range 24.5-46.7\%) in a total of 2399 patients experienced an anxiety disorder, with GAD as the most frequent disorder (14.1\%), followed by social phobia (13.8\%) and clinically relevant anxiety not meeting criteria for any specific anxiety diagnoses (anxiety NOS, 13.3\%) (Table 4). Thirty-one percent (31.1\%) of patients fulfilled criteria for current multiple anxiety disorders, having two different or more anxiety disorders at one time point. Of the studies reporting a total prevalence of anxiety disorders, we compared the weighted prevalence of anxiety disorders in multicenter versus single center studies, which was $32.8 \%$ in multicenter (1086 patients ( 9 , 21-23)) versus 31.5\% in single center studies (929 patients (7, 15, 16, 24, 26, 29, 30, 33)). Studies conducted in the USA, Europe and one in India found a higher overall prevalence of anxiety disorders compared to the multicenter study conducted in China (21) (Table 2). Based on anxiety rating scale cutoff scores, clinically significant anxiety symptoms were present in a weighted average of $25.7 \%$ (range $6.9 \%$ to $55 \%$ ). 
Table 4.

Weighted prevalences of anxiety disorders in Parkinson disease patients

\begin{tabular}{l|l|l|l|l}
\hline Anxiety disorder & $\begin{array}{l}\text { Number } \\
\text { of studies }\end{array}$ & $\begin{array}{l}\text { Total no. PD } \\
\text { patients }\end{array}$ & Range & $\begin{array}{l}\text { Weighted preva- } \\
\text { lence }\end{array}$ \\
\hline Any anxiety disorder & 13 & 2399 & $24.5-46.7$ & $31.0 \%$ \\
\hline - Generalized anxiety disorder & 14 & 2080 & $2.6-52.5$ & $14.1 \%$ \\
\hline - Panic disorder & 13 & 2040 & $2.3-30.0$ & $6.8 \%$ \\
\hline - Agoraphobia & 7 & 1684 & $1.6-15.5$ & $8.6 \%$ \\
\hline - Social phobia & 11 & 1823 & $6.8-50.0$ & $13.8 \%$ \\
\hline - Phobia other & 4 & 705 & $2.4-16.7$ & $13.0 \%$ \\
\hline - OCD & 9 & 1270 & $0.3-13.3$ & $2.6 \%$ \\
\hline - Anxiety NOS & 4 & 766 & $2.4-22.0$ & $13.3 \%$ \\
\hline Two or more comorbid anxiety disorders* & 4 & 1337 & $23.7-37.0$ & $31.1 \%$ \\
\hline $\begin{array}{l}\text { Clinically relevant anxiety symptoms accord- } \\
\text { ing to scale }\end{array}$ & 27 & 7212 & $6.9-55.0$ & $25.7 \%$ \\
\hline
\end{tabular}

*Percentage of patients diagnosed with anxiety

\section{DISCUSSION}

This is the first systematic review examining the prevalence of anxiety disorders and anxiety symptoms in PD. It shows that the average point prevalence of anxiety disorders in $\mathrm{PD}$ is $31 \%$. This is a substantial percentage that exceeds the average point prevalence of depressive disorders in PD (17\%) (34). Non-episodic anxiety was more prevalent than episodic anxiety with generalized anxiety disorder as the most frequent diagnosis in $14.1 \%$ of PD patients, and was followed by social phobia in $13.8 \%$ and panic disorder with or without agoraphobia in $6.8 \%$. Approximately one third of patients diagnosed with anxiety experienced multiple anxiety disorders, which makes the construct validity of the current DSM classification of anxiety questionable, at least in PD patients. Notably, anxiety NOS had a weighted prevalence similar to GAD and social phobia (13.3\%), and this is a category often used to describe significant anxiety that do not neatly meet criteria for a standard DSM disorder.

The weighted average of clinically relevant anxiety symptoms assessed by a rating scale was lower $(25.7 \%)$ than the weighted average of DSM defined anxiety disorders (31\%). It is well known that most anxiety rating scales are inappropriate to diagnose anxiety disorders in PD $(18,19)$. A possible explanation for the lower prevalence of anxiety when anxiety rating scales are used, is the fact that some anxiety disorders take place in special situations, such as social phobia, and the commonly used anxiety rating scales do not contain items that explore such situations. Second, the inclusion of anxiety NOS in the prevalence estimates of anxiety disorders may also explain the discrepancy bet- 
ween the prevalence finding of DSM anxiety disorders and rating scale anxiety. This is because rating scales may not capture symptoms of anxiety disorder NOS, which may be a predominant construct of PD-specific anxiety symptoms $(1,35,36)$. Furthermore, authors have used different cut-off scores, and the focus of specific anxiety symptoms may differ between rating scales. For example, the BAI focuses mainly on symptoms of panic, while the HARS predominantly consists of items assessing generalized anxiety. The positive predictive values of these popular scales are suggested to be low in PD, and consequently may contribute to a poor diagnostic accuracy (18). The recently designed Parkinson Anxiety Scale, could possibly overcome some of these problems (23).

\section{Comparing anxiety in PD and the general population or other illnesses}

The weighted prevalence of anxiety disorders in PD is much higher than those reported in the general population or other medically ill patients, without PD $(24,37)$. A large community survey from the World Health Organization found a 12-month prevalence of $8.3 \%$ of any anxiety disorder. In addition, an extensive review of epidemiological surveys on anxiety disorders in the general population found 12-month prevalences of panic disorder range of 0.7-3.1\%, GAD 0.2-4.3\% and social phobia of 0.6-7.9\% (38). GAD and social or specific phobias seem to be the most common anxiety disorders in PD and panic disorder, agoraphobia and OCD the least frequent. These observations are in line with studies focusing on anxiety in the general population $(39,40)$. About one third of patients had two or more comorbid anxiety disorders, and having multiple anxiety disorders is associated with greater morbidity (41). GAD with another non-episodic anxiety disorder like social phobia or agoraphobia seems to be the most frequent comorbid disorders in PD (22), and in the general population (42, 43). In addition, there is a particular high correlation between major depression and GAD in general (44). Depression is common in PD and has a clear symptom overlap with GAD, which may explain the high prevalence of GAD in general and in PD. Although investigating the lifetime prevalence of anxiety disorders in PD was not our primary objective, we noted two studies reporting a lifetime prevalence of anxiety disorders in PD. Pontone et al. (45) reported a lifetime prevalence of anxiety disorders of 49\% in 127 patients, with specific phobia as the most frequent disorder. Lauterbach et al. (3) reported $25 \%$ of 28 patients with a life time panic disorder, none with GAD and $32 \%$ with anxiety NOS. The lifetime prevalence of anxiety in PD thus also seem to be higher than in the general population, in which prevalence rates range from 15-34\% (38).

\section{Variation of reported prevalences}

There is a wide range of reported prevalence across studies included in this review, which most likely is attributable to methodological differences. Three studies in the early nineties used DSM-III criteria, whereas later ones used the DSM-IV criteria. No studies using DSM-5 criteria in PD have yet been published. Secondly, in the general popula- 
tion there are some slight differences between the MINI and the SCID interview; the MINI being slightly more over inclusive in making the diagnosis hence possible leading to a higher prevalence rate (46). Thirdly, individual differences in the extent of history taking and the conscientiousness of the assessor may affect the decision to code the patient complaints as one single or as two disorders and interpretation of MINI formulations or DSM criteria may be different between studies. For example, some researchers used hierarchal DSM criteria and ruled out GAD if another current anxiety disorder was diagnosed, whereas others included secondary GAD as a disorder when evaluating frequency. We decided to include the latter prevalence in our review when both were reported (7). In addition, using an "inclusive" approach, where overlapping symptoms of anxiety and PD is taken together in the diagnosis regardless of the causal attribution, when applying diagnostic criteria tend to give a higher prevalence than an "exclusive" approach (47). Furthermore, differences in the characteristics of the study samples could also influence the reported prevalence. Anxiety is more common in western developed countries; for example anxiety is more common in the United States compared with China, which is in line with our findings (48). Also, some studies did not include the whole spectrum of anxiety disorders, such as anxiety NOS or phobias other than social phobia, but did report a total percentage of anxiety disorders $(7,15,20,23,26,29)$, which could have led to an underestimation of the true prevalence of anxiety disorders in PD. Last, although some described differences between multi- and single center trials (49), we found no difference in the prevalence of the total number of anxiety disorders.

A different classification, such as the one recently proposed by Starkstein et al. could aid in differentiating clinical profiles of anxiety in PD. This study identified three different presentations of anxiety, namely episodic anxiety which is not associated with depressive symptoms, persistent anxiety with depression, or both persistent and episodic anxiety with depression. These clinical phenotypes may correspond better to the anxiety syndromes encountered in clinical practice than those listed in the DSM classifications (50).

There are a number of limitations of this review. Although we attempted to identify all suitable publications and exclude publications stemming from the same database, we may have missed some of these overlapping publications. Secondly, although all articles were assessed by quality criteria, the inclusion criteria chosen was subjective to authors. Third, we cannot completely rule out a possible influence of recruitment bias. Most of the studies were conducted at specialized movement disorder clinics, where they may encounter more complex patients with a higher prevalence of anxiety disorders. Fourth, 92\% of studies met QUADAS criteria, which is much higher than other systematic reviews in PD (14) and other chronic diseases (12, 51). Having a search strategy incorporating some of the quality criteria may explain this high percentage. Lastly, since this review depends on the quality of the studies included, we cannot rule out possible 
influences of pharmacological treatment of anxiety on the reported prevalences. For example, patients successfully treated with anxiolytics may not be recognized, and this may lead to an under-reporting of anxiety in this review.

However, taking all these considerations into account, we calculated weighted averages of prevalence reported in available studies with the intention to provide a reliable estimate of the frequency of anxiety disorders in PD patients. Although anxiety in PD was relatively neglected for a long time, it receives more and more intention in the last 10-15 years. However, studies have indicated that still over half of clinically significant anxiety cases are not recognized by clinicians, and therefore anxiety is undertreated both in PD and in the general elderly population $(35,52-54)$. By demonstrating a high weighted point prevalence rate for anxiety disorders in PD (31\%), the present systematic review suggests the need for efficient identification of anxiety in PD, which occur at a much higher average prevalence than depressive disorders in PD (17\%). Given this high prevalence of anxiety, pharmacological and non-pharmacological treatment of anxiety needs to be further studied and optimized for PD patients $(34,55)$.

\section{CONCLUSION}

In this review we aimed to determine the prevalence of anxiety in patients with PD. The average prevalence of anxiety disorder was $31 \%$, with GAD as the most frequent in $14.1 \%$ followed by social phobia (13.8\%), anxiety disorder NOS (13.3\%) and specific phobia (13.0\%). About one third of diagnosed patients had two or more anxiety disorders. This study confirms that anxiety, although often unrecognized, is very common in PD. 


\section{REFERENCES}

1. Dissanayaka NN, White E, O'Sullivan JD, Marsh R, Pachana NA, Byrne GJ. The clinical spectrum of anxiety in Parkinson's disease. Mov Disord. 2014;29(8):967-75.

2. Henderson R, Kurlan R, Kersun JM, Como P. Preliminary examination of the comorbidity of anxiety and depression in Parkinson's disease. J Neuropsychiatry Clin Neurosci. 1992;4(3):257-64.

3. Lauterbach EC, Freeman A, Vogel RL. Correlates of generalized anxiety and panic attacks in dystonia and Parkinson disease. Cogn Behav Neurol. 2003;16(4):225-33.

4. Siemers ER, Shekhar A, Quaid K, Dickson H. Anxiety and motor performance in Parkinson's disease. Mov Disord. 1993;8(4):501-6.

5. Marinus J, Leentjens AF, Visser M, Stiggelbout AM, van Hilten JJ. Evaluation of the hospital anxiety and depression scale in patients with Parkinson's disease. Clin Neuropharmacol. 2002;25(6):318-24.

6. Marinus J, Visser M, Stiggelbout AM, Rabey JM, Martinez-Martin P, Bonuccelli U, et al. A short scale for the assessment of motor impairments and disabilities in Parkinson's disease: the SPES/SCOPA. J Neurol Neurosurg Psychiatry. 2004;75(3):388-95.

7. Dissanayaka NN, Sellbach A, Matheson S, O'Sullivan JD, Silburn PA, Byrne GJ, et al. Anxiety disorders in Parkinson's disease: prevalence and risk factors. Mov Disord. 2010;25(7):838-45.

8. Yamanishi T, Tachibana H, Oguru M, Matsui K, Toda K, Okuda B, et al. Anxiety and depression in patients with Parkinson's disease. Intern Med. 2013;52(5):539-45.

9. Pontone GM, Williams JR, Anderson
KE, Chase G, Goldstein SR, Grill S, et al. Anxiety and self-perceived health status in Parkinson's disease. Parkinsonism Relat Disord. 2011;17(4):249-54.

10. Chaudhuri KR, Martinez-Martin P, Brown RG, Sethi K, Stocchi F, Odin P, et al. The metric properties of a novel non-motor symptoms scale for Parkinson's disease: Results from an international pilot study. Mov Disord. 2007;22(13):1901-11.

11. Gallagher DA, Goetz CG, Stebbins G, Lees AJ, Schrag A. Validation of the MDS-UPDRS Part I for nonmotor symptoms in Parkinson's disease. Mov Disord. 2012;27(1):79-83.

12. Leboeuf-Yde C, Lauritsen JM. The prevalence of low back pain in the literature. A structured review of 26 Nordic studies from 1954 to 1993. Spine (Phila Pa 1976). 1995;20(19):2112-8.

13. Whiting PF, Weswood ME, Rutjes AW, Reitsma JB, Bossuyt PN, Kleijnen J. Evaluation of QUADAS, a tool for the quality assessment of diagnostic accuracy studies. BMC Med Res Methodol. 2006;6:9.

14. Broen MP, Braaksma MM, Patijn J, Weber WE. Prevalence of pain in Parkinson's disease: a systematic review using the modified QUADAS tool. Mov Disord. 2012;27(4):480-4.

15. Montel S, Bonnet AM, Bungener C. Quality of life in relation to mood, coping strategies, and dyskinesia in Parkinson's disease. J Geriatr Psychiatry Neurol. 2009;22(2):95-102.

16. Solla P, Cannas A, Floris GL, Orofino G, Costantino E, Boi A, et al. Behavioral, neuropsychiatric and cognitive disor- 
ders in Parkinson's disease patients with and without motor complications. Prog Neuropsychopharmacol Biol Psychiatry. 2011;35(4):1009-13.

17. Bjelland I, Dahl AA, Haug TT, Neckelmann D. The validity of the Hospital Anxiety and Depression Scale. An updated literature review. J Psychosom Res. 2002;52(2):69-77.

18. Leentjens AF, Dujardin K, Marsh L, Richard IH, Starkstein SE, Martinez-Martin P. Anxiety rating scales in Parkinson's disease: a validation study of the Hamilton anxiety rating scale, the Beck anxiety inventory, and the hospital anxiety and depression scale. Mov Disord. 2011;26(3):407-15.

19. Dissanayaka NN, Torbey E, Pachana NA. Anxiety rating scales in Parkinson's disease: a critical review updating recent literature. Int Psychogeriatr. 2015;27(11):1777-84.

20. de Rijk C, Bijl RV. [Prevalence of mental disorders in persons with Parkinson's disease]. Ned Tijdschr Geneeskd. 1998;142(1):27-31.

21. Chen YK, Lu JY, Chan DM, Mok VC, Yeung MA, Wong KS, et al. Anxiety disorders in Chinese patients with Parkinson's disease. Int J Psychiatry Med. 2010;40(1):97-107.

22. Leentjens AF, Dujardin K, Marsh L, Martinez-Martin P, Richard IH, Starkstein SE. Symptomatology and markers of anxiety disorders in Parkinson's disease: a cross-sectional study. Mov Disord. 2011;26(3):484-92.

23. Leentjens AF, Dujardin K, Pontone GM, Starkstein SE, Weintraub D, Martinez-Martin P. The Parkinson Anxiety Scale (PAS): development and validati- on of a new anxiety scale. Mov Disord. 2014;29(8):1035-43.

24. Menza MA, Robertson-Hoffman DE, Bonapace AS. Parkinson's disease and anxiety: comorbidity with depression. Biol Psychiatry. 1993;34(7):465-70.

25. Starkstein SE, Robinson RG, Leiguarda R, Preziosi TJ. Anxiety and depression in Parkinson's disease. Behav Neurol. 1993;6(3):151-4.

26. Stein MB, Heuser IJ, Juncos JL, Uhde TW. Anxiety disorders in patients with Parkinson's disease. Am J Psychiatry. 1990;147(2):217-20.

27. Bolluk B, Ozel-Kizil ET, Akbostanci MC, Atbasoglu EC. Social anxiety in patients with Parkinson's disease. J Neuropsychiatry Clin Neurosci. 2010;22(4):390-4.

28. Gultekin BK, Ozdilek B, Bestepe EE. Social phobia in Parkinson's disease: Prevalence and risk factors. Neuropsychiatr Dis Treat. 2014;10:829-34.

29. Nuti A, Ceravolo R, Piccinni A, Dell'Agnello G, Bellini G, Gambaccini G, et al. Psychiatric comorbidity in a population of Parkinson's disease patients. Eur J Neurol. 2004;11(5):315-20.

30. Pellicano C, Assogna F, Cravello L, Langella R, Caltagirone C, Spalletta G, et al. Neuropsychiatric and cognitive symptoms and body side of onset of parkinsonism in unmedicated Parkinson's disease patients. Parkinsonism Relat Disord. 2015;21(9):1096-100.

31. Dias FM, Kummer A, Doyle FC, Harsanyi E, Cardoso F, Fontenelle LF, et al. Psychiatric disorders in primary focal dystonia and in Parkinson's disease. Neuropsychiatr Dis 
Treat. 2011;7:111-6.

32. Kummer A, Cardoso F, Teixeira AL. Frequency of social phobia and psychometric properties of the Liebowitz social anxiety scale in Parkinson's disease. Mov Disord. 2008;23(12):1739-43.

33. Rai NK, Goyal V, Kumar N, Shukla G, Srivastava AK, Singh S, et al. Neuropsychiatric co-morbidities in non-demented Parkinson's disease. Ann Indian Acad Neurol. 2015;18(1):33-8.

34. Reijnders JS, Ehrt U, Weber WE, Aarsland D, Leentjens AF. A systematic review of prevalence studies of depression in Parkinson's disease. Mov Disord. 2008;23(2):183-9; quiz 313.

35. Dissanayaka NN, White E, O'Sullivan DJ, Marsh R, Silburn PA, Coplan DA, et al. Characteristics and Treatment of Anxiety Disorders in Parkinson's Disease. Movement Disorders Clinical Practice. 2015;2(2):155-62.

36. Dissanayaka NN, O'Sullivan DJ, Pachana NA, Marsh R, Silburn PA, White EX, et al. Disease specific anxiety symptomatology in Parkinson's disease. International Psychogeriatrics. In press.

37. Marrie RA, Fisk JD, Tremlett H, Wolfson C, Warren S, Tennakoon A, et al. Differences in the burden of psychiatric comorbidity in MS vs the general population. Neurology. 2015.

38. Bandelow B, Michaelis S. Epidemiology of anxiety disorders in the 21st century. Dialogues Clin Neurosci. 2015;17(3):327-35.

39. Alonso J, Lepine JP, Committee ESMS. Overview of key data from the European Study of the Epidemiology of Mental Disorders (ESEMeD). J Clin Psychiatry. 2007;68 Suppl 2:3-9.

40. Kessler RC, Petukhova M, Sampson NA, Zaslavsky AM, Wittchen HU. Twel- ve-month and lifetime prevalence and lifetime morbid risk of anxiety and mood disorders in the United States. Int J Methods Psychiatr Res. 2012;21(3):169-84.

41. Sherbourne CD, Sullivan G, Craske MG, Roy-Byrne P, Golinelli D, Rose RD, et al. Functioning and disability levels in primary care out-patients with one or more anxiety disorders. Psychol Med. 2010;40(12):2059-68.

42. Brawman-Mintzer O, Lydiard RB, Emmanuel N, Payeur R, Johnson M, Roberts J, et al. Psychiatric comorbidity in patients with generalized anxiety disorder. Am J Psychiatry. 1993;150(8):1216-8.

43. Weisberg RB. Overview of generalized anxiety disorder: epidemiology, presentation, and course. J Clin Psychiatry. 2009;70 Suppl 2:4-9.

44. Kessler RC, Chiu WT, Demler O, Merikangas KR, Walters EE. Prevalence, severity, and comorbidity of 12-month DSMIV disorders in the National Comorbidity Survey Replication. Arch Gen Psychiatry. 2005;62(6):617-27.

45. Pontone GM, Williams JR, Anderson KE, Chase G, Goldstein SA, Grill S, et al. Prevalence of anxiety disorders and anxiety subtypes in patients with Parkinson's disease. Mov Disord. 2009;24(9):1333-8.

46. Sheehan DV, Lecrubier Y, Sheehan KH, Janavs J, Weiller E, Keskiner A, et al. The validity of the Mini International Neuropsychiatric Interview (MINI) according to the SCID-P and its reliability. . Eur Psychiatry. 1997;12:232-41.

47. Hoogendijk WJ, Sommer IE, Tissingh G, Deeg DJ, Wolters EC. Depression in Parkinson's disease. The impact of symptom overlap on prevalence. Psychosomatics. 1998;39(5):416-21. 
48. Kessler RC, Aguilar-Gaxiola S, Alonso J, Chatterji S, Lee S, Ormel J, et al. The global burden of mental disorders: an update from the WHO World Mental Health (WMH) surveys. Epidemiol Psichiatr Soc. 2009;18(1):23-33.

49. Dechartres A, Boutron I, Trinquart L, Charles P, Ravaud P. Single-center trials show larger treatment effects than multicenter trials: evidence from a meta-epidemiologic study. Ann Intern Med. 2011;155(1):39-51.

50. Starkstein SE, Dragovic M, Dujardin K, Marsh L, Martinez-Martin P, Pontone GM, et al. Anxiety Has Specific Syndromal Profiles in Parkinson Disease: A Data-Driven Approach. Am J Geriatr Psychiatry. 2013.

51. van den Beuken-van Everdingen $\mathrm{MH}$, de Rijke JM, Kessels AG, Schouten HC, van Kleef M, Patijn J. High prevalence of pain in patients with cancer in a large population-based study in The Netherlands. Pain. 2007;132(3):312-20.

52. Hu M, Cooper J, Beamish R, Jones E, Butterworth R, Catterall L, et al. How well do we recognise non-motor symptoms in a British Parkinson's disease population? J Neurol. 2011;258(8):1513-7.

53. Shulman LM, Taback RL, Rabinstein AA, Weiner WJ. Non-recognition of depression and other non-motor symptoms in Parkinson's disease. Parkinsonism Relat Disord. 2002;8(3):193-7.

54. Bryant C, Mohlman J, Gum A, Stanley M, Beekman AT, Wetherell JL, et al. Anxiety disorders in older adults: looking to DSM5 and beyond. Am J Geriatr Psychiatry. 2013;21(9):872-6.

55. Pontone GM, Williams JR, Anderson KE, Chase G, Goldstein SR, Grill S, et al. Phar- macologic treatment of anxiety disorders in Parkinson disease. Am J Geriatr Psychiatry. 2013;21(6):520-8. 


\section{SUPPLEMENTARY FILES}

Table S1.

Study quality according to the modified QUADAS tool.

\begin{tabular}{|c|c|c|c|c|c|c|c|c|c|c|c|}
\hline Article & A1 & A2 & A3 & B4 & B5 & B6 & C7 & $\mathrm{C} 8$ & C9 & D10 & Total \\
\hline Aarsland et al. 2009 & 2 & 2 & 1 & 2 & 2 & 1 & 2 & 2 & 1 & 1 & 16 \\
\hline Bolluk et al. 2010 & 2 & 0 & 0 & 2 & 2 & 3 & 2 & 2 & 1 & 1 & 15 \\
\hline Brown et al. 2011 & 2 & 2 & 0 & 1 & 2 & 3 & 2 & 2 & 1 & 1 & 16 \\
\hline Bugalho et al. 2012 & 2 & 0 & 0 & 2 & 2 & 3 & 2 & 2 & 1 & 1 & 15 \\
\hline Carod-Artal et al. 2007 & 2 & 0 & 0 & 1 & 2 & 3 & 2 & 2 & 1 & 1 & 14 \\
\hline Carod-Artal et al. 2008 & 2 & 0 & 0 & 1 & 2 & 3 & 2 & 2 & 1 & 1 & 14 \\
\hline De Rijk et al. 1998 & 2 & 2 & 0 & 2 & 2 & 3 & 2 & 2 & 1 & 1 & 17 \\
\hline Dias et al. 2011 & 2 & 2 & 2 & 2 & 2 & 3 & 2 & 2 & 1 & 1 & 19 \\
\hline Dissanayaka et al. 2010 & 2 & 2 & 0 & 2 & 2 & 3 & 2 & 2 & 1 & 1 & 17 \\
\hline Gultekin et al. 2014 & 2 & 2 & 2 & 2 & 2 & 3 & 2 & 1 & 1 & 1 & 18 \\
\hline Havlikova et al. 2008 & 2 & 0 & 0 & 1 & 2 & 3 & 2 & 2 & 1 & 1 & 14 \\
\hline Hu et al. 2011 & 2 & 0 & 0 & 1 & 2 & 3 & 2 & 2 & 1 & 1 & 14 \\
\hline Kulisevsky et al. 2008 & 2 & 2 & 2 & 2 & 2 & 3 & 2 & 2 & 1 & 1 & 19 \\
\hline Kummer et al. 2008 & 2 & 0 & 0 & 2 & 2 & 3 & 2 & 2 & 1 & 1 & 15 \\
\hline Leentjens et al. 2011 & 2 & 0 & 0 & 1 & 2 & 3 & 2 & 2 & 1 & 1 & 14 \\
\hline Leroi et al. 2012 & 2 & 0 & 0 & 2 & 2 & 1 & 2 & 2 & 1 & 1 & 13 \\
\hline Marinus et al. 2002 & 2 & 0 & 1 & 2 & 2 & 3 & 2 & 2 & 1 & 1 & 16 \\
\hline McKinlay et al. 2008 & 2 & 2 & 0 & 1 & 1 & 3 & 2 & 2 & 1 & 1 & 15 \\
\hline Menza et al. 1993 & 2 & 0 & 0 & 1 & 2 & 3 & 2 & 2 & 1 & 1 & 14 \\
\hline Monastero et al. 2013 & 2 & 0 & 0 & 1 & 2 & 1 & 2 & 2 & 1 & 1 & 12 \\
\hline Mondolo et al. 1997 & 2 & 0 & 0 & 1 & 2 & 3 & 2 & 2 & 1 & 1 & 14 \\
\hline Montel et al. 2009 & 2 & 2 & 1 & 1 & 2 & 3 & 2 & 2 & 1 & 1 & 17 \\
\hline Negre-Pages et al. 2009 & 2 & 0 & 2 & 2 & 2 & 3 & 2 & 2 & 1 & 1 & 17 \\
\hline Nuti et al. 2004 & 2 & 0 & 0 & 2 & 2 & 3 & 2 & 2 & 1 & 1 & 15 \\
\hline Pontone et al. 2011 & 2 & 2 & 2 & 1 & 2 & 3 & 2 & 2 & 1 & 1 & 18 \\
\hline Quelhas et al. 2009 & 2 & 0 & 0 & 1 & 2 & 3 & 2 & 2 & 1 & 1 & 14 \\
\hline Qureshi et al. 2010 & 0 & 0 & 2 & 2 & 2 & 1 & 2 & 1 & 1 & 1 & 12 \\
\hline Rodriguez-Blazquez et al. 2009 & 2 & 0 & 0 & 1 & 2 & 3 & 2 & 2 & 1 & 1 & 14 \\
\hline Schulman et al. 2001 & 2 & 0 & 2 & 1 & 2 & 3 & 2 & 2 & 1 & 1 & 16 \\
\hline Siri et al. 2010 & 2 & 0 & 0 & 2 & 2 & 3 & 2 & 2 & 1 & 1 & 15 \\
\hline Solla et al. 2011 & 2 & 2 & 2 & 2 & 2 & 3 & 2 & 2 & 1 & 1 & 19 \\
\hline Stefanova et al. 2013 & 2 & 2 & 2 & 2 & 2 & 3 & 2 & 2 & 1 & 1 & 19 \\
\hline Yamanishi et al. 2013 & 2 & 0 & 0 & 2 & 2 & 3 & 2 & 2 & 1 & 1 & 15 \\
\hline Starkstein et al. 19«3 & 2 & 0 & 2 & 2 & 2 & 3 & 2 & 1 & 1 & 1 & 16 \\
\hline
\end{tabular}




\begin{tabular}{l|l|l|l|l|l|l|l|l|l|l|l}
\hline Ozdilek et al. 2012 & 2 & 0 & 0 & 1 & 2 & 3 & 2 & 2 & 1 & 1 & 14 \\
\hline Chen et al. 2010 & 2 & 2 & 1 & 2 & 2 & 3 & 2 & 2 & 1 & 1 & 18 \\
\hline Stein et al. 1990 & 2 & 0 & 2 & 2 & 2 & 3 & 2 & 2 & 1 & 1 & 17 \\
\hline Henderson et al. 1992 & 2 & 2 & 0 & 2 & 2 & 3 & 2 & 1 & 1 & 1 & 16 \\
\hline Borek et al. 2006 & 2 & 2 & 0 & 1 & 2 & 3 & 2 & 2 & 1 & 1 & 16 \\
\hline Zarowitz et al. 2013 & 0 & 0 & 2 & 2 & 2 & 1 & 2 & 1 & 1 & 1 & 12 \\
\hline Rai et al. 2015 & 2 & 0 & 2 & 2 & 2 & 3 & 2 & 2 & 1 & 1 & 17 \\
\hline Baig et al. 2015 & 2 & 2 & 0 & 2 & 2 & 3 & 2 & 2 & 1 & 1 & 17 \\
\hline Fereshtehnejad et al. 2015 & 2 & 0 & 0 & 1 & 2 & 3 & 2 & 1 & 1 & 1 & 14 \\
\hline Jiang et al. 2015 & 2 & 0 & 0 & 1 & 2 & 3 & 2 & 2 & 1 & 1 & 14 \\
\hline Pellicano et al. 2015 & 2 & 0 & 0 & 1 & 2 & 3 & 2 & 2 & 1 & 1 & 14 \\
\hline Rutten et al. 2015 & 2 & 2 & 0 & 1 & 2 & 3 & 2 & 2 & 1 & 1 & 16 \\
\hline Weintraub et al. 2015 & 2 & 0 & 0 & 2 & 2 & 3 & 2 & 2 & 1 & 1 & 15 \\
\hline Wu et al. 2015 & 2 & 0 & 0 & 2 & 2 & 3 & 2 & 2 & 1 & 1 & 15 \\
\hline Leentjens et al 2014 & 2 & 0 & 0 & 1 & 2 & 3 & 2 & 2 & 1 & 1 & 14 \\
\hline
\end{tabular}





\section{Chapter 3}

Modeling anxiety in Parkinson's disease.

Broen MP, Köhler S, Moonen AJ, Kuijf ML, Dujardin K, Marsh L, Richard IH, Starkstein SE, Martinez-Martin P, Leentjens AF. Mov Disord. 2016 Mar;31(3):310-6. 


\section{ABSTRACT}

\section{Objective:}

To construct a model for anxiety in Parkinson's disease (PD) and to compare the relative contributions of PD-specific and nonspecific general population risk factors for anxiety in this model.

\section{Methods:}

Structural equation modelling of associations of risk factors with the anxiety outcome using a cross-sectional dataset of 342 patients with PD.

\section{Results:}

A model with acceptable to good fit was generated that explained 65\% of the variance in anxiety scores. A previous history of depression and the severity of the depressive symptoms scored on the Hamilton Depression Rating Scale were the only nonspecific variables with a direct effect on anxiety. The presence of motor fluctuations and disease-related decline in activities of daily living were PD-specific markers of anxiety. Nonspecific risk factors had a greater influence in the model than PD-specific risk factors. Standardized regression coefficients suggested that the Hamilton Depression Rating Scale- score was the most important contributor to the variation in anxiety. A post hoc analysis showed that the effects of the following variables on anxiety levels were fully mediated via depression: sex, family history of depression, previous history of anxiety, cognitive status, difficulties in non-disease-specific activities of daily living and severity of motor signs.

\section{Conclusion:}

In this cross-sectional study, we showed that nonspecific general population risk factors are more important markers for anxiety than PD-specific risk factors. Depression was the most prominent marker. PD-specific markers for anxiety appear to be more situational, and related to 'off periods and disease-specific disturbances of activities of daily living. 


\section{INTRODUCTION}

Parkinson's disease (PD) is a neurodegenerative disease in which non-motor symptoms, such as anxiety, depression and apathy are common and an important determinant for quality of life (1). Anxiety disorders include, amongst others, generalized anxiety, panic attacks and social phobia. These disorders contribute to the severity of motor signs, motor complications such as dyskinesias and on/off fluctuations, gait disturbances including freezing of gait and cognitive impairment (2-4). As for the general population, anxiety disorders in PD develop in the context of multiple interacting risk and protective factors. These factors may or may not be specific to PD itself. In the general population, longitudinal studies have shown that risk factors for anxiety include female sex and comorbid physical disease. Moreover, personal circumstances such as personality traits, coping, and stressful life events also play a role (5-7). In cross-sectional studies, some PD specific risk factors for anxiety have been identified, including longer disease duration, presence of motor fluctuations and levodopa use $(3,8,9)$. Only a few studies have investigated the role of general risk factors for anxiety in PD.

For depression, we recently showed that the more prominent markers for depression are non-PD specific, in contrast to PD-specific factors (10). The objective of this study was to construct and test a similar model of factors related to anxiety in PD, and to compare the relative contributions of $\mathrm{PD}$-specific and nonspecific general population markers to the anxiety outcome.

\section{METHODS}

Data from the database of a cross-sectional multicenter study on anxiety disorders in PD conducted in 2008 and 2009 were used, the results of which have been described earlier $(9,11)$.

\section{Population}

The database includes 342 patients with idiopathic PD, diagnosed according to the Queen Square Brain Bank criteria (12). Patients were recruited from consecutive referrals to movement disorders clinics, neurology clinics and psychiatry clinics of 6 centers in the United States, Europe, and Australia. All subjects underwent a comprehensive neurologic and neuropsychiatric assessment. Patients with clinically relevant cognitive impairment were excluded, which was operationalized as a Mini-Mental State Examination (MMSE) score below 26 following the recommendation of a Movement Disorder Society (MDS) Task Force $(13,14)$. In addition, patients with neurodegenerative disorders other than $\mathrm{PD}$ and patients who had undergone deep brain stimulation were 
excluded. All types of medication, including neurologic and psychotropic agents, were allowed.

\section{Standard protocol approvals, registrations, and patient consents}

The study was approved by the local Medical Ethics Committee at each participating institution. Participants gave written informed consent before inclusion in the study.

\section{Assessment}

In accordance with MDS Task Force recommendations, subjects who experienced motor fluctuations were examined only during "on" states and rated using an "inclusive" approach, meaning that the symptoms were scored as observed or reported irrespective of their assumed etiology (15). Demographic and disease-related variables were assessed during a clinical interview. Disease stage was rated with the Hoehn \&Yahr staging system (16) and motor function, disease-related decline in activities of daily living (ADL) or complications of therapy with the Unified Parkinson's Disease Rating Scale (UPDRS, section II-IV) (17). Cognitive functioning and instrumental ADL were assessed with the MMSE and Lawton Instrumental ADL (IADL) scale, respectively $(14,18)$. Anxiety was quantified with the clinician-rated Hamilton Anxiety Rating Scale (HARS) (19) and depression with the 17-item Hamilton Depression Rating Scale (HAMD) (20). The presence of anxiety disorders and depressive disorders according to the criteria of the 4th edition of the Diagnostic and Statistical Manual (DSM IV) were determined using the Mini International Neuropsychiatric Inventory (MINI), which is a structured interview for DSM-IV disorders, in particular the sections for anxiety (D, E, F, H) and depression $(\mathrm{A}, \mathrm{B})(21)$.

\section{Statistical analysis}

The total score on the HARS was chosen as outcome measure. This scale is particularly sensitive for symptoms of generalized anxiety disorder, the most prevalent anxiety disorder in PD(9). Structural equation modeling (SEM) was performed in Mplus 7 (Muthén \& Muthén, Los Angeles, CA) with the aim of identifying the most parsimonious model (taking into account model fit and number of included parameters and model complexity) that still accounted for a substantial part of the variance in the total score on the HARS. Variables were chosen on the basis of their known contribution to anxiety from the available literature. To discover collinearity between potential variables, an exploratory correlation analysis was performed. If the Spearman correlation coefficient " $r$ " between 2 potential parameters was both significant $(p<0.005$ after correction for multiple testing) and $>0.40$, a decision was made to include only one of these parameters in the model, based on clinical relevance. An exception was made for the HAMD score. Although this score showed a relatively strong and significant correlation with the HARS outcome, it was decided to keep this variable in the model, in order to be able 
to identify its potential contribution to the anxiety model. Persistent anxiety in PD is almost invariably associated with depression (22).

An initial theoretic path model was constructed with the remaining parameters (model 1). Because the path model included continuous, binary, and ordered categorical variables, a mean- and variances- corrected weighted least-squares estimator was used. All parameters were evaluated in a simultaneous fashion. Model 1 included direct and indirect paths of the variables hypothesized to influence the anxiety outcome in order to test putative effect mediation. Model fit was primarily assessed by inspecting the root mean square error of approximation (RMSEA) and the Comparative Fit Index (CFI). For the RMSEA, scores $\leq 0.05$ indicate good fit, and scores $\leq 0.08$ indicate acceptable fit. The CFI ranges from 0 to 1 with scores $\geq 0.95$ indicating good fit and scores $\geq 0.90$ indicating acceptable fit (23). Because the $\chi^{2}$ test is known to become positively biased with increasing sample size, this measure was not used to assess model fit (23). Based on model fit, the model was re-specified. First, paths that did not contribute substantially ( $p>0.10)$ to the model were removed manually in a backward 1-to-1 fashion, starting with the path with the highest $p$ value, resulting in a second model (model 2). Next, modification indices (MIs) were inspected to explore whether the model could be improved by specifying additional paths among the remaining variables. Additional paths (e.g., mediation paths or correlations) were included based on the MIs and substantive interpretation (model 3).

In a last step, we examined the contribution of PD-specific versus PD-nonspecific variables to the anxiety outcome. Two continuous latent variables (factors) were generated and regressed on anxiety. Their standardized regression coefficients were compared using a Wald test. To have both factors on the same scale, their factors variances were fixed to 1 .

\section{RESULTS}

\section{Sample characteristics}

The demographic and disease characteristics of the included sample are listed in Table $1(9,11)$. The study population comprised 207 men and 134 women with an average age of 64.8 years (SD 9.2 years). Based on the MINI, 70 participants (21\%) met the diagnostic criteria for a generalized anxiety disorder (GAD), 53 (16\%) for agoraphobia without panic disorder, 13 (4\%) for panic disorder and 34 participants (10\%) met the diagnostic criteria for social phobia. Thirty-four percent of patients met the DSM-IV criteria for at least one anxiety disorder. 
Table 1.

Demographic and disease characteristics of the sample $(n=341)$.

\begin{tabular}{|c|c|c|}
\hline Variable & Percentage & Mean (SD) or median (range) \\
\hline Female sex & 39 & \\
\hline Age & & $64.8(9.2)$ \\
\hline Duration of PD & & $8.3(5.6)$ \\
\hline UPDRS section 2 (ADL) & & $11.6(6.8)$ \\
\hline UPDRS section 3 (motor) & & $26.4(12.4)$ \\
\hline UPDRS section 4 (complications) & & $3.5(3.5)$ \\
\hline Hoehn \& Yahr stage & & $2(1-5)$ \\
\hline On/off fluctuations & 52 & \\
\hline Generalized anxiety disorder & 20.5 & \\
\hline Panic disorder & 3.9 & \\
\hline Agoraphobia without panic disorder & 15.5 & \\
\hline Social phobia & 10.0 & \\
\hline Major depression & 14.1 & \\
\hline Dysthymia & 5.6 & \\
\hline Previous history depression & 46.1 & \\
\hline Previous history anxiety disorder & 31.9 & \\
\hline Family history depression & 33.4 & \\
\hline Family history anxiety disorder & 19.4 & \\
\hline Family history of PD & 19.7 & \\
\hline HAMD score (SD; range) & & $7.7(5.9 ; 0-32)$ \\
\hline HARS score (SD; range) & & $11.3(8.5 ; 0-50)$ \\
\hline IADL score & & $7(1.5)$ \\
\hline MMSE score & & $28.5(1.7)$ \\
\hline Use of levodopa & 85.3 & \\
\hline Use of dopamine-agonist & 61.6 & \\
\hline Use of antipsychotic & 3.8 & \\
\hline
\end{tabular}

PD = Parkinson's disease; UPDRS = Unified Parkinson's Disease Rating Scale; ADL = Activities of Daily Living; HAMD $=$ Hamilton Depression Rating Scale; HARS = Hamilton Anxiety Rating Scale; IADL = Lawton's Instrumental Activities of Daily Living scale; MMSE = Mini Mental State Examination.

Results of the exploratory correlation analysis between variables that may be included in the regression analysis are shown in table e-1 (supplementary data). Based on the correlation, disease stage (Hoehn \& Yahr classification) was excluded from the model because of a moderate strong correlation with UPDRS sections II, III and IADL $(r=0.55, r=$ 0.56 and $r=-0.48$, respectively; all $p<0.01$ ). Separate parameters for the presence of motor fluctuations and dyskinesias were included in the model. It was decided to keep both the UPDRS section II (PD-specific ADL) and the score on the Lawton IADL scale 
in the model, despite moderate correlation $(r=-0.52, p<0.01)$. This was done because the UPDRS section II scores PD-related physical ADLs, whereas the IADL Scale can be considered a more general measure of independent functioning. It was also decided to keep the UPDRS section II score in the model despite its moderate correlation with UPDRS section III $(r=0.64, p<0.01)$.

The initial theoretical model is shown in figure 1 and specified in table e-2 (supplementary data). Nonspecific parameters included in this model were sex, age, previous history of anxiety, previous history of depression, family history of anxiety, family history of depression, depression score (HAMD total score), instrumental ADL function (IADL total score), and cognitive status (MMSE total score). PD-specific parameters in the model were disease duration, motor symptom severity (UPDRS section III total score), disease-specific ADL (UPDRS section II total score), presence of motor fluctuations (based on UPDRS section IV), use of levodopa, and use of a dopamine agonist. However, because this model showed a poor fit $(\mathrm{RMSEA}=0.134,90 \% \mathrm{CI}=0.125-0.144$; CFI 0.600), it was rejected and exploratory SEM analyses were started.

\section{Figure 1.}

Inital model of anxiety in PD (model 1)

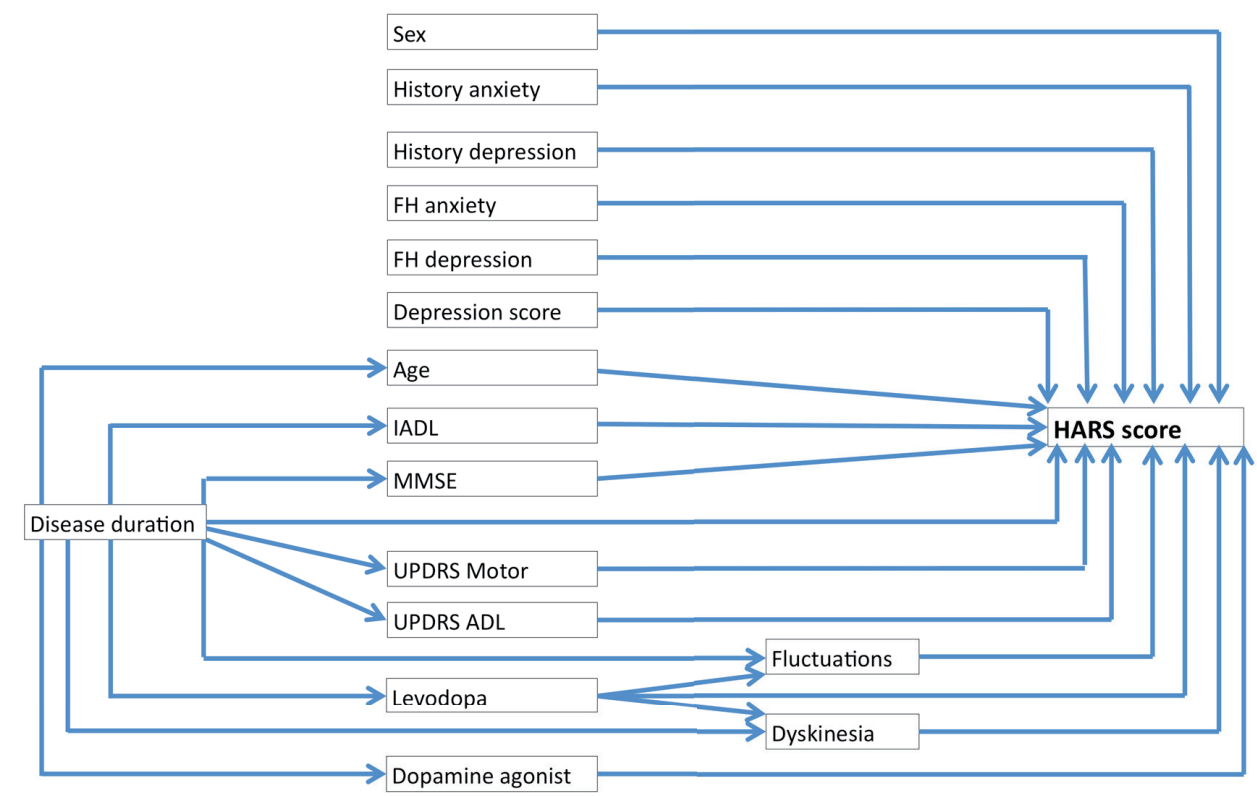

Legend: $A D L=$ activities of daily living; $F H$ = family history; HAMD = Hamilton Depression Rating Scale; $I A D L=$ Instrumental Activities of Daily Living; MMSE = Mini-Mental State Examination; PD = Parkinson disease; UPDRS = Unified Parkinson's Disease Rating Scale. 
In a first revision, paths that did not contribute significantly to the model were deleted in a one-by-one fashion. This resulted in deletion of 11 of the 16 variables: sex, history of anxiety, family history of anxiety, family history of depression, age, instrumental ADL score, cognitive status, motor symptom severity, levodopa use, dopamine agonist use, and presence of dyskinesia. This second, simpler model (model 2) still showed inadequate fit (RMSEA 0.210, 90\% CI =0.182-0.239; CFI 0.846). A second revision (model 3), which allowed for correlated residuals among variables and extra paths as suggested by MI, resulted in a third model with acceptable to good fit (RMSEA $=0.076,90 \% \mathrm{CI}=$ 0.028-0.127; CFI 0.992). This final model is shown in figure 2 and specified in table 2 . It explains $65.2 \%$ of the observed variance in the HARS outcome.

Table 2.

Standardized regression coefficients for the final model including 5 variables showing direct or indirect effects on anxiety (model 3 ).

\begin{tabular}{l|l|l|l|l|l|l}
\hline Parameter & Dependent variable & B & SE & $\beta$ & $z$ Statistic & $\boldsymbol{p}$ \\
\hline
\end{tabular}

Direct effect on HARS score:

\begin{tabular}{l|l|l|l|l|l|l}
\hline HAMD score & HARS score & 1.047 & 0.038 & 0.729 & 27.588 & 0.000 \\
\hline History depression & HARS score & 1.676 & 0.584 & 0.099 & 2.870 & 0.004 \\
\hline Motor fluctuations & HARS score & 0.922 & 0.299 & 0.120 & 3.078 & 0.002 \\
\hline UPDRS II (ADL) & HARS score & 0.165 & 0.043 & 0.133 & 3.854 & 0.000 \\
\hline
\end{tabular}

Indirect effect on HARS score mediated through other variable:

\begin{tabular}{l|l|l|l|l|l|l}
\hline $\begin{array}{l}\text { HAMD score through } \\
\text { UPDRS II (ADL) }\end{array}$ & HARS score & 0.042 & 0.014 & 0029 & 2.97 & 0.003 \\
\hline $\begin{array}{l}\text { Motor fluctuations } \\
\text { through UPDRS II } \\
\text { (ADL) }\end{array}$ & HARS score & -0.424 & 0.140 & -0.055 & -3.02 & 0.002 \\
\hline $\begin{array}{l}\text { Disease duration } \\
\text { through UPDRS II } \\
\text { (ADL) }\end{array}$ & HARS score & 0.086 & 0.027 & 0.057 & 3.241 & 0.001 \\
\hline $\begin{array}{l}\text { Disease duration } \\
\text { through motor fluctu- } \\
\text { ations }\end{array}$ & HARS score & 0.077 & 0.028 & 0.051 & 2.716 & $0.007^{*}$ \\
\hline $\begin{array}{l}\text { Disease duration } \\
\text { through motor fluctu- } \\
\text { ations and UPDRS II } \\
\text { (ADL) }\end{array}$ & HARS score & -0.035 & 0.013 & -0.023 & -2.709 & $0.007^{*}$ \\
\hline
\end{tabular}

Abbreviations: HAMD = Hamilton Depression Rating Scale; HARS = Hamilton Anxiety Rating Scale; UPDRS = Unified Parkinson's Disease Rating Scale; ADL = Activities of Daily Living; SE = standard error.

* Path would become non-significant if Bonferroni-corrected (4 direct+5 indirect paths tested: $\alpha_{\text {Bonferroni }}=0.05 / 9=$ $0.0055)$. Please note that paths are likely correlated and thus Bonferroni is overly conservative. 


\section{Figure 2.}

Final (third) model after removal of non-significant paths ands specifying additional indirect paths.

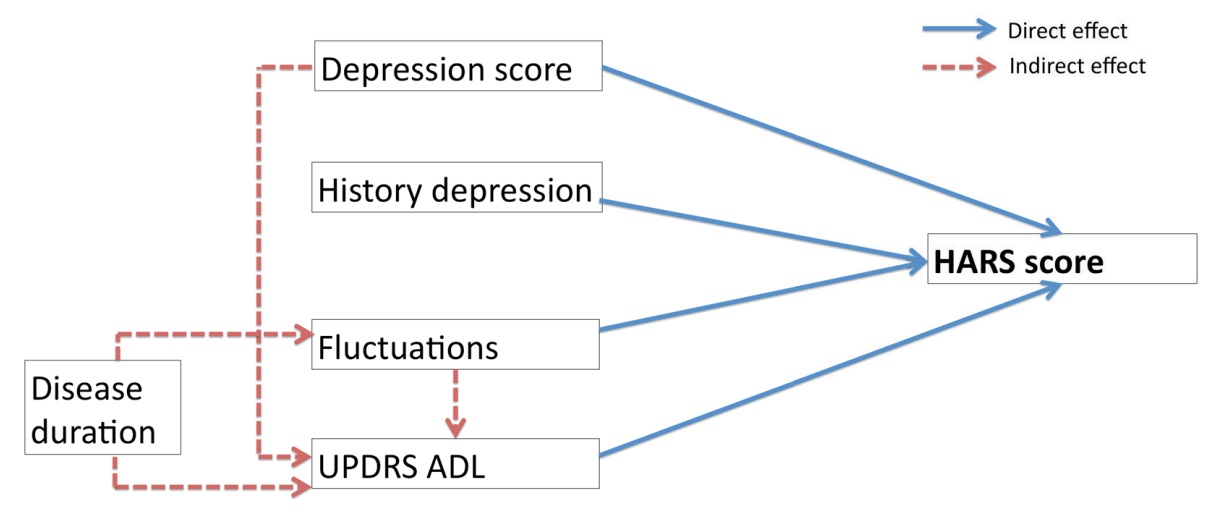

Legend: UPDRS = Unified Parkinson's Disease Rating Scale; ADL= Activities of Daily Living.

Standardized regression coefficients suggested that HAMD depression scores contributed most to variation in HARS outcome $(\beta=0.729, \mathrm{p}<0.01)$, with relatively modest direct effects for history of depression, motor fluctuations and disease-related impairment in ADL. Longer disease duration had a significant indirect effect only via its positive association with presence of motor fluctuations and PD-specific ADL. To compare the relative contribution of $\mathrm{PD}$-specific and nonspecific factors, we factorized depression and history of depression on one factor (PD-nonspecific) and disease duration, motor fluctuations and PD-specific ADL on another factor (PD-specific). This showed that the effects of both factors differed (Wald $=46.40, \mathrm{df}=1, \mathrm{p}<.001$ ), with the PD-nonspecific being significantly associated with anxiety scores $(\beta=0.913, \mathrm{p}<.001)$ while the PD-specific factor was not $(\beta=0.060, \mathrm{p}=.376)$.

Given the very strong contribution of HAMD depression scores in model 3, we conducted an exploratory post-hoc analysis to test whether depression explained or mediated the effect of the variables specified in the initial model 1 . We thus repeated the analytic approach from step 1 to step 3 as described above but removed the variable depression score from the model. The resulting post-hoc model, after removal of non-significant paths and specification of additional paths based on MI again, had poor fit (RMSEA = $0.112,90 \% \mathrm{CI}=0.095-0.130$ ); CFI 0.699), but was much more elaborate than model 3 , which included depression. We then added the depression variable in this post hoc model to see which variables influenced the HARS score through the depression score. 
This resulted in a second post hoc model (shown in figure 3 and specified in table e-3), which had an acceptable fit $($ RMSEA $=0.076,90 \% \mathrm{CI}=0.059-0.093$; CFI 0.868) and explained $68.9 \%$ of the observed variance in the HARS outcome.

\section{Figure 3.}

Model of anxiety in PD showing indirect effect mediated thougt depression (Second post-hoc model)

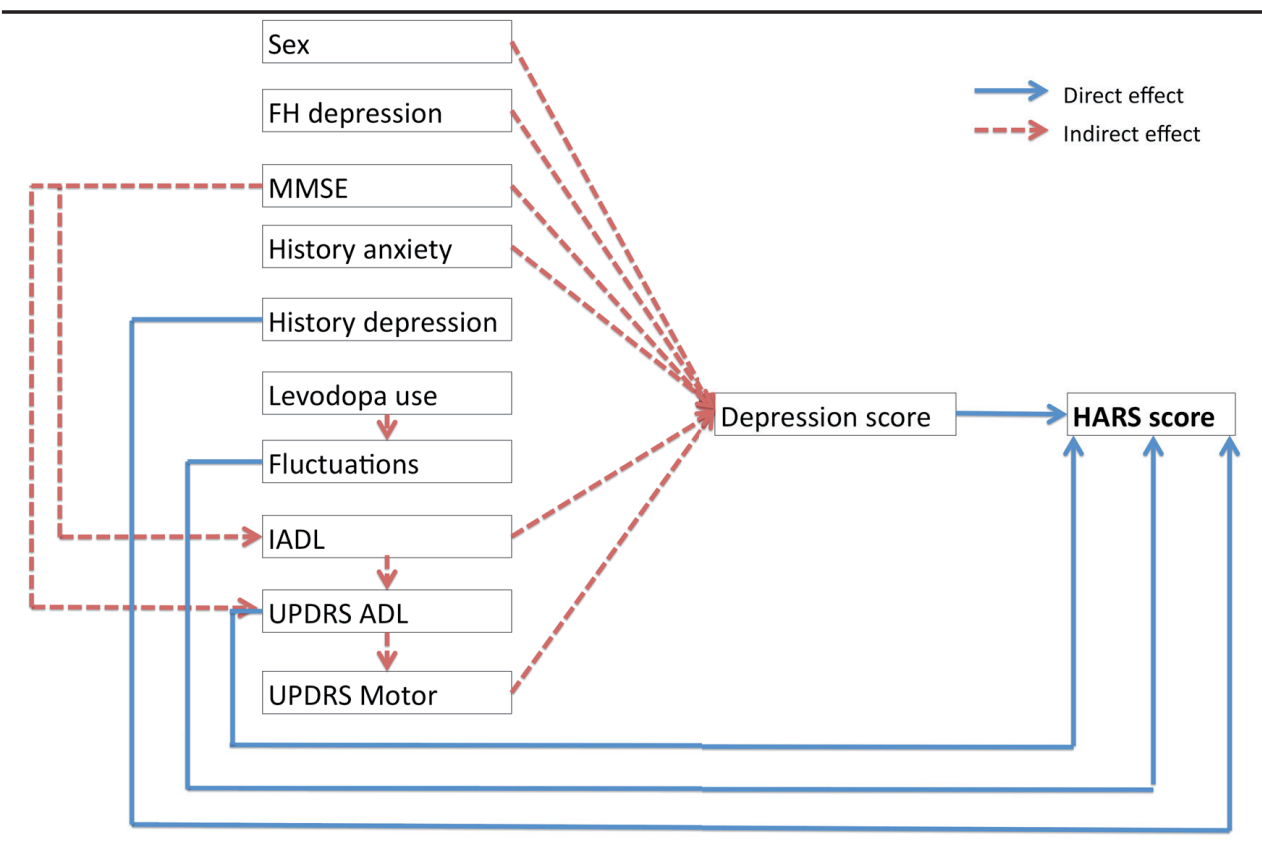

Legend: $A D L=$ activities of daily living; $F H=$ family history; HAMD = Hamilton Depression Rating Scale; IADL = Instrumental Activities of Daily Living; MMSE = Mini-Mental State Examination; PD = Parkinson disease; UPDRS = Unified Parkinson's Disease Rating Scale.

Only previous history of depression, motor fluctuations, and PD-specific ADLs had direct effects on HARS outcome that were not mediated by HAMD scores. In contrast, sex, family history of depression, history of anxiety, MMSE scores, difficulties in IADLs, and UPDRS motor signs were related to the HARS outcome only via their relation with depression score. 


\section{DISCUSSION}

Our results show that anxiety and depression in PD are closely related. Depression score appears to be the main marker for anxiety; an increase in HAMD score of 1 point resulted in an increased HARS score of 1.09 (via direct as well as indirect paths). Other direct markers of anxiety are a previous history of depression, presence of motor fluctuations, and more disease specific problems in ADL function. Our final model (model 3, figure 2) explains $65 \%$ of the variance in HARS outcome. Nonspecific risk factors seem to have a greater influence in the model than PD-specific risk factors.

The presence of motor fluctuations and disease-specific problems in ADL functioning are the only significant PD-related direct markers in our model. We hypothesize that this may reflect situational anxiety related to 'off' periods and to specific ADL activities. Insufficient coping mechanisms and psychological factors related to fluctuations and impairments in ADL, such as fear of falls, future dependency, and burdening of others, in addition to alterations in the dopamine system, may elevate the risk for anxiety (24). This is in line with other cross-sectional studies evaluating markers for anxiety or anxiety disorders in PD $(2,3$, $8,24,25)$. The finding that PD-specific risk factors seem to be more contextual or situational, opens the opportunity to develop preventative measures or interventions that target those specific situations. Consistent with this, cognitive-behavioral treatments, customized for PD patients with anxiety and depression, are one potentially beneficial approach (26).

With respect to other variables in our model, it is evident that levodopa affects motor fluctuations, but there was no direct effect on the HARS score. Dopamine agonists were not associated with higher anxiety levels. Some studies suggest that anti-parkinsonian medication may be a risk factor for anxiety (9), but others $\operatorname{do} \operatorname{not}(8,25)$. Long term use of levodopa may lead to motor fluctuations, in which 'off periods are associated with anxiety. Second, although female gender is considered an established risk factor for depression, it is also associated with anxiety in some studies $(25,27,28)$, but not in others (2, 29-31). Our findings suggest that women have more depressive symptoms, which in turn, appears to affect severity of anxiety. Third, in our study disease severity and cognitive function also had only indirect effects on anxiety. Some studies report a possible correlation between $\operatorname{MMSE}(32,33)$ or disease severity $(8,30,34)$ with anxiety disorders, while others do not $(25,27,35,36)$. The influence of cognitive decline and disease severity on depression scores, and subsequently on anxiety, is in line with studies examining risk factors for depression. Last, younger age is frequently reported to be an important risk factor for developing anxiety disorders $(8,35,37)$, but was dropped in a first step of optimization of the anxiety model. A possible explanation is that we considered the HARS total score but did not look at specific disorders. For example, social phobia, in particular, is associated with younger age (38). 
A recent study proposed different clinical profiles of anxiety in PD, with patients having no anxiety or depression, episodic anxiety without depression, persistent anxiety with depression, or both persistent and episodic anxiety with depression (22). Our model supports and provides a possible explanation for these profiles; apart from depression, only contextual or episodic factors directly influenced anxiety levels. Similar to depression in PD, it seems that general, non PD-specific risk factors are more important markers for anxiety in PD than PD-specific risk factors (10). This is consistent with the identified phenotypes in PD, where persistent anxiety is almost invariably associated with depression (22). Further studies could perhaps bring more clarity in the contribution of specific subdomains of depression in the etiology of anxiety in PD. PD-specific markers for anxiety appear to be more situational, and related to 'off periods and disease-specific ADL disturbances. PD, in itself, appears to be a marker for anxiety, with depression and situational factors, in particular, exerting pre-existing vulnerability.

This study has several limitations. First, the analysis was performed on an existing database of a cross-sectional study. Parameters selected to be included in the model were based on availability, which implies that other important markers of anxiety, such as personality, coping style, marital status, or life events were not included. Inclusion of additional variables in the model would provide a more complete psychosomatic overview of all factors associated with anxiety in PD. Second, establishing true prevalence of anxiety or depression in PD remains a diagnostic challenge. The assessment is complicated by symptomatic overlap between the somatic features of the neuropsychiatric and underlying movement disorders. Third, the high correlation of the HAMD and the HARS may introduce the problem of collinearity. However, when we compared our different models, no acceptable fit was acquired without including the HAMD-variable. Only when the HAMD-variable was included, an acceptable fit was reached, with clarification of mediation pathways of other variables through depression - as illustrated by our post-hoc analysis. In addition, in a previous study focusing on modeling depression in $\mathrm{PD}(10)$, the final depression model showed a good fit without including the HARS variable. This suggests that HARS and the HAMD have differential explanatory value in models of anxiety and depression. Next, it is difficult to strictly separate markers that are directly related to PD and those that are not. This is why the authors used the terms "PD-specific" and "nonspecific" rather than "PD-related" and "PD-unrelated" factors. Finally, the study is based on a cross-sectional dataset, which implies that no causal inferences can be drawn. In addition, the number of variables that could be included in the analysis was limited because of the sample size. However, the database was large enough to allow structural equation modeling analyses with a substantial number of parameters. Whereas our sample can be considered representative to populations that clinicians encounter in an outpatient clinic, our exploratory model requires confirmation in a longitudinal design, preferably with inclusion of more psychological and contextual variables. 
This could clarify causal inferences and allow for investigation of whether risk factors change with disease progression.

In summary, in our anxiety model depression mediates the associations between most of the included variables and the anxiety outcome. The direct influence of motor fluctuations and PD-specific difficulties in ADLs suggests that, apart from depression, situational or contextual factors seem to be the most important markers for anxiety. Clinicians should make every effort to explore situational or contextual anxiety in PD patients and initiate individualized measures to prevent or mitigate anxiety. It is also crucial to be aware of the common co-occurrence of anxiety with depression but that specific inquiry is needed to identify anxiety disturbances (39) and non-PD general population factors mainly contribute to anxiety levels. Research to better understand the complexities of anxiety and depression in PD is clearly warranted. Future studies of anxiety in PD may further benefit from use of a measure such as the Parkinson Anxiety Scale (PAS), which is better able to discriminate between episodic and non-episodic anxiety or between anxiety and depression (40). 


\section{REFERENCES}

1. Barone P, Antonini A, Colosimo C, Marconi R, Morgante L, Avarello TP, et al. The PRIAMO study: A multicenter assessment of nonmotor symptoms and their impact on quality of life in Parkinson's disease. Mov Disord. 2009;24(11):1641-9.

2. Pontone GM, Williams JR, Anderson KE, Chase G, Goldstein SA, Grill S, et al. Prevalence of anxiety disorders and anxiety subtypes in patients with Parkinson's disease. Mov Disord. 2009;24(9):1333-8.

3. Sagna A, Gallo JJ, Pontone GM. Systematic review of factors associated with depression and anxiety disorders among older adults with Parkinson's disease. Parkinsonism Relat Disord. 2014;20(7):708-15.

4. Yamanishi T, Tachibana H, Oguru M, Matsui K, Toda K, Okuda B, et al. Anxiety and depression in patients with Parkinson's disease. Intern Med. 2013;52(5):539-45.

5. Beekman AT, Bremmer MA, Deeg DJ, van Balkom AJ, Smit JH, de Beurs E, et al. Anxiety disorders in later life: a report from the Longitudinal Aging Study Amsterdam. Int J Geriatr Psychiatry. 1998;13(10):71726.

6. Schoevers RA, Beekman AT, Deeg DJ, Jonker C, van Tilburg W. Comorbidity and risk-patterns of depression, generalised anxiety disorder and mixed anxiety-depression in later life: results from the AMSTEL study. Int J Geriatr Psychiatry. 2003;18(11):994-1001.

7. Vink D, Aartsen MJ, Schoevers RA. Risk factors for anxiety and depression in the elderly: a review. J Affect Disord. 2008;106(1-2):29-44.

8. Dissanayaka NN, Sellbach A, Matheson S,
O'Sullivan JD, Silburn PA, Byrne GJ, et al. Anxiety disorders in Parkinson's disease: prevalence and risk factors. Mov Disord. 2010;25(7):838-45.

9. Leentjens AF, Dujardin K, Marsh L, Martinez-Martin P, Richard IH, Starkstein SE. Symptomatology and markers of anxiety disorders in Parkinson's disease: a cross-sectional study. Mov Disord. 2011;26(3):48492.

10. Leentjens AF, Moonen AJ, Dujardin K, Marsh L, Martinez-Martin P, Richard IH, et al. Modeling depression in Parkinson disease: disease-specific and nonspecific risk factors. Neurology. 2013;81(12):1036-43.

11. Leentjens AF, Dujardin K, Marsh L, Richard IH, Starkstein SE, Martinez-Martin P. Anxiety rating scales in Parkinson's disease: a validation study of the Hamilton anxiety rating scale, the Beck anxiety inventory, and the hospital anxiety and depression scale. Mov Disord. 2011;26(3):407-15.

12. de Rijk MC, Rocca WA, Anderson DW, Melcon MO, Breteler MM, Maraganore DM. A population perspective on diagnostic criteria for Parkinson's disease. Neurology. 1997;48(5):1277-81.

13. Dubois B, Burn D, Goetz C, Aarsland D, Brown RG, Broe GA, et al. Diagnostic procedures for Parkinson's disease dementia: recommendations from the movement disorder society task force. Mov Disord. 2007;22(16):2314-24.

14. Folstein MF, Folstein SE, McHugh PR. "Mini-mental state". A practical method for grading the cognitive state of patients for the clinician. J Psychiatr Res. 1975;12(3):189-98. 
15. Schrag A, Barone P, Brown RG, Leentjens AF, McDonald WM, Starkstein S, et al. Depression rating scales in Parkinson's disease: critique and recommendations. Mov Disord. 2007;22(8):1077-92.

16. Hoehn MM, Yahr MD. Parkinsonism: onset, progression and mortality. Neurology. 1967;17(5):427-42.

17. Fahn S, Elton RL. Members of the UPDRS Committee. Unified Parkinson's Disease Rating Scale. In: Fahn S, Marsden CD, Goldstein M, Calne DB, editors. Recent Developments in Parkinson's Disease. Florham Park, NJ: MacMillan Health Care; 1987. p. 153-63.

18. Lawton MP, Brody EM. Assessment of older people: self-maintaining and instrumental activities of daily living. Gerontologist. 1969;9(3):179-86.

19. Hamilton M. The assessment of anxiety states by rating. Br J Med Psychol. 1959;32(1):50-5.

20. Hamilton M. A rating scale for depression. J Neurol Neurosurg Psychiatry. 1960;23:56-62.

21. Sheehan DV, Lecrubier Y, Sheehan KH, Amorim P, Janavs J, Weiller E, et al. The Mini-International Neuropsychiatric Interview (M.I.N.I.): the development and validation of a structured diagnostic psychiatric interview for DSM-IV and ICD-10. J Clin Psychiatry. 1998;59 Suppl 20:2233; quiz 4-57.

22. Starkstein SE, Dragovic M, Dujardin K, Marsh L, Martinez-Martin P, Pontone GM, et al. Anxiety has specific syndromal profiles in Parkinson disease: a data-driven approach. Am J Geriatr Psychiatry.
2014;22(12):1410-7.

23. Byrne BM. Structural Equation Modeling with Mplus: Basic Concepts, Applications, and Programming. New York: Taylor \& Francis Group; 2011.

24. Dissanayaka NN, White E, O'Sullivan JD, Marsh R, Pachana NA, Byrne GJ. The clinical spectrum of anxiety in Parkinson's disease. Mov Disord. 2014;29(8):967-75.

25. Negre-Pages L, Grandjean H, Lapeyre-Mestre M, Montastruc JL, Fourrier A, Lepine JP, et al. Anxious and depressive symptoms in Parkinson's disease: the French cross-sectionnal DoPaMiP study. Mov Disord. 2010;25(2):157-66.

26. Calleo JS, Amspoker AB, Sarwar AI, Kunik ME, Jankovic J, Marsh L, et al. A Pilot Study of a Cognitive-Behavioral Treatment for Anxiety and Depression in Patients With Parkinson Disease. J Geriatr Psychiatry Neurol. 2015.

27. Mondolo F, Jahanshahi M, Grana A, Biasutti E, Cacciatori E, Di Benedetto P. Evaluation of anxiety in Parkinson's disease with some commonly used rating scales. Neurol Sci. 2007;28(5):270-5.

28. Solla P, Cannas A, Floris GL, Orofino G, Costantino E, Boi A, et al. Behavioral, neuropsychiatric and cognitive disorders in Parkinson's disease patients with and without motor complications. Prog Neuropsychopharmacol Biol Psychiatry. 2011;35(4):1009-13.

29. Bolluk B, Ozel-Kizil ET, Akbostanci MC, Atbasoglu EC. Social anxiety in patients with Parkinson's disease. J Neuropsychiatry Clin Neurosci. 2010;22(4):390-4.

30. Kulisevsky J, Pagonabarraga J, Pascual-Se- 
dano B, Garcia-Sanchez C, Gironell A, Trapecio Group S. Prevalence and correlates of neuropsychiatric symptoms in Parkinson's disease without dementia. Mov Disord. 2008;23(13):1889-96.

31. Martinez-Martin P, Falup Pecurariu C, Odin P, van Hilten JJ, Antonini A, Rojo-Abuin JM, et al. Gender-related differences in the burden of non-motor symptoms in Parkinson's disease. J Neurol. 2012;259(8):1639-47.

32. Foster PS, Drago V, Mendez K, Witt JC, Crucian GP, Heilman KM. Mood disturbances and cognitive functioning in Parkinson's disease: the effects of disease duration and side of onset of motor symptoms. J Clin Exp Neuropsychol. 2013;35(1):7182.

33. Lee WJ, Tsai CF, Gauthier S, Wang SJ, Fuh JL. The association between cognitive impairment and neuropsychiatric symptoms in patients with Parkinson's disease dementia. Int Psychogeriatr. 2012;24(12):1980-7.

34. Stefanova E, Ziropadja L, Petrovic M, Stojkovic T, Kostic V. Screening for anxiety symptoms in Parkinson disease: a cross-sectional study. J Geriatr Psychiatry Neurol. 2013;26(1):34-40.

35. Burn DJ, Landau S, Hindle JV, Samuel M, Wilson KC, Hurt CS, et al. Parkinson's disease motor subtypes and mood. Mov Disord. 2012;27(3):379-86.

36. Menza MA, Robertson-Hoffman DE, Bonapace AS. Parkinson's disease and anxiety: comorbidity with depression. Biol Psychiatry. 1993;34(7):465-70.

37. Chen YK, Lu JY, Chan DM, Mok VC, Yeung MA, Wong KS, et al. Anxiety disorders in Chinese patients with Parkinson's disease. Int J Psychiatry Med. 2010;40(1):97-107.
38. Gultekin BK, Ozdilek B, Bestepe EE. Social phobia in Parkinson's disease: Prevalence and risk factors. Neuropsychiatr Dis Treat. 2014;10:829-34.

39. Calleo J, Williams JR, Amspoker AB, Swearingen L, Hirsch ES, Anderson K, et al. Application of depression rating scales in patients with Parkinson's disease with and without co-Occurring anxiety. J Parkinsons Dis. 2013;3(4):603-8.

40. Leentjens AF, Dujardin K, Pontone GM, Starkstein SE, Weintraub D, Martinez-Martin P. The Parkinson Anxiety Scale (PAS): Development and validation of a new anxiety scale. Mov Disord. 2014;29(8):1035-43. 


\section{SUPPLEMENTARY FILES}

Table e-1.

Spearman coefficients between variables included in the hypothesized model.

\begin{tabular}{l|l|l|l|l|l|l|l|l|l}
\hline & Dyskinesia & Fluctuations & $\begin{array}{l}\text { UPDRS } \\
\text { motor }\end{array}$ & $\begin{array}{l}\text { UPDRS } \\
\text { ADL }\end{array}$ & $\begin{array}{l}\text { HARS } \\
\text { total }\end{array}$ & $\begin{array}{l}\text { HAMD } \\
\text { total }\end{array}$ & IADL & H\&Y & Depression \\
\hline Dyskinesia & $\mathrm{x}$ & .43 & & & & & & & \\
\hline Fluctuations & & $\mathrm{x}$ & & & & & & & \\
\hline UPDRS motor & & & $\mathrm{x}$ & .64 & & & -.44 & .56 & \\
\hline UPDRS ADL & & & & $\mathrm{x}$ & & & -.52 & .55 & \\
\hline HARS total & & & & & $\mathrm{x}$ & .80 & & & .42 \\
\hline HAMD total & & & & & & $\mathrm{x}$ & & & .53 \\
\hline IADL & & & & & & & $\mathrm{x}$ & -.48 & \\
\hline H\&Y & & & & & & & $\mathrm{x}$ & \\
\hline Depression & & & & & & & & & $\mathrm{x}$ \\
\hline
\end{tabular}

Only parameters with significant correlation coefficients larger than 0.4 are shown. Significance is defined here as $\mathrm{p}<0.005$ (after correction for multiple testing). Variables not shown (sex, age, disease duration, MMSE score, history of anxiety, history of depression, dysthymia, the use of a dopamine agonist or levodopa) have either no significant $(p \geq 0.005)$ or only weak $(r \leq 0.4)$ correlations with any of the other variables.

Abbreviations: UPDRS: Unified Parkinson Disease Rating Scale; ADL = Activities of Daily Living; IADL = Lawton's Instrumental Activities of Daily Living scale.; HARS = Hamilton Anxiety Rating Scale; HAMD = Hamilton Depression Rating Scale; $P D=$ Parkinson Disease; $H \& Y=$ Hoehn and Yahr score in ON phase 
Table e-2.

Standardized regression coefficients of the initial (theoretical) model including 16 variables (model 1)

\begin{tabular}{l|l|l|l|l|l|l}
\hline Parameter & Dependent variable & B & SE & $\beta$ & z Statistic & $p$ \\
\hline
\end{tabular}

Direct effect on HARS score:

\begin{tabular}{l|l|l|l|l|l|l}
\hline Age & HARS score & 0.014 & 0.031 & 0.014 & 0.433 & 0.665 \\
\hline Sex & HARS score & -0.031 & 0.617 & -0.002 & -0.050 & 0.960 \\
\hline HAMD score & HARS score & 1.101 & 0.039 & 0.768 & 28.486 & 0.000 \\
\hline FH depression & HARS score & -0.557 & 0.715 & -0.031 & -0.779 & 0.436 \\
\hline IADL score & HARS score & -0.461 & 0.180 & -0.076 & -2.556 & 0.011 \\
\hline MMSE score & HARS score & 0.065 & 0.170 & 0.012 & 0.382 & 0.702 \\
\hline History anxiety & HARS score & 0.190 & 0.634 & 0.011 & 0.300 & 0.764 \\
\hline History depression & HARS score & 1.657 & 0.669 & 0.098 & 2.476 & 0.013 \\
\hline FH anxiety & HARS score & 1.275 & 0.838 & 0.059 & 1.521 & 0.128 \\
\hline Dopamine agonist use & HARS score & 0.049 & 0.299 & 0.006 & 0.162 & 0.871 \\
\hline Levodopa use & HARS score & -0.126 & 1.374 & -0.019 & -0.091 & 0.927 \\
\hline Motor fluctuations & HARS score & 0.410 & 0.499 & 0.065 & 0.821 & 0.412 \\
\hline Dyskinesias & HARS score & 0.289 & 0.642 & 0.053 & 0.450 & 0.652 \\
\hline UPDRS III (motor) & HARS score & 0.061 & 0.032 & 0.049 & 1.913 & 0.056 \\
\hline UPDRS II (ADL) & HARS score & 0.160 & 0.034 & 0.120 & 4.637 & 0.000 \\
\hline Disease duration & HARS score & -0.103 & 0.110 & -0.068 & -0.937 & 0.349 \\
\hline
\end{tabular}

Indirect effect on HARS score:

\begin{tabular}{l|l|l|l|l|l|l}
\hline Levodopa use & Motor fluctuations & 0.691 & 0.136 & 0.660 & 5.071 & 0.000 \\
\hline Disease duration & Motor fluctuations & 0.003 & 0.025 & 0.013 & 0.121 & 0.903 \\
\hline Levodopa use & Dyskinesias & 0.963 & 0.251 & 0.806 & 3.842 & 0.000 \\
\hline Disease duration & Dyskinesias & -0.022 & 0.034 & -0.081 & -0.656 & 0.512 \\
\hline Disease duration & Age & 0.125 & 0.102 & 0.080 & 1.217 & 0.223 \\
\hline Disease duration & IADL score & -0.066 & 0.014 & -0.266 & -4.847 & 0.000 \\
\hline Disease duration & MMSE score & -0.024 & 0.017 & -0.082 & -1.399 & 0.162 \\
\hline Disease duration & UPDRS III (motor) & 0.271 & 0.070 & 0.227 & 3.840 & 0.000 \\
\hline Disease duration & UPDRS II (ADL) & 0.369 & 0.062 & 0.326 & 5.928 & 0.000 \\
\hline Disease duration & Levodopa use & 0.143 & 0.021 & 0.0626 & 6.698 & 0.000 \\
\hline Disease duration & Dopamie agonist use & 0.031 & 0.012 & 0.170 & 2.571 & 0.010 \\
\hline
\end{tabular}

Abbreviations: $\mathrm{FH}=$ Family history; IADL = Lawton's Instrumental Activities of Daily Living scale; $M M S E=$ Mini

Mental State Examination; UPDRS = Unified Parkinson Disease Rating Scale; ADL = Activities of Daily Living;HAMD

= Hamilton Depression Rating Scale; HARS = Hamilton Anxiety Rating Scale; SE = standard error. 
Table e-3.

Standardized regression coefficients showing direct effects within specified paths for the second post-hoc model.

\begin{tabular}{l|l|l|l|l|l|l}
\hline Parameter & Dependent variable & B & SE & $\beta$ & $z$ Statistic & $\boldsymbol{p}$ \\
\hline
\end{tabular}

Direct effect on HARS score:

\begin{tabular}{l|l|l|l|l|l|l}
\hline HAMD score & HARS score & 1.048 & 0.043 & 0.701 & 24.538 & 0.000 \\
\hline History depression & HARS score & 4.245 & 1.089 & 0.252 & 3.897 & 0.000 \\
\hline Motor fluctuations & HARS score & 1.616 & 0.493 & 0.201 & 3.276 & 0.001 \\
\hline UPDRS II (ADL) & HARS score & 0.168 & 0.038 & 0.128 & 4.409 & 0.000 \\
\hline
\end{tabular}

Indirect effect on HARS score:

\begin{tabular}{l|l|l|l|l|l|l}
\hline Levodopa use & Motor fluctuations & 0.871 & 0.225 & 0.295 & 3.877 & 0.000 \\
\hline UPDRS ADL & UPDRS III(motor) & 0.763 & 0.048 & 0.692 & 15.842 & 0.000 \\
\hline Sex & HAMD score & -1.559 & 0.625 & -0.136 & -2.493 & 0.013 \\
\hline FH depression & HAMD score & 1.961 & 0.743 & 0.165 & 2.640 & 0.008 \\
\hline IADL score & HAMD score & -0.454 & 0.141 & -0.114 & -3.212 & 0.001 \\
\hline MMSE score & HAMD score & -0.549 & 0.164 & -0.166 & -3.351 & 0.001 \\
\hline History anxiety & HAMD score & 2.327 & 0.678 & 0.199 & 3.432 & 0.001 \\
\hline UPDRS III (motor) & HAMD score & 0.211 & 0.034 & 0.266 & 6.190 & 0.000 \\
\hline MMSE score & IADL score & 0.167 & 0.038 & 0.202 & 4.438 & 0.000 \\
\hline MMSE score & UPDRS II(ADL) & -0.640 & 0.214 & -0.170 & -2.995 & 0.003 \\
\hline IADL score & UPDRS II (ADL) & -4.699 & 0.530 & -0.538 & -8.870 & 0.000 \\
\hline
\end{tabular}

Abbreviations: $\mathrm{FH}=$ Family history; IADL = Lawton's Instrumental Activities of Daily Living scale; $M$ MSE = Mini Mental State Examination; UPDRS = Unified Parkinson Disease Rating Scale; $A D L=$ Activities of Daily Living; HAMD $=$ Hamilton Depression Rating Scale;HARS $=$ Hamilton Anxiety Rating Scale; SE = standard error. 



\section{Chapter 4}

\section{Factor analysis of the Hamilton Depression Rating Scale in Parkinson's disease.}

Broen MPG, Moonen AJH, Kuijf ML, Dujardin K, Marsh L, Richard IH, Starkstein SE, Martinez-Martin P, Leentjens AFG Parkinsonism Relat Disord. 2015 Feb;21(2):142-6. 


\section{ABSTRACT}

\section{Introduction:}

Several studies have validated the Hamilton Depression Rating Scale (HAMD) in patients with Parkinson's disease (PD), and reported adequate reliability and construct validity. However, the factorial validity of the HAMD has not yet been investigated. The aim of our analysis was to explore the factor structure of the HAMD in a large sample of $\mathrm{PD}$ patients.

\section{Methods:}

A principal component analysis of the 17-item HAMD was performed on data of 341 PD patients, available from a previous cross sectional study on anxiety. An eigenvalue $\geq 1$ was used to determine the number of factors. Factor loadings $\geq 0.4$ in combination with oblique rotations were used to identify which variables made up the factors. Kaiser-Meyer-Olkin measure (KMO), Cronbach's alpha, Bartlett's test, communality, percentage of non-redundant residuals and the component correlation matrix were computed to assess factor validity.

\section{Results:}

KMO verified the sample's adequacy for factor analysis and Cronbach's alpha indicated a good internal consistency of the total scale. Six factors had eigenvalues $\geq 1$ and together explained $59.19 \%$ of the variance. The number of items per factor varied from 1 to 6 . Inter-item correlations within each component were low. There was a high percentage of non-redundant residuals and low communality.

\section{Conclusion:}

This analysis demonstrates that the factorial validity of the HAMD in PD is unsatisfactory. This implies that the scale is not appropriate for studying specific symptom domains of depression based on factorial structure in a PD population. 


\section{INTRODUCTION}

Depression is common in patients with Parkinson's disease (PD) and recent studies show that up to $35 \%$ of patients have clinically relevant depressive symptoms (1). Adequate recognition and treatment lead to a better quality of life (2), which underlines the importance of valid depression scales. The Hamilton Depression Rating Scale (HAMD) is the most commonly used measure of depressive symptoms (3). It was developed in the late 1950s to assess the effectiveness of the first generation of antidepressants (4). Throughout the years, several studies have demonstrated adequate reliability and construct validity of the HAMD in PD patients $(5,6)$. However, none of these studies addressed the factor structure of the HAMD in this population. Factor analyses of the HAMD in the general population are not easily generalizable to the PD population, since symptoms of PD and depression may overlap. The aim of this analysis is to explore the multidimensionality of the HAMD in a large PD population by conducting an exploratory factor analysis.

\section{METHOD}

\section{Population and assessment}

The present study is a secondary analysis of a cross sectional observational study conducted in 2008 and 2009 that was aimed at validating anxiety rating scales. (7). The database included 341 patients with PD, diagnosed according to the Queen Square Brain Bank clinical criteria. Inclusion and exclusion criteria and assessment procedures were published previously (7). All patients underwent a comprehensive neurologic and neuropsychiatric assessment, including the 17-item HAMD. The HAMD, an interview-based rating scale, consists of 17 items: 16 question-based items and one observational item. The scale covers the whole spectrum of depressive symptoms, including affective, cognitive and somatic symptoms. The item scores range from 0-4 (symptom is absent, mild, moderate, or severe) or 0-2 (absent, slight or trivial, clearly present). The total score can range from 0 to 54 . A cut-off score of $9 / 10$ has been suggested for screening purposes in PD patients (6). The presence of a DSM- $I V$-defined depressive disorder was determined using the Mini International Neuropsychiatric Inventory (MINI), sections for depression (A, B). The local Medical Ethics Committees of all participating institutions approved the study. Patients gave written informed consent before inclusion in the study. 


\section{Statistical analyses}

A principal component analysis (PCA) was conducted on the 17 items of the HAMD. Initially, we used an eigenvalue $\geq 1$ to determine the number of factors, in combination with scree plots. Since we expected that underlying factors may be related, we used oblique rotation (direct oblimin) to optimise configuration on factors, allowing for maximum amount of non-orthogonality (Delta $=0$ ). We used factor loadings with an absolute value greater than 0.4 , which explains around $16 \%$ of the variance in the variable (8). When items loadings were $>0.4$ on more than one factor, one factor was selected based on the clinically most plausible solution. We then compared pattern and structure matrices to reveal the influence of shared variance. Communality was calculated to show the proportion of variance explained by the extracted factors. In addition, we conducted a Bartlett's test to check for intercorrelation between variables, measured the percentage of non-redundant residuals and calculated the component correlation matrix to check for correlations between the factors. The Kaiser-Meyer-Olkin measure of sampling adequacy (KMO) was computed to determine adequacy of sample size and the internal consistency of the scale was measured with Cronbach's alpha $(\alpha)$. To determine the most appropriate number of factors, we re-run the analysis with a fixed number of 2, 3, 4, 5 , and 7 extracted factors. All analyses were computed with SPSS 20 (Chicago).

\section{RESULTS}

The study population consisted of 207 men and 134 women (total $n=341$ ) with an average age of 64.8 years (SD 9.2; range 34 to 87 ), mean disease duration of 8.3 years (SD 5.6), mean UPDRS III score 26.4 (SD 12.4), and an average Hoehn and Yahr stage of 2. Half of the patients experienced on/off fluctuations and 39\% suffered from dyskinesias. Eighty-five percent of patients used levodopa and 62\% dopamine agonists. Mean MMSE score was 28.5 (SD 1.7). Based on the MINI, 48 participants (14\%) met the DSM IV criteria for a current major depressive episode, $19(6 \%)$ met the DSM IV criteria for dysthymia, and $64(19 \%)$ suffered from clinically relevant depressive symptoms (defined here as a HAMD score $\geq 12$ ), but did not meet the DSM IV diagnostic criteria for major depressive episode or dysthymia. The mean HAMD-score of patients with a major depressive episode was 16.8 (SD 5.5) and 6.2 (SD 4.4) for patients without a major depressive episode. Cronbach's alpha $(\alpha)$ was 0.79 , which indicates a good reliability of the total HAMD scale. More demographic and disease-related characteristics of the sample are listed in Table $s 1$ of the supplementary data.

The Kaiser-Meyer-Olkin measure verified the sampling adequacy for the analysis. A $\mathrm{KMO}$ value of 0.78 confirms that sampling adequacy was tolerable. All but one KMO values for individual items were above the acceptable limit of 0.5 . Item 17 Insight- no 
acknowledgment of illness had an individual KMO of 0.45 . Bartlett's test of sphericity indicated that correlations between items were sufficiently large for PCA ( 2 (136) = 1114.315, p <0.01). An initial analysis was conducted to obtain eigenvalues for each component in the data. Six components had eigenvalues over Kaiser's criterion of 1 and together they explained $59.2 \%$ of the variance. The scree plot showed many small inflexions. Table 1 shows the factor loadings after rotation for the six factor solution based on the Kaiser criterion. Only item 7 Difficulty with work and activities had more than one factor loading $>0.4$. Based on the clinically most plausible solution, it was decided to place this item in component 1 .

Table 1.

Rotated factor loadings $(\mathrm{N}=341)$

\begin{tabular}{|c|c|c|c|c|c|c|}
\hline \multirow[b]{2}{*}{ Item } & \multicolumn{6}{|c|}{ Rotated Factor Loadings } \\
\hline & 1 & 2 & 3 & 4 & 5 & 6 \\
\hline 1. Depressed mood & 0.46 & -0.02 & -0.35 & -0.14 & 0.22 & 0.06 \\
\hline 2. Feelings of guilt & 0.08 & 0.04 & -0.71 & 0.05 & 0.05 & -0.04 \\
\hline 3. Suicide & 0.11 & 0.09 & -0.74 & -0.03 & -0.04 & -0.04 \\
\hline 4. Insomnia early-falling asleep & -0.07 & -0.46 & -0.14 & -0.09 & 0.31 & -0.23 \\
\hline 5. Insomnia middle- waking during night & 0.16 & -0.80 & 0.18 & -0.04 & 0.02 & 0.01 \\
\hline 6. Insomnia late- early morning waking & 0.06 & -0.72 & -0.07 & 0.11 & -0.03 & 0.20 \\
\hline 7. Difficulty with work and activities & 0.42 & 0.06 & -0.06 & -0.16 & 0.44 & 0.26 \\
\hline 8. Retardation- psychomotor & 0.59 & 0.23 & 0.10 & 0.05 & 0.30 & 0.11 \\
\hline 9. Agitation & -0.06 & -0.09 & -0.66 & -0.00 & -0.04 & 0.16 \\
\hline 10. Anxiety-psychic & 0.78 & -0.11 & -0.09 & 0.17 & -0.15 & -0.11 \\
\hline 11. Anxiety-somatic & 0.62 & -0.19 & -0.24 & -0.07 & -0.07 & 0.10 \\
\hline 12. Somatic- gastro-intestinal and appetite & -0.16 & -0.01 & -0.14 & 0.39 & 0.21 & 0.59 \\
\hline 13. Somatic- general & -0.08 & 0.01 & -0.29 & 0.11 & 0.71 & -0.08 \\
\hline 14. Genital symptoms & 0.09 & -0.11 & 0.22 & -0.03 & 0.68 & 0.05 \\
\hline 15. Hypochondriasis & 0.61 & -0.15 & -0.01 & 0.02 & 0.01 & -0.03 \\
\hline 16. Loss of weight & 0.06 & -0.10 & -0.02 & -0.16 & -0.08 & 0.80 \\
\hline 17. Insight- no acknowledgment of illness & 0.15 & -0.03 & 0.02 & 0.92 & -0.00 & -0.08 \\
\hline Eigenvalues & 4.06 & 1.52 & 1.22 & 1.13 & 1.09 & 1.04 \\
\hline$\%$ of variance & 23.89 & 8.96 & 7.15 & 6.67 & 6.41 & 6.11 \\
\hline$\alpha$ & 0.77 & 0.53 & 0.60 & - & 0.38 & 0.35 \\
\hline
\end{tabular}

Note: Factor loadings over .40 appear in bold. Results of pattern analysis are shown. 
Table 2 gives an overview of the items clustering when 2, 3, 4, 5, 6 or 7 components were extracted. Results following PCA indicated that component 1 represents the core symptoms of depression: depressed mood, anxiety, decreased activity, psychomotor retardation and hypochondriasis. Component 2 represents sleep difficulties and component 3 clusters delusions, agitation and suicide together. Component 4 represents the only observation item insight of illness. Component 5 includes the general somatic symptoms and loss of libido, component 6 gastrointestinal symptoms and loss of weight. However, since a factor must consist of at least two joined items and component 4 represents only one item, the total number of genuine factors is 5 .

\section{Correlations}

Although Bartlett's test turned out to be significant, the correlation matrix (Supplementary data, Table s2) shows that correlations between several items are not very strong (all $r<0.3$ ). Especially item 17 Insight (acknowledgment of illness) appears to be weakly correlated to other items (all $r<0.2$ ). In addition, variables 4 Insomnia early (falling asleep), 12 Somatic (gastro-intestinal and appetite), 14 Genital symptoms and 16 Loss of weight all have correlations below 0.3. To assess the fit of the model we looked at the differences between the observed correlations and the correlations based on the model, using the reproduced matrix (Supplementary data, Table s3). A good model should have low residual values $(<0.05)$. However, this model shows $52 \%$ non-redundant residuals with absolute values greater than 0.05 .

\section{Communality}

Communality measures the proportion of common variance present in a variable. According to Kaiser's criterion, an individual value of $>0.7$ or an average value of $>0.6$ when sample size exceeds 250 , indicates sufficient communality. In this sample, only 2 items (5 Insomnia middle-waking during night) and 17 Insight have values $>0.7$. The average of the communalities $(10.062 / 17)=0.59$ which is just below the acceptable 0.6. None of the variables have values below 0.4 . 
Table 2.

Overview of factor components when 2-7 factors are calculated.

\begin{tabular}{|c|c|c|c|c|c|c|}
\hline $\begin{array}{l}\text { Number of } \\
\text { factors }\end{array}$ & 2 & 3 & 4 & 5 & 6 & 7 \\
\hline Communality & 0.33 & 0.40 & 0.47 & 0.53 & 0.59 & 0.65 \\
\hline \multirow{18}{*}{$\begin{array}{l}\% \text { variance } \\
\text { explained }\end{array}$} & 33 & 40 & 47 & 53 & 59 & 65 \\
\hline & $\begin{array}{l}\text { 1. Depressed } \\
\text { mood }\end{array}$ & $\begin{array}{l}\text { 4. Insomnia } \\
\text { early-falling } \\
\text { asleep }\end{array}$ & $\begin{array}{l}\text { 2. Feelings of } \\
\text { guilt }\end{array}$ & $\begin{array}{l}\text { 1. Depressed } \\
\text { mood }\end{array}$ & $\begin{array}{l}\text { 1. Depressed } \\
\text { mood }\end{array}$ & $\begin{array}{l}\text { 1. Depressed } \\
\text { mood }\end{array}$ \\
\hline & $\begin{array}{l}\text { 5. Insomnia } \\
\text { middle- waking } \\
\text { during night } \\
\end{array}$ & \begin{tabular}{|l|} 
5. Insomnia \\
middle- waking \\
during night \\
\end{tabular} & 3. Suicide & $\begin{array}{l}\text { 7. Difficulty } \\
\text { with work and } \\
\text { activities }\end{array}$ & $\begin{array}{l}\text { 7. Difficulty } \\
\text { with work and } \\
\text { activities }\end{array}$ & $\begin{array}{l}\text { 8. Retardation- } \\
\text { psychomotor }\end{array}$ \\
\hline & $\begin{array}{l}\text { 6. Insomnia } \\
\text { late- early } \\
\text { morning waking }\end{array}$ & $\begin{array}{l}\text { 6. Insomnia } \\
\text { late-early } \\
\text { morning waking }\end{array}$ & 9. Agitation & $\begin{array}{l}\text { 8. Retardation- } \\
\text { psychomotor }\end{array}$ & $\begin{array}{l}\text { 8. Retardation- } \\
\text { psychomotor }\end{array}$ & $\begin{array}{l}\text { 10. Anxiety- } \\
\text { psychic }\end{array}$ \\
\hline & $\begin{array}{l}\text { 7. Difficulty } \\
\text { with work and } \\
\text { activities }\end{array}$ & $\begin{array}{l}\text { 10. Anxiety- } \\
\text { psychic }\end{array}$ & $\begin{array}{l}\text { 5. Insomnia } \\
\text { middle- waking } \\
\text { during night }\end{array}$ & $\begin{array}{l}\text { 10. Anxiety- } \\
\text { psychic }\end{array}$ & $\begin{array}{l}\text { 10. Anxiety- } \\
\text { psychic }\end{array}$ & $\begin{array}{l}\text { 11. Anxiety- } \\
\text { somatic }\end{array}$ \\
\hline & $\begin{array}{l}\text { 8. Retardation- } \\
\text { psychomotor }\end{array}$ & $\begin{array}{l}\text { 11. Anxiety- } \\
\text { somatic }\end{array}$ & $\begin{array}{l}\text { 6. Insomnia } \\
\text { late- early } \\
\text { morning waking }\end{array}$ & $\begin{array}{l}\text { 11. Anxiety-so- } \\
\text { matic }\end{array}$ & $\begin{array}{l}\text { 11. Anxiety-so- } \\
\text { matic }\end{array}$ & $\begin{array}{l}\text { 15. Hypochon- } \\
\text { driasis }\end{array}$ \\
\hline & $\begin{array}{l}\text { 10. Anxiety- } \\
\text { psychic }\end{array}$ & $\begin{array}{l}\text { 15. Hypochon- } \\
\text { driasis }\end{array}$ & $\begin{array}{l}\text { 10. Anxiety- } \\
\text { psychic }\end{array}$ & $\begin{array}{l}\text { 15. Hypochon- } \\
\text { driasis }\end{array}$ & $\begin{array}{l}\text { 15. Hypochon- } \\
\text { driasis }\end{array}$ & $\begin{array}{l}\text { 5. Insomnia } \\
\text { middle- waking } \\
\text { during night }\end{array}$ \\
\hline & $\begin{array}{l}\text { 11. Anxiety- } \\
\text { somatic }\end{array}$ & $\begin{array}{l}\text { 2. Feelings of } \\
\text { guilt }\end{array}$ & $\begin{array}{l}\text { 11. Anxiety- } \\
\text { somatic }\end{array}$ & $\begin{array}{l}\text { 16. Loss of } \\
\text { weight }\end{array}$ & $\begin{array}{l}\text { 4. Insomnia } \\
\text { early- falling } \\
\text { asleep }\end{array}$ & $\begin{array}{l}\text { 6. Insomnia } \\
\text { late- ealy } \\
\text { morning waking }\end{array}$ \\
\hline & $\begin{array}{l}\text { 14. Genital } \\
\text { symptoms }\end{array}$ & 3. Suicide & $\begin{array}{l}\text { 15. Hypochon- } \\
\text { driasis }\end{array}$ & $\begin{array}{l}\text { 2. Feelings of } \\
\text { guilt }\end{array}$ & $\begin{array}{l}\text { 5. Insomnia } \\
\text { middle- waking } \\
\text { during night } \\
\end{array}$ & $\begin{array}{l}\text { 2. Feelings of } \\
\text { guilt }\end{array}$ \\
\hline & $\begin{array}{l}\text { 15. Hypochon- } \\
\text { driasis }\end{array}$ & 9. Agitation & $\begin{array}{l}\text { 1. Depressed } \\
\text { mood }\end{array}$ & 3. Suicide & $\begin{array}{l}\text { 6. Insomnia } \\
\text { late- early } \\
\text { morning waking }\end{array}$ & 3. Suicide \\
\hline & $\begin{array}{l}\text { 2. Feelings of } \\
\text { guilt }\end{array}$ & $\begin{array}{l}\text { 1. Depressed } \\
\text { mood }\end{array}$ & $\begin{array}{l}\text { 7. Difficulty } \\
\text { with work and } \\
\text { activities }\end{array}$ & 9. Agitation & $\begin{array}{l}\text { 2. Feelings of } \\
\text { guilt }\end{array}$ & 9. Agitation \\
\hline & 3. Suicide & $\begin{array}{l}\text { 7. Difficulty } \\
\text { with work and } \\
\text { activities }\end{array}$ & $\begin{array}{l}\text { 8. Retardation- } \\
\text { psychomotor }\end{array}$ & $\begin{array}{l}\text { 13. Somatic- } \\
\text { general }\end{array}$ & 3. Suicide & $\begin{array}{l}\text { 12. Somatic- } \\
\text { gastro-intestinal } \\
\text { and appetite } \\
\end{array}$ \\
\hline & 9. Agitation & $\begin{array}{l}\text { 8. Retardation- } \\
\text { psychomotor }\end{array}$ & $\begin{array}{l}\text { 13. Somatic- } \\
\text { general }\end{array}$ & $\begin{array}{l}\text { 14. Genital } \\
\text { symptoms }\end{array}$ & 9. Agitation & $\begin{array}{l}\text { 16. Loss of } \\
\text { weight }\end{array}$ \\
\hline & $\begin{array}{l}\text { 12. Somat- } \\
\text { ic- gastro-in- } \\
\text { testinal and } \\
\text { appetite }\end{array}$ & $\begin{array}{l}\text { 12. Somat- } \\
\text { ic- gastro-in- } \\
\text { testinal and } \\
\text { appetite }\end{array}$ & $\begin{array}{l}14 . \text { Genital } \\
\text { symptoms }\end{array}$ & $\begin{array}{l}\text { 12. Somat- } \\
\text { ic- gastro-in- } \\
\text { testinal and } \\
\text { appetite }\end{array}$ & $\begin{array}{l}\text { 17. Insight- no } \\
\text { acknowledg- } \\
\text { ment of illness }\end{array}$ & $\begin{array}{l}\text { 7. Difficulty } \\
\text { with work and } \\
\text { activities }\end{array}$ \\
\hline & $\begin{array}{l}\text { 13. Somatic- } \\
\text { general }\end{array}$ & $\begin{array}{l}\text { 13. Somatic- } \\
\text { general }\end{array}$ & $\begin{array}{l}\text { 12. Somatic- } \\
\text { gastro-intestinal } \\
\text { and appetite }\end{array}$ & $\begin{array}{l}\text { 17. Insight- no } \\
\text { acknowledg- } \\
\text { ment of illness }\end{array}$ & $\begin{array}{l}\text { 13. Somatic- } \\
\text { general }\end{array}$ & $\begin{array}{l}\text { 13. Somatic- } \\
\text { general }\end{array}$ \\
\hline & & $\begin{array}{l}\text { 14. Genital } \\
\text { symptoms }\end{array}$ & $\begin{array}{l}\text { 16. Loss of } \\
\text { weight }\end{array}$ & $\begin{array}{l}\text { 4. Insomnia } \\
\text { early-falling } \\
\text { asleep }\end{array}$ & $\begin{array}{l}\text { 14. Genital } \\
\text { symptoms }\end{array}$ & $\begin{array}{l}\text { 14. Genital } \\
\text { symptoms }\end{array}$ \\
\hline & & & $\begin{array}{l}\text { 17. Insight- no } \\
\text { acknowledg- } \\
\text { ment of illness }\end{array}$ & $\begin{array}{l}\text { 5. Insomnia } \\
\text { middle- waking } \\
\text { during night }\end{array}$ & $\begin{array}{l}\text { 12. Somatic- } \\
\text { gastro-intestinal } \\
\text { and appetite }\end{array}$ & $\begin{array}{l}\text { 17. Insight- no } \\
\text { acknowledg- } \\
\text { ment of illness }\end{array}$ \\
\hline & & & & $\begin{array}{l}\text { 6. Insomnia } \\
\text { late- early } \\
\text { morning } \\
\text { waking }\end{array}$ & $\begin{array}{l}\text { 16. Loss of } \\
\text { weight }\end{array}$ & $\begin{array}{l}\text { 4. Insomnia } \\
\text { early-falling } \\
\text { asleep }\end{array}$ \\
\hline
\end{tabular}




\section{Pattern and structure matrix}

The structure matrix differs from the pattern matrix in that shared variance is not ignored. The pattern matrix contains information about the unique contribution of a variable to a factor. When we compared the pattern with the structure matrix, the only difference was that item 7 (Difficulty with work and activities) had a higher factor loading on component 1 (0.57), instead of component 5 (0.56) (Supplementary data, Table s4). The component correlation matrix (Supplementary data, Table s5) shows that there were little or no relationships between the factors (all $r<0.3$ ), which were suspected since we allowed maximum amount of non-orthogonality.

\section{Cronbach's alpha}

To measure the scale reliability we calculated the Cronbach's alpha $(\alpha)$ for each component. Component 1 (item 1, 7, 8, 10, 11, 15) had an $\alpha$ of 0.77. Components 2, 3, 5 and 6 had $\alpha$ values of $0.53,0.60,0.38$ and 0.35 respectively. Component 4 consisted of 1 item and had no $\alpha$. In general, a value of 0.7 to 0.8 is considered an acceptable value, indicating sufficient reliability. However, in psychological constructs values below 0.7 can be expected because of the diversity of the constructs being measured. In addition, the value of $\alpha$ is influenced by the number of items. As the number of items increase $\alpha$ will also increase. Subsequently, component 1 which consists of 6 items had a higher $\alpha$ in comparison with component 5 and 6 ( 2 items).

\section{Components}

After extracting 2, 3 and 4 components the factor loading of respectively 3, 2 and 1 variables were below 0.4 , which is in general the absolute value indicating an important, significant factor loading. With 5 or 6 extracted components, the clustering variables were fairly similar, with the only different items being 16 Loss of weight and 17 Insight (Table 2). With 7 extracted components item 4 Insomnia early was split off and item 7 Difficulty with work and activities made up a component with items 12 Somatic-general and 14 Genital symptoms. As expected, communalities and total percentage of explained variance increased as the number of components increased likewise.

\section{DISCUSSION}

This PCA of the HAMD in a large sample of PD patients revealed six components. However, because of low correlations between variables within the components, as well as the varying number of items per component (varying from 1 to 6 ), and a high percentage of non-redundant residuals and low communality, factor validity appeared to be unsatisfactory. 
We believe that our sample, with respect to demographic and disease characteristics as well as medication use, is comparable to a population that clinicians encounter in outpatient clinics $(9,10)$. The HAMD was initially developed to measure change over time in depressive symptoms in a psychiatric population with known depressive disorders. Throughout the years the scale utility has been studied in general populations as well as in neurological conditions and shown to have a good predictive validity for presence of major depression. It is remarkable how well the HAMD has performed in psychometric evaluations, especially since Hamilton mentioned there was "room for improvement" and the HAMD remained almost unchanged after 50 years in practice (4). There are only a few studies that describe a factor analysis of the HAMD in the general population (11). These studies argue that the HAMD is admittedly multidimensional, but with poor replication across samples. In agreement, insomnia items appeared to load consistently on the same factor in our study. However, other components such as depressed mood, suicide and psychic anxiety or a component of psychic anxiety, somatic anxiety and agitation were not found. A possible explanation for the fact that item 17 made up a component of its own in our analysis is that item 17 is the only observational item of the scale and requires clinical interpretation and experience. Some patients predominantly form anhedonia and may not appear depressed, which makes rating difficult. The reported number of factors identified in studies in the general population ranged from two to eight (11). In addition, a meta-analysis of factor structures of four depression questionnaires, including the HAMD, showed that a four-component solution appeared to be the most generalizable, although it was mostly based on small studies (12). Comparable to the factorial structure of the HAMD across studies in the general population, it appears also unsatisfactory in the PD population. However, other clinimetric properties of the scale are satisfactory. Several other studies have shown that the scale has a high sensitivity and specificity, good inter-rater reliability and high negative predictive value with acceptable positive predictive values (6). The scale is appropriate as a screening measure for depression, evaluating its severity and monitor change over time. However, our analysis proves that it is not suitable for studying specific symptom domains based on factorial structure in a PD population. This aids in interpreting study results and designing future studies in PD. In addition, the analysis complements the validation of the most widely used depression scale in PD.

In conclusion, our study shows that the HAMD is a multidimensional scale. Although studies have shown adequate reliability and construct validity of the HAMD in PD patients, factor validity is unsatisfactory. As such, there is still room for improvement, just as Hamilton stated more than 50 years ago. 


\section{REFERENCES}

1. Reijnders JS, Ehrt U, Weber WE, Aarsland D, Leentjens AFG. A systematic review of prevalence studies of depression in Parkinson's disease. Mov Disord. 2008;23(2):183-9; quiz 313.

2. Schrag A. Quality of life and depression in Parkinson's disease. J Neurol Sci. 2006;248(1-2):151-7.

3. Bech P. Rating scales in depression: limitations and pitfalls. Dialogues Clin Neurosci. 2006;8(2):207-15.

4. Hamilton M. A rating scale for depression. J Neurol Neurosurg Psychiatry. 1960;23:56-62.

5. Leentjens AFG, Verhey FRJ, Lousberg R, Spitsbergen H, Wilmink FW. The validity of the Hamilton and Montgomery-Asberg depression rating scales as screening and diagnostic tools for depression in Parkinson's disease. Int J Geriatr Psychiatry. 2000;15(7):644-9.

6. Schrag A, Barone P, Brown RG, Leentjens AFG, McDonald WM, Starkstein S, et al. Depression rating scales in Parkinson's disease: critique and recommendations. Mov Disord. 2007;22(8):1077-92.

7. Leentjens AFG, Dujardin K, Marsh L, Richard IH, Starkstein SE, Martinez-Martin P. Anxiety rating scales in Parkinson's disease: a validation study of the Hamilton anxiety rating scale, the Beck anxiety inventory, and the hospital anxiety and depression scale. Mov Disord. 2011;26(3):407-15.

8. Stevens JP. Applied multivariate statistics for the social sciences. $4^{\text {th }}$ ed. Hillsdale, NJ: Erlbaum; 2002.

9. Barone P, Antonini A, Colosimo C, Marconi R, Morgante L, Avarello TP et al. The
PRIAMO study: A multicenter assessment of nonmotor symptoms and their impact on quality of life in Parkinson's disease. Mov Disord. 2009 Aug 15;24(11):1641-9. Nègre-Pagès L, Grandjean $H$, Lapeyre-Mestre M, Montastruc JL, Fourrier A, Lépine JP et al. Anxious and depressive symptoms in Parkinson's disease: the French cross-sectionnal DoPaMiP study. Mov Disord. 2010 Jan 30;25(2):157-66

11. Bagby RM, Ryder AG, Schuller DR, Marshall MB. The Hamilton Depression Rating Scale: has the gold standard become a lead weight? Am J Psychiatry. 2004;161(12):2163-77.

12. Shafer AB. Meta-analysis of the factor structures of four depression questionnaires: Beck, CES-D, Hamilton, and Zung. J Clin Psychol. 2006;62(1):123-46. 


\section{SUPPLEMENTARY FILES}

Table s1.

Demographic and disease characteristics of the sample $(n=341)$.

\begin{tabular}{|c|c|c|}
\hline Variable & Percentage & Mean (SD) \\
\hline Female sex & 39 & \\
\hline Age & & $64.8(9.2)$ \\
\hline Duration of PD & & $8.3(5.6)$ \\
\hline UPDRS section 2 (ADL) & & $11.6(6.8)$ \\
\hline UPDRS section 3 (motor) & & $26.4(12.4)$ \\
\hline UPDRS section 4 (complications) & & $3.5(3.5)$ \\
\hline Hoehn \& Yahr stage (median; range) & & $2(1-5)$ \\
\hline On/off fluctuations & 52 & \\
\hline Dyskinesias & 30 & \\
\hline Major depression & 14 & \\
\hline Dysthymia & 6 & \\
\hline Previous history depression & 46 & \\
\hline Previous history anxiety disorder & 32 & \\
\hline Family history depression & 33 & \\
\hline Family history anxiety disorder & 19 & \\
\hline Family history of PD & 20 & \\
\hline HAMD score & & $7.7(5.9)$ \\
\hline HARS score & & $11.3(8.5)$ \\
\hline IADL score & & $7(1.5)$ \\
\hline MMSE score & & $28.5(1.7)$ \\
\hline Use of levodopa & 85 & \\
\hline Use of dopamine-agonist & 62 & \\
\hline Use of antidepressant & 34 & \\
\hline
\end{tabular}

PD = Parkinson's Disease UPDRS = Unified Parkinson's Disease Rating Scale; $A D L=$ Activities of Daily Living; HAMD = Hamilton Depression Scale; HARS = Hamilton Anxiety Rating Scale; IADL = Lawton's Instrumental Activities of Daily Living scale; MMSE = Mini Mental State Examination. 


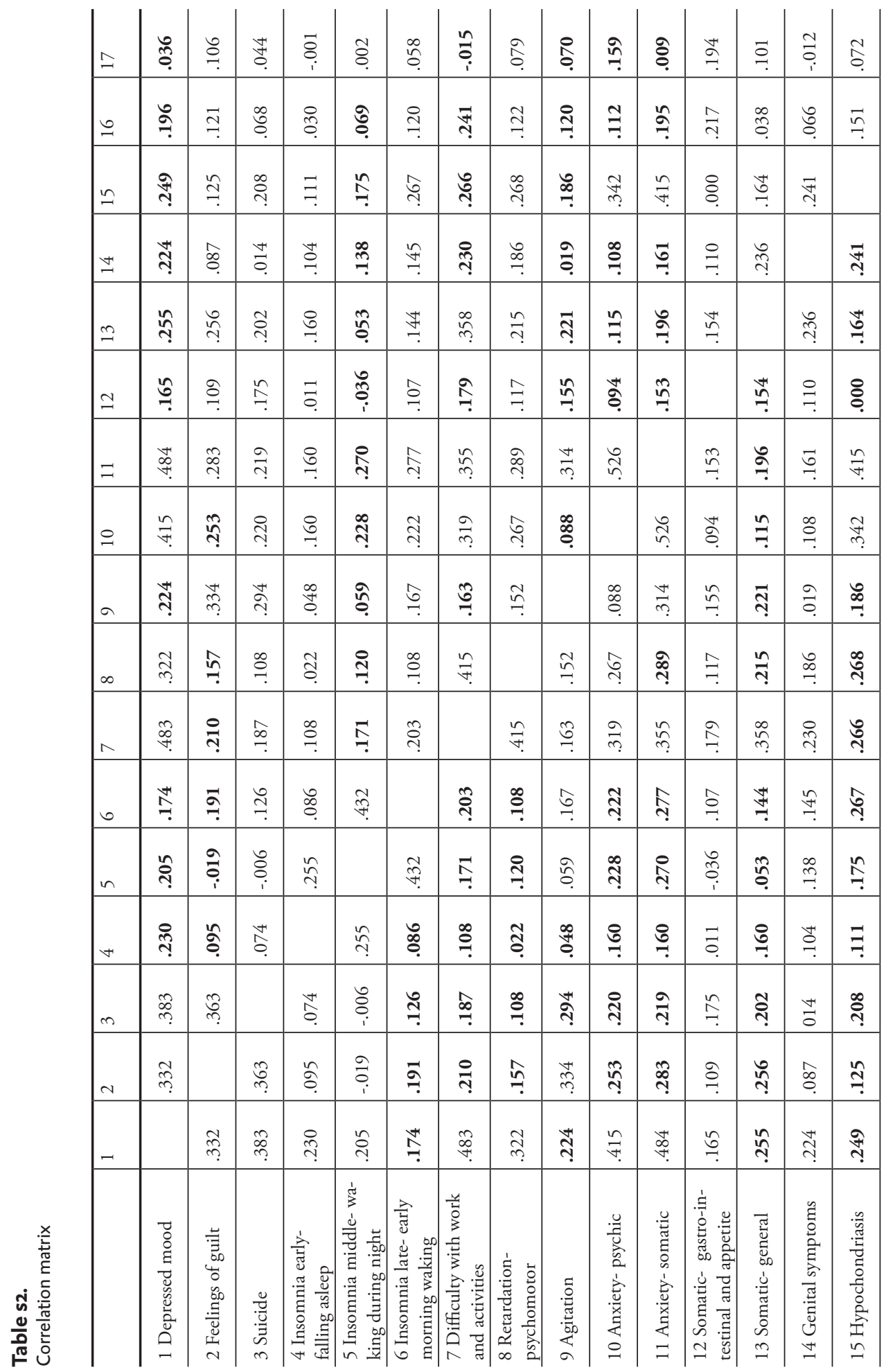




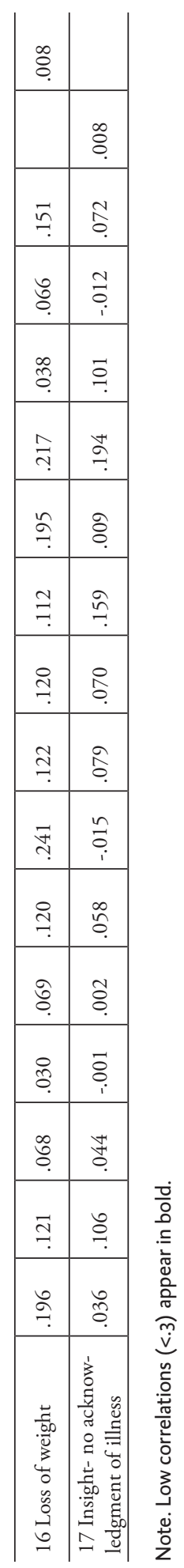




\begin{tabular}{|c|c|c|c|c|c|c|c|c|c|c|c|c|c|c|c|c|}
\hline$I$ & $\hat{\mathscr{c}}$ & 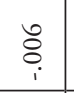 & ६ & $\begin{array}{l}\tilde{\sigma} \\
\tilde{\sigma}\end{array}$ & $\stackrel{\infty}{0}$ & $\underset{i}{0}$ & : & 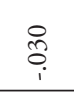 & $\widetilde{a}$ & 它 & $\stackrel{\infty}{\circ}$ & 苦 & 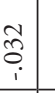 & ర్ & 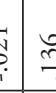 & \\
\hline$\because$ & ồ & $\hat{\hat{a}}$ & ฮี & 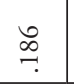 & git & $\underset{i}{i}$ & $\stackrel{0}{a}$ & $\stackrel{\vec{r}}{i}$ & \begin{tabular}{c}
$\mathscr{D}$ \\
\hdashline \\
$i$
\end{tabular} & $\frac{7}{3}$ & 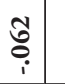 & 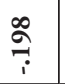 & 节 & $\bar{t}$ & & $\stackrel{0}{9}$ \\
\hline$\cong$ & $\vec{n}$ & क्ष & 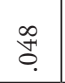 & $\tilde{\Xi}$ & $\frac{\pi}{7}$ & $\frac{m}{b}$ & $\stackrel{\infty}{a}$ & $\grave{\jmath}$ & \begin{tabular}{c}
$\infty$ \\
$\vdots$ \\
\hdashline
\end{tabular} & مُ & : & oे & 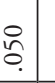 & है. & $\mathscr{c}$ & $\overrightarrow{\mathrm{s}}$ \\
\hline \pm & $\begin{array}{l}0 \\
i \\
i\end{array}$ & $\stackrel{0}{0}$ & $\stackrel{0}{\mathscr{a}}$ & $\begin{array}{l}\infty \\
\rightarrow \\
i\end{array}$ & $\stackrel{\infty}{\infty}$ & oे & $\stackrel{\vec{\infty}}{i}$ & $\stackrel{7}{7}$ & : & ֻ. & 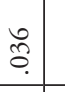 & 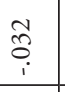 & $\stackrel{\infty}{7}$ & & 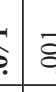 & $\tilde{~}$ \\
\hline$\stackrel{2}{2}$ & $\hat{a}_{i}^{n}$ & $\begin{array}{l}N \\
\hat{D} \\
i\end{array}$ & âa & $\hat{m}$ & $\stackrel{\infty}{0}$ & $\vec{F}$ & 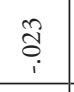 & $\underset{\hat{i}}{i}$ & $\begin{array}{l}0 \\
0 \\
i \\
\end{array}$ & 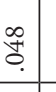 & $\begin{array}{l}0 \\
\stackrel{\infty}{0} \\
\stackrel{\leftrightarrow}{0}\end{array}$ & $\begin{array}{c}\infty \\
\stackrel{a}{a} \\
i\end{array}$ & & 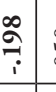 & 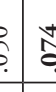 & م్రి \\
\hline$\simeq$ & 速 & $\begin{array}{l}n \\
\hat{c} \\
i\end{array}$ & ? & $\dddot{l}$ & $\stackrel{8}{\circ}$ & 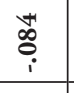 & 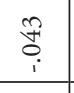 & $\stackrel{\infty}{i}$ & ồ & 亏ั. & : & & 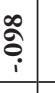 & 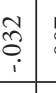 & $\left(\begin{array}{l}\infty \\
\hdashline \\
\hdashline\end{array}\right.$ & ț \\
\hline$\Rightarrow$ & \begin{tabular}{l}
$\infty$ \\
d \\
\multirow{2}{*}{}
\end{tabular} & $\begin{array}{l}\text { îf } \\
\text { क्रें }\end{array}$ & $\cong$ & $\stackrel{\circ}{\circ}$ & 落 & $\hat{i}_{i}^{\infty}$ & $\begin{array}{l}0 \\
i \\
i\end{array}$ & $\stackrel{\infty}{\infty}$ & $\begin{array}{l}0 \\
\vdots \\
\vdots\end{array}$ & : & & 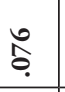 & 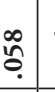 & : & 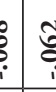 & $\stackrel{\infty}{\stackrel{\infty}{i}}$ \\
\hline$\cong$ & $\hat{\text { ô. }}$ & $\hat{\mathrm{g}}$ & $\begin{array}{l}\text { 范 } \\
\text { in }\end{array}$ & ؛ั. & $\underset{i}{\text { for }}$ & 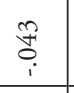 & 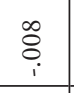 & $\stackrel{\dddot{7}}{7}$ & $\begin{array}{c}0 \\
\stackrel{0}{0} \\
i\end{array}$ & & 菅 & ذ̆ & $\begin{array}{c}\infty \\
⿱ 亠 䒑 \\
\vdots \\
\vdots\end{array} \mid$ & శ్ & 8 & $\stackrel{\text { ò }}{i}$ \\
\hline$\sigma$ & $\stackrel{\vec{q}}{i}$ & \begin{tabular}{l}
\multirow{7}{7}{} \\
$i$
\end{tabular} & 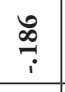 & $\overrightarrow{\overrightarrow{0}}$ & $\stackrel{\infty}{\stackrel{0}{0}}$ & $\begin{array}{c}\hat{\tilde{o}} \\
i \\
i\end{array}$ & $\stackrel{\circ}{0}$ & $\Xi$ & & . & $\begin{array}{l}\text {. } \\
\text { d. }\end{array}$ & ôa & 苋 & إ. & $a_{0}^{0}$ & శ్ర \\
\hline$\infty$ & $\stackrel{\infty}{\infty}$ & 范 & 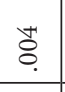 & $\begin{array}{l}0 \\
\stackrel{8}{0}\end{array}$ & gे & $\begin{array}{l}\infty \\
\stackrel{\infty}{a}\end{array}$ & $\begin{array}{l}\infty \\
\stackrel{\infty}{0} \\
i\end{array}$ & & Э઼ & 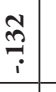 & 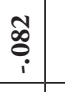 & ְֶ. & $\begin{array}{c}\text { ô. } \\
i \\
i\end{array}$ & $\stackrel{7}{7}$ & 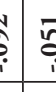 & ্ֻণi \\
\hline 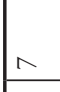 & बे. & $\vec{c}_{i}$ & \begin{tabular}{c}
$\infty$ \\
$\vdots$ \\
\hdashline \\
\end{tabular} & $\begin{array}{l}\infty \\
0 \\
i\end{array}$ & $\hat{\tilde{o}}$ & $\begin{array}{l}\infty \\
\text { 車. }\end{array}$ & & $\stackrel{\infty}{\infty}$ & $\begin{array}{l}0 \\
0 \\
i\end{array}$ & \begin{tabular}{l}
0 \\
\hdashline \\
\end{tabular} & $\begin{array}{l}0 \\
\stackrel{0}{0} \\
i\end{array}$ & 蛋 & ְ. & 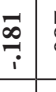 & 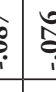 & ִֶ \\
\hline 0 & 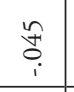 & $\vec{n}$ & 啇 & $\hat{\vec{y}}$ & $\overrightarrow{\vec{n}}$ & & 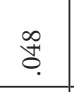 & $\begin{array}{l}\infty \\
\stackrel{0}{c}\end{array}$ & $\begin{array}{c}\hat{n} \\
\stackrel{a}{i} \\
i\end{array}$ & 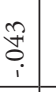 & $\begin{array}{c}\tilde{s} \\
i \\
i\end{array}$ & 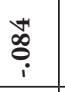 & $\vec{F}$ & કे. & 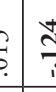 & $\begin{array}{l}0 \\
0 \\
i \\
i\end{array}$ \\
\hline$n$ & 范 & $\stackrel{m}{\circ}$ & : & ते & & $\frac{\overline{5}}{7}$ & $\hat{\beta}$ & $\hat{a}$ & $\begin{array}{c}\infty \\
\tilde{c} \\
\end{array}$ & क्षे & 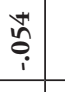 & $\stackrel{0}{\circ}$ & $\begin{array}{l}\infty \\
\vdots \\
\end{array}$ & 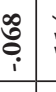 & 8 & $\begin{array}{l}\infty \\
\stackrel{\infty}{\circ}\end{array}$ \\
\hline H & $\begin{array}{l}0 \\
0 \\
0\end{array}$ & $\begin{array}{l}n \\
\hat{a} \\
i\end{array}$ & $\begin{array}{c}0 \\
\stackrel{0}{0} \\
i \\
i\end{array}$ & & নे & $\hat{\bar{i}}$ & $\begin{array}{l}\infty \\
0 \\
i\end{array}$ & $\stackrel{0}{0}$ & $\begin{array}{c}5 \\
\vdots \\
i\end{array}$ & . & ః & $\cong$ & के & $\begin{array}{c}\infty \\
\stackrel{\infty}{7} \\
i\end{array}$ & $\stackrel{\infty}{\infty}$ & ְֶ. \\
\hline$m$ & $\begin{array}{l}\infty \\
\stackrel{0}{1} \\
i\end{array}$ & $\stackrel{\overbrace{}}{\beth}$ & & $\begin{array}{l}0 \\
\stackrel{0}{0} \\
i\end{array}$ & $\stackrel{0}{0}$ & $\stackrel{8}{\circ}$ & $\stackrel{\infty}{0}$ & $\stackrel{+}{\circ}$ & $\begin{array}{c}0 \\
\stackrel{\infty}{7} \\
i\end{array}$ & ¿্ & $\cong$ & 尊 & ڤ్ & 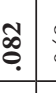 & 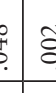 & ఏ \\
\hline$\sim$ & $\begin{array}{l}0 \\
0 \\
i\end{array}$ & & $\stackrel{9}{7}$ & 管 & $\stackrel{0}{c}$ & $\vec{n}$ & $\bar{i}_{i}$ & 落 & \begin{tabular}{l}
0 \\
7 \\
\hdashline \\
$ن$
\end{tabular} & ڤે & 管 & 柋 & : & ఫิ & : & $\stackrel{8}{\circ}$ \\
\hline- & & $\begin{array}{l}\hat{0} \\
i \\
i\end{array}$ & $\begin{array}{l}\infty \\
\vdots \\
\vdots \\
\end{array}$ & $\begin{array}{l}0 \\
\stackrel{0}{0} \\
\end{array}$ & 落 & $\begin{array}{l}i \\
\dot{c} \\
i\end{array}$ & ఫ્రి & $\stackrel{\infty}{i}$ & $\vec{\Xi}$ & ڤ્ & $\begin{array}{l}\infty \\
\text { do } \\
\text { i } \\
\end{array}$ & 苦 & tô. & : & 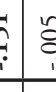 & $\stackrel{n}{\mathscr{a}}$ \\
\hline & 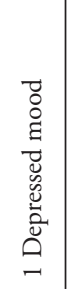 & 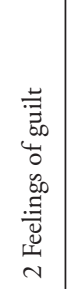 & & $\begin{array}{l}0 \\
0\end{array}$ & 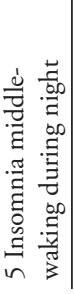 & & 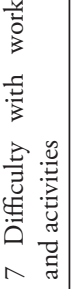 & & 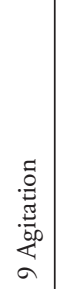 & $\mid$ & & & & 离 & & 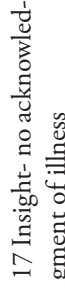 \\
\hline
\end{tabular}


Table s4.

Rotated factor loadings, structure matrix

\begin{tabular}{l|l|l|l|l|l|l}
\hline Item & $\mathbf{1}$ & $\mathbf{2}$ & $\mathbf{3}$ & $\mathbf{4}$ & $\mathbf{5}$ & $\mathbf{6}$ \\
\hline 1. Depressed mood & $\mathbf{0 . 6 1}$ & -0.19 & $\mathbf{- 0 . 4 9}$ & -0.11 & $\mathbf{0 . 4 0}$ & 0.18 \\
\hline 2. Feelings of guilt & 0.24 & -0.08 & $\mathbf{- 0 . 7 3}$ & 0.11 & 0.18 & 0.07 \\
\hline 3. Suicide & 0.24 & -0.03 & $\mathbf{- 0 . 7 3}$ & 0.03 & 0.09 & 0.06 \\
\hline 4. Insomnia early- falling asleep & 0.08 & $\mathbf{- 0 . 5 0}$ & -0.20 & -0.12 & 0.34 & -0.26 \\
\hline 5. Insomnia middle- waking during night & 0.28 & $\mathbf{- 0 . 8 1}$ & 0.04 & -0.09 & 0.12 & 0.01 \\
\hline 6. Insomnia late- early morning waking & 0.24 & $\mathbf{- 0 . 7 3}$ & -0.21 & 0.10 & 0.10 & 0.22 \\
\hline 7. Difficulty with work and activities & $\mathbf{0 . 5 7}$ & -0.09 & -0.24 & -0.14 & $\mathbf{0 . 5 6}$ & 0.37 \\
\hline 8. Retardation- psychomotor & $\mathbf{0 . 6 1}$ & 0.09 & -0.08 & 0.05 & $\mathbf{0 . 4 1}$ & 0.23 \\
\hline 9. Agitation & 0.13 & -0.17 & $\mathbf{- 0 . 6 7}$ & 0.06 & 0.09 & 0.22 \\
\hline 10. Anxiety- psychic & $\mathbf{0 . 7 7}$ & -0.25 & -0.36 & 0.15 & 0.06 & 0.03 \\
\hline 11. Anxiety- somatic & $\mathbf{0 . 7 2}$ & -0.35 & $\mathbf{- 0 . 4 0}$ & -0.07 & 0.15 & 0.22 \\
\hline 12. Somatic- gastro-intestinal and appetite & 0.01 & -0.01 & -0.24 & $\mathbf{0 . 4 5}$ & 0.26 & $\mathbf{0 . 6 3}$ \\
\hline 13. Somatic- general & 0.14 & -0.10 & -0.39 & 0.13 & $\mathbf{0 . 7 3}$ & 0.01 \\
\hline 14. Genital symptoms & 0.23 & -0.18 & 0.07 & -0.04 & $\mathbf{0 . 6 8}$ & 0.10 \\
\hline 15. Hypochondriasis & $\mathbf{0 . 6 4}$ & -0.27 & -0.17 & 0.00 & 0.17 & 0.08 \\
\hline 16. Loss of weight & 0.20 & -0.11 & -0.12 & -0.11 & 0.03 & $\mathbf{0 . 8 0}$ \\
\hline 17. Insight- no acknowledgment of illness & 0.12 & -0.02 & -0.08 & $\mathbf{0 . 9 1}$ & 0.03 & 0.01 \\
\hline
\end{tabular}

Note. Factor loadings over .40 appear in bold. 



\section{Chapter 5}

Trajectories of recovery in depressed Parkinson's disease patients treated with paroxetine or venlafaxine

Broen MPG. Leentjens AFG, Köhler S, Kuijf ML, McDonald WM, Richard IH. Parkinsonism Relat Disord. 2016 Feb;23:80-5. 


\section{ABSTRACT}

\section{Introduction:}

Depression is considered a syndrome with a constellation of symptoms that are frequently categorized into 3 domains including affective, somatic and cognitive. There has been limited research into the domain specific magnitude or relative timing of treatment response in patients with Parkinson's disease (PD). In addition, antidepressant trials involving patients with PD have demonstrated a similar robust placebo response to that seen in other populations. However, the timing of the placebo response has not been carefully studied.

\section{Methods:}

We studied differential responses to antidepressant treatment in affective, somatic and cognitive domains of depression. Patients were treated for twelve weeks with placebo, venlafaxine or paroxetine as part of the Study of Antidepressants in Parkinson's Disease (SAD-PD) randomized controlled trial. Depressive symptoms were evaluated with three commonly used rating scales.

\section{Results:}

All symptom domains improved during the study period, There was a significant placebo effect, especially in the first two weeks that had diminished by week 12. Compared to placebo, the affective symptoms significantly improved during treatment as early as week 4 , followed by the somatic symptoms of depression in week 6 and cognitive symptoms in week 8 . The largest response was seen in the affective domain.

\section{Conclusion:}

In depressed PD patients treated with venlafaxine or paroxetine, affective symptoms improved first, followed by somatic symptoms and cognitive symptoms. These findings could guide patient counselling and increase patient compliance by informing about the expected treatment responses. The substantial placebo effect underlines the importance of a sufficiently long study period in future studies. 


\section{INTRODUCTION}

Clinically significant depressive symptoms are found in up to $50 \%$ of Parkinson's disease (PD) patients, with an estimated prevalence of major depressive disorder of $17 \%$ (1). Depressed PD patients report a decreased quality of life and consistently rate the effect of their psychiatric disturbances as more detrimental to their well-being than the severity of motor symptoms $(2,3)$. However, only about $20 \%$ of depressed PD patients receives treatment for depression (4) and despite extensive research, there is still discussion about the optimal treatment strategy $(5,6)$. In addition, several studies showed that up to $67 \%$ of PD patients have a low medication adherence (7-9). Mood disorders, especially depressive disorders, seem to be the most important factor for non-adherence (10). Studies in psychiatric populations show that education of depressed patients when starting antidepressants greatly improves compliance (11).

Symptoms of depression are frequently subdivided in three domains including affective, somatic and cognitive symptoms (concentration and ideational). Research exploring domain specific magnitude or timing of treatment response is scarce. A more thorough understanding of this response in depressed PD patients could aid patient counseling by informing the patients about the expected response. In addition, although antidepressant trials involving PD patients have demonstrated robust placebo responses similar to that seen in other population, there is no thorough study of the timing of this response.

The aim of this analysis is to explore differential response patterns to treatment with venlafaxine or paroxetine in the affective, somatic and cognitive domains of depressed PD patients using data of the largest placebo-controlled randomized controlled trial (RCT) of antidepressants for the treatment of depression in PD patients to date.

\section{METHODS}

This study is a secondary analysis on the dataset of the Study of Antidepressants in PD (SAD-PD) (12). This study showed superior efficacy of treatment with venlafaxine or paroxetine over placebo treatment in depressed PD patients.

\section{Participants}

The SAD-PD study enrolled 115 participants from 20 centers in the United States, Canada, and Puerto Rico from 2005 through 2009. Patients with idiopathic PD, diagnosed according to the Queen Square Brain Bank criteria (13) had to meet diagnostic criteria of the 4th edition of the Diagnostic and Statistical Manual (DSM-IV) (14) for major depressive disorder, dysthymic disorder or minor depression. Patients with de- 
mentia as defined by the DSM-IV criteria, or those with a Mini Mental Sate Examination (MMSE) (15) score <23 were excluded. Antidepressant medication other than the study drugs, as well as antipsychotics and MAO inhibitors were not permitted.

\section{Standard protocol approvals, registrations, and patient consents}

The study was approved by the local Medical Ethics Committees of all participating institutions. Patients gave written informed consent before inclusion in the study. The study was registered with clinicaltrials.gov (registration no. NCT00086190).

\section{Assessment and randomization}

During a screening visit informed consent was obtained and eligibility criteria were verified. During the baseline visit $(\mathrm{t}=0)$ the participants were randomized to venlafaxine, paroxetine or placebo in a 1:1:1 ratio. Double-blind treatment lasted 12 weeks and consisted of a 6-week dosage titration and a 6-week maintenance period. The first two weeks participants received $10 \mathrm{mg}$ of paroxetine or $37,5 \mathrm{mg}$ of venlafaxine XR or matching placebos. The following 4 weeks the investigator then adjusted the dosage as necessary and tolerated up to a maximum daily dosage of $40 \mathrm{mg}$ for paroxetine and $225 \mathrm{mg}$ for venlafaxine XR to achieve the optimal dosage. Patients were evaluated at 2, 4, 6, 8 and 12 weeks after randomization. During these evaluations participants were assessed in the "on" state. Antidepressant efficacy was rated by the 17-item Hamilton Depression Rating Scale (HAMD) (16), Montgomery-Åsberg Depression Rating Scale (MADRS) (17) and the Beck Depression Inventory II (BDI-II) (18).

\section{Statistical methods}

None of the depression rating scales used in the study has a satisfactory factorial structure on the basis of which symptom domains could be defined (19). In order to formulate symptom domains we subdivided the items of the HAMD, BDI-II and MADRS into "affective", "somatic" or "cognitive", based on face validity (Table 1). Only items with clear affective, cognitive or somatic characteristics were included. Items that could not be easily attributed to one of these domains, such as agitation, were not included. The cognitive domain consisted of both symptoms of cognitive dysfunction (such as concentration difficulties, lack of insight) as well as of depressive-related ideation. The final affective domain included 14 items, the cognitive domain 14 items and the somatic domain 16 items. All three domains showed excellent internal consistency with Cronbach's $\alpha 0.96,0.95$ and 0.94 respectively. Since the three depression scales had different ranges, means and standard deviations, we standardized the scores by calculating z-scores of each domain. First we calculated the z-score of the patient per scale and per domain, after which we averaged the domain-specific z-scores on the three scales into one single score. 
Table 1.

Overview of HAM-D, MADRS and BDI-II items classified per domain based on face validity.

\begin{tabular}{|c|c|c|}
\hline $\begin{array}{l}\text { Affective domain } \\
(\mathrm{N}=14)\end{array}$ & $\begin{array}{l}\text { Cognitive domain } \\
(\mathrm{N}=14)\end{array}$ & $\begin{array}{l}\text { Somatic domain } \\
(\mathrm{N}=16)\end{array}$ \\
\hline HAM-D 1. Depressed mood & HAM-D 2. Feelings of guilt & HAM-D 4. Insomnia early \\
\hline HAM-D 3. Suicide & HAM-D 15. Hypochondriasis & HAM-D 5. Insomnia middle \\
\hline $\begin{array}{l}\text { HAM-D 7. Loss of interest in work } \\
\text { and activities }\end{array}$ & HAM-D 17. Insight illness & HAM-D 6. Insomnia late \\
\hline HAM-D 10. Anxiety (psychological) & $\begin{array}{l}\text { MADRS 6. Concentration difficul- } \\
\text { ties }\end{array}$ & HAM-D 11. Anxiety somatic \\
\hline MADRS 1. Apparent sadness & MADRS 9. Pessimistic thoughts & HAM-D 12. Somatic symptoms (GI) \\
\hline MADRS 2. Reported Sadness & BDI 2. Pessimism & $\begin{array}{l}\text { HAM-D 13. Somatic symptoms } \\
\text { (general) }\end{array}$ \\
\hline MADRS 8. Inability to feel & BDI 3. Past failure & HAM-D 14. Genital symptoms \\
\hline MADRS 10. Suicidal thoughts & BDI 5. Guilty feelings & HAM-D 16. Loss of weight \\
\hline BDI 1. Sadness & BDI 6. Punishment feelings & MADRS 4. Reduced sleep \\
\hline BDI 4. Loss of pleasure & BDI 7. Self-dislike & MADRS 5. Reduced appetite \\
\hline BDI 9. Suicidal thoughts & BDI 8. Self-criticalness & MADRS 7. Lassitude \\
\hline BDI 10. Crying & BDI 13. Indecisiveness & BDI 15. Loss of energy \\
\hline BDI 12. Loss of interest & BDI 14. Worthlessness & BDI 16. Changes in sleep pattern \\
\hline \multirow[t]{3}{*}{ BDI 17. Irritability } & BDI 19. Concentration difficulty & BDI 18. Changes in appetite \\
\hline & & BDI 20. Tiredness or fatigue \\
\hline & & BDI 21. Loss of interest in sex \\
\hline
\end{tabular}

Abbreviations: HAM-D, Hamilton Depression Rating Scale; MADRS, Montgomery-Asberg Depression Rating Scale; BDI, Beck Depression Inventory II.

Since there was no difference in the depression outcome between patients treated with venlafaxine and paroxetine (12), we decided to combine these two treatment groups to increase the power of our analysis. The between group difference in change in domain-specific z-scores compared to baseline was evaluated at 2,4,8 and 12 weeks using a repeated measures analysis of variance (rm-ANOVA). The dependent variable was the domain-specific averaged z-score, and the within-subject factor was "time" (6-levels: baseline, week 2,4,6,8 and 12). Since Mauchly's test of sphericity was significant, all F- and df-values were adjusted following the method of Greenhouse-Geisser if Epsilon was $<0.75$ (cognitive domain) or Huynh-Feldt if Epsilon was $>0.75$ (affective and somatic domain). The between-subject factor was group ("placebo" or "active treatment"). The interaction between treatment and time was of most interest as it indicates differential improvement between groups in the dependent variable. All analyses were computed with SPSS 21 (Chicago). In order to further test whether change across domains was significantly different, we compared the delta scores per domain (defined as the score at last observation minus the score at baseline) using three paired-sample t-tests in a post-hoc analysis. 


\section{RESULTS}

A total of 115 subjects were randomized to receive paroxetine $(n=42)$, venlafaxine XR $(n=34)$, or placebo $(n=39)$. Eighteen subjects $(16 \%)$ withdrew participation and $4(3 \%)$ were not assessed on all measurement points (2,4,6,8,12 weeks). For the final analyses the placebo group consisted of 32 subjects and the treatment group of 61 (33 on paroxetine and 28 on venlafaxine). The demographic and disease characteristics of the two groups are listed in Supplementary table 1. Fifty-nine percent of patients in the active treatment group had a diagnosis of major depressive disorder versus $56 \%$ in the placebo treated group. The active treatment group was slightly older than the placebo treated group (64.2 years versus 61.4 years), mean disease duration in the treatment group was 5.3 years, in the placebo group 5.5 years. Mean scores on the HAM-D, MADRS and BDI-II at baseline were comparable in both groups.

RM-ANOVA showed a significant time effect in all three domains for both groups, with a significant group-by-time interaction in the 3 depression symptom domains (affective: Wilks' Lambda $=0.86, \mathrm{~F}(4.24,73.78)=4.17, p=0.003$; somatic: Wilks' Lambda $=0.86, \mathrm{~F}(3.73,65.08)=3.36, p=0.012$; cognitive: Wilks' Lambda $=0.87, \mathrm{~F}$ (3.4, $59.16)=4.42, p=0.003)$. We then examined the treatment-by-time interaction for each measurement moment (Supplementary table 2). There was a significant $(p<0.05)$ treatment-by-time interaction in the affective domain from week 4 onwards (Figure 1), suggesting greater reduction in the treatment group. In addition, rm-ANOVA resulted in a significant treatment-by-time interaction on the somatic domain from week 6 onwards (Figure 2) and in the cognitive domain from week 8 onwards (Figure 3). In all three domains the placebo effect diminished over time, with even an increase of mean $\mathrm{z}$-scores in week 12. Affective symptoms seemed to improve the most (z-score at week $12=-1.6)$, followed by cognitive $(\mathrm{z}$-score $=-1.3)$ and somatic symptoms $(\mathrm{z}$-score $=-1.0)$. Post hoc t-tests showed that, at the last follow-up, the treatment group had improved significantly more in the affective than in the somatic (mean difference $=-0.65, \mathrm{t}=$ $-6.13, \mathrm{df}=60, \mathrm{p}<.001$ ) and in the cognitive domain (mean difference $=-0.30, \mathrm{t}=-2.74$, $\mathrm{df}=60, \mathrm{p}=.008)$. In addition, the cognitive domain had improved significantly more than the somatic domain (mean difference $=-0.35, \mathrm{t}=-2.80, \mathrm{df}=60, \mathrm{p}=.007$ ). 


\section{Figure 1.}

Trajectories of symptom change in the affective domain.

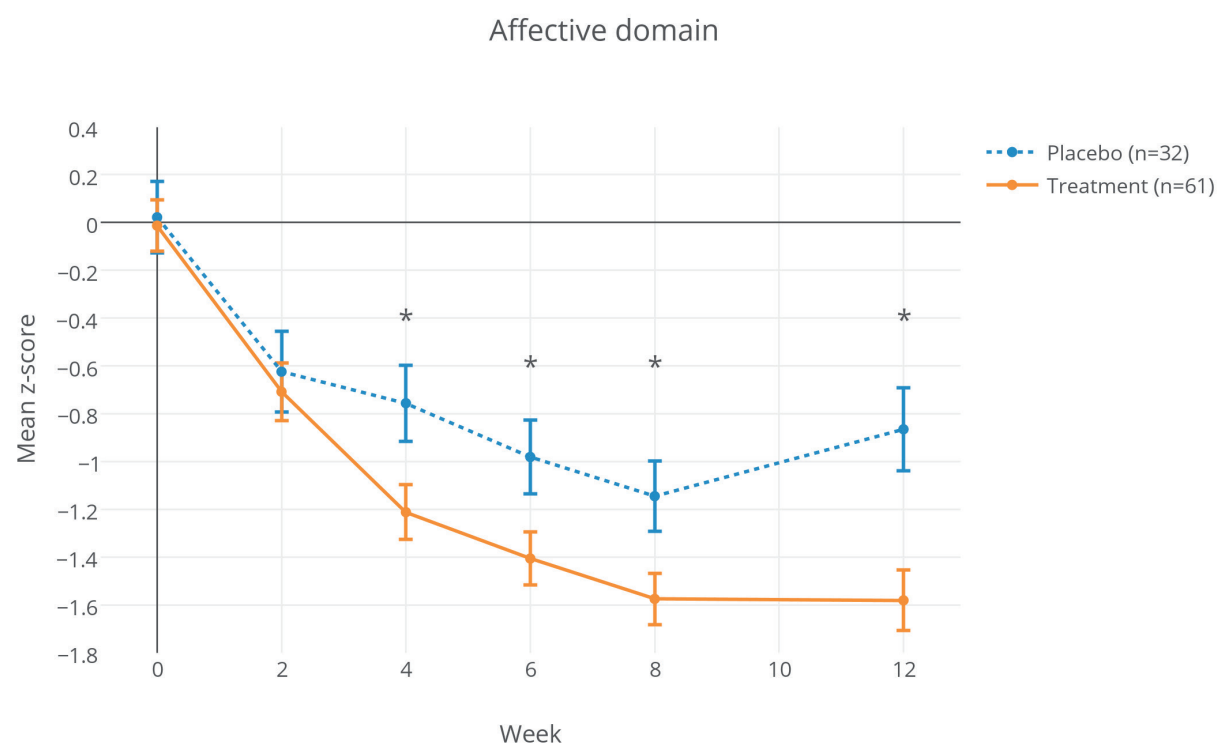

Note: An asterisk is shown when there was a significant difference $(<.05)$ between the scores of the placebo and the treatment group; Standard error bars are displayed. 
Figure 2.

Trajectories of symptom change in the somatic domain.

Somatic domain

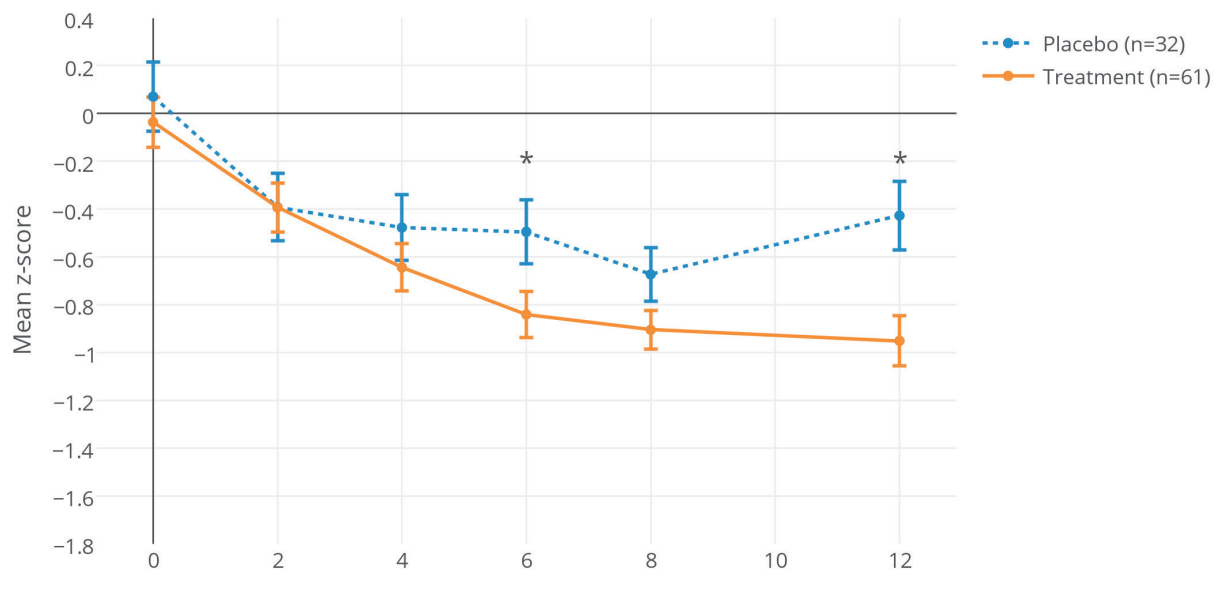

Week

Note: An asterisk is shown when there was a significant difference (<.05) between the scores of the placebo and the treatment group; Standard error bars are displayed. 


\section{Figure 3.}

Trajectories of symptom change in the cognitive domain.

\section{Cognitive domain}

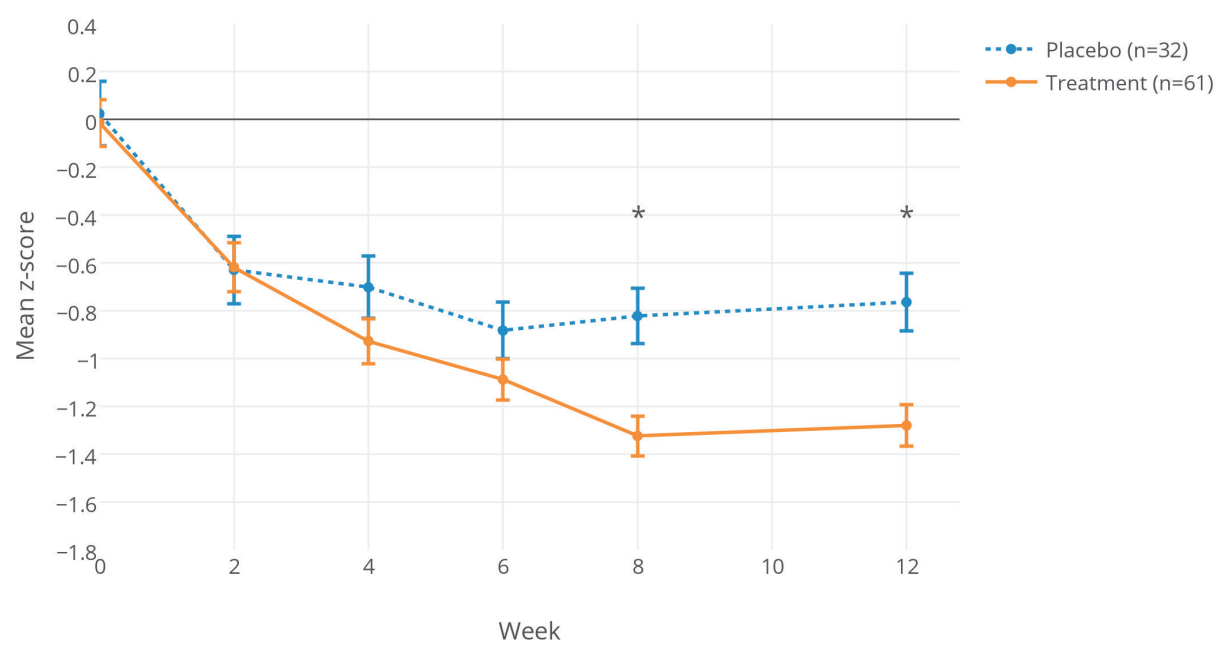

Note: An asterisk is shown when there was a significant difference (<.05) between the scores of the placebo and the treatment group; Standard error bars are displayed. 


\section{DISCUSSION}

This study shows that all 3 domains of depressive symptoms (affective, somatic and cognitive) improve during treatment with venlafaxine or paroxetine compared to the placebo treated group. Affective symptoms showed a significant response to treatment from week 4 onwards, followed by somatic symptoms from week 6 onwards and cognitive symptoms from week 8 onwards. At the end of the trial, after 12 weeks, the affective symptoms showed the largest response to treatment, followed by cognitive (ideational) and somatic symptoms. As such, our study does not support the older vision that improvement of affect is preceded by improvement in energy or volition that often was used to explain suicidal behavior in patients shortly after the initiation of antidepressant therapy.

A significant placebo effect is seen in all three domains, most prominently in the first 2 weeks, with a trend of a reducing placebo effect towards week 12 .

In clinical research, RCTs of treatment of depression are generally designed to evaluate efficacy at endpoint, and not to examine the onset and time course of improvement. A recent meta-analysis (6) of the efficacy of antidepressant therapies in depressed PD patients included 9 RCTs, of which four studies used change in the MADRS score as the primary outcome, another four used the HAMD and one study used the clinician rated Inventory of Depressive Symptomatology (IDS-C). However, changes in total scores of depression scales may not reflect improvements in specific symptom domains, e.g. there may be a positive effect on affective symptoms, but a negative effect on sleep as an early side effect of the treatment drug. Only one study (20), which evaluated the effect of desipramide and escitalopram in PD patients, included a three factor model of the MADRS in the analysis. Both the "psychic anxiety/dysphoria" and "apathy/retardation" factor as well as the" vegetative symptom" factor changed over a 30 day period, but there was no main effect of time or treatment on any factor. Studies of the trajectory response in the primary psychiatric population are also sparse and show heterogeneous results. Some studies report early improvement of anhedonia, sometimes as early as week one (21), whereas others showed early improvement of depression-related ideation followed by improvements in anxiety and somatisation (22). Possible explanations for these varying results are the heterogeneity of the studies, the confounding influences of placebo and the focus on individual item scores on the HAMD or MADRS instead of looking at domains consisting of grouped items.

The late improvement of depression-related ideation is in line with observations that depressive ideation and concentration difficulties in general seems to be one of the most frequent residual symptoms of major depression (23). 
Knowledge of the different treatment response patterns can aid in patient counseling. Perceived lack of symptom relief is a primary reason of non-adherence or discontinuation of treatment. For example, patients expecting a rapid relief of somatic symptoms (e.g., insomnia) may discontinue the treatment since they believe that they are receiving no benefit from it (25). In addition, adverse effects most frequent appear in the first weeks, which lead to discontinuation of treatment in the first 3 months in up to $40 \%$ of depressed patients in a psychiatric population (11). Reassuring of patients with expected outcome/response may promote patient compliance and may increase treatment effect.

There is a large and significant, placebo effect on all symptom domains, especially in the first two weeks. After two weeks the placebo effect on the affective, somatic symptoms and cognitive symptoms seem to decline, with a trend of worsening towards week 12 . The placebo effect is a well-known phenomenon in depression studies, and may be responsible for improvement of up to $34 \%$ of depressive symptoms in PD patients $(21,26)$. Since there seems to be a trend in diminishing placebo response between assessments at week 8 and 12, future studies should have a longer duration in order to better discriminate sustained response to active treatment from time-limited placebo response.

This study has several limitations. First of all, the sample size is small and, in addition, $19 \%$ of randomized patients could not be included because they withdrew or had some missing data. In order to increase the power we decided to combine the paroxetine and venlafaxine groups. Although the mechanism of action differs between the two treatments (one is an selective serotonin reuptake inhibitor and the other a serotonin and noradrenalin reuptake inhibitor) we speculate that their treatment effects would be comparable in this population (12). An exploratory post-hoc analysis of paroxetine or venlafaxine alone versus placebo showed response patterns similar to our primary analysis. Recent papers identified individual trajectories of recovery of depressed patients in a primary psychiatric population using growth mixture modelling (GMM) $(27,28)$. GMM has the advantage that it allows for different treatment effects in different trajectories classes, so that fundamentally different trajectories shapes can be detected. However, GMM also requires a larger sample sizes than available in the SAD-PD database. This is why we decided to use the repeated measurement model to detect trajectory "shape" response pattern over time. Last, we based our symptom domains on face validity since the factor analyses of the scales are unsatisfactory (19). In order to increase the stability of these domains and the likelihood of identifying different trajectories we included different depression scales. In addition, items of the three scales overlap, which we believe strengthened the differentiation between affective, cognitive and somatic trajectories of recovery. 


\section{CONCLUSIONS}

In this study, affective symptoms showed the earliest treatment effect in depressed PD patients treated with paroxetine or venlafaxine, followed by somatic symptoms and last cognitive/ideational symptoms. A more thorough understanding of the treatment response patterns may facilitate patient counseling with regard to treatment expectations, which may lead to improved medication adherence and hopefully a better treatment outcome. Another important conclusion is that our analysis underlines the importance of a sufficiently long study period in future studies, preferable longer than 12 weeks, in order to be able to separate persistent response to active treatment and time-limited placebo response. 


\section{REFERENCES}

1 Reijnders JS, Ehrt U, Weber WE, Aarsland $\mathrm{D}$, Leentjens AF. A systematic review of prevalence studies of depression in Parkinson's disease. Mov Disord. 2008;23(2):183-9; quiz 313.

2 Carod-Artal FJ, Ziomkowski S, Mourao Mesquita H, Martinez-Martin P. Anxiety and depression: main determinants of health-related quality of life in Brazilian patients with Parkinson's disease. Parkinsonism Relat Disord. 2008;14(2):102-8. Hely MA, Morris JG, Reid WG, Trafficante R. Sydney Multicenter Study of Parkinson's disease: non-L-dopa-responsive problems dominate at 15 years. Mov Disord. 2005;20(2):190-9.

Frisina PG, Borod JC, Foldi NS, Tenenbaum HR. Depression in Parkinson's disease: health risks, etiology, and treatment options. Neuropsychiatr Dis Treat. 2008;4(1):81-91.

5 Skapinakis P, Bakola E, Salanti G, Lewis G, Kyritsis AP, Mavreas V. Efficacy and acceptability of selective serotonin reuptake inhibitors for the treatment of depression in Parkinson's disease: a systematic review and meta-analysis of randomized controlled trials. BMC Neurol. 2010;10:49.

6 Troeung L, Egan SJ, Gasson N. A meta-analysis of randomised placebo-controlled treatment trials for depression and anxiety in Parkinson's disease. PLoS One. 2013;8(11):e79510.
Kulkarni AS, Balkrishnan R, Anderson RT, Edin HM, Kirsch J, Stacy MA. Medication adherence and associated outcomes in medicare health maintenance organization-enrolled older adults with Parkinson's disease. Mov Disord. 2008;23(3):359-65.

Wei YJ, Palumbo FB, Simoni-Wastila L, Shulman LM, Stuart B, Beardsley R, et al. Antiparkinson drug use and adherence in medicare part D beneficiaries with Parkinson's disease. Clin Ther. 2013;35(10):1513$25 \mathrm{e} 1$.

Daley DJ, Myint PK, Gray RJ, Deane KH. Systematic review on factors associated with medication non-adherence in Parkinson's disease. Parkinsonism Relat Disord. 2012;18(10):1053-61.

Bull SA, Hunkeler EM, Lee JY, Rowland CR, Williamson TE, Schwab JR, et al. Discontinuing or switching selective serotonin-reuptake inhibitors. Ann Pharmacother. 2002;36(4):578-84.

12 Richard IH, McDermott MP, Kurlan R, Lyness JM, Como PG, Pearson N, et al. A randomized, double-blind, placebo-controlled trial of antidepressants in Parkinson disease. Neurology. 2012;78(16):1229-36. de Rijk MC, Rocca WA, Anderson DW, Melcon MO, Breteler MM, Maraganore DM. A population perspective on diagnostic criteria for Parkinson's disease. Neurology. 1997;48(5):1277-81.

14 Diagnostic and Statistical Manusal of Mental Disorders. Association AP, editor. Washington, DC: American Psychiatric Association; 1994. 2010;25(4):474-80.
Folstein MF, Folstein SE, McHugh PR. "Mini-mental state". A practical method 
for grading the cognitive state of patients for the clinician. J Psychiatr Res. 1975;12(3):189-98.

Hamilton M. A rating scale for depression. J Neurol Neurosurg Psychiatry. 1960;23:56-62.

Montgomery SA, Asberg M. A new depression scale designed to be sensitive to change. Br J Psychiatry. 1979;134:382-9.

Beck AT, Steer RA, Ball R, Ranieri W. Comparison of Beck Depression Inventories -IA and -II in psychiatric outpatients. J Pers Assess. 1996;67(3):588-97.

Broen MP, Moonen AJ, Kuijf ML, Dujardin K, Marsh L, Richard IH, et al. Factor analysis of the Hamilton Depression Rating Scale in Parkinson's disease. Parkinsonism Relat Disord. 2015;21(2):142-6.

Devos D, Dujardin K, Poirot I, Moreau C, Cottencin O, Thomas P, et al. Comparison of desipramine and citalopram treatments for depression in Parkinson's disease: a double-blind, randomized, placebo-controlled study. Mov Disord. 2008;23(6):850-7.

Laux G, Friede M, Muller WE. Treatment of comorbid anxiety and depression with escitalopram: results of a post-marketing surveillance study. Pharmacopsychiatry. 2013;46(1):16-22.

22 Tollefson GD, Sayler ME. Course of psychomotor agitation during pharmacotherapy of depression: analysis from double-blind controlled trials with fluoxetine. Depress Anxiety. 1996;4(6):294-311.

23 Bortolato B, Carvalho AF, McIntyre RS. Cognitive dysfunction in major depressive disorder: a state-of-the-art clinical review. CNS Neurol Disord Drug Targets. 2014;13(10):1804-18.

24 Weintraub D, Mavandadi S, Mamikonyan
E, Siderowf AD, Duda JE, Hurtig HI, et al. Atomoxetine for depression and other neuropsychiatric symptoms in Parkinson disease. Neurology. 2010;75(5):448-55. Masand PS. Tolerability and adherence issues in antidepressant therapy. Clin Ther. 2003;25(8):2289-304.

26 Wermuth L, Sorensen PS, Timm S, Christensen B, Utzon NP. Depression in idiopathic parkinson's disease treated with citalopram: a placebo-controlled trial. . Nord J Psychiatry. 1988;52:163-9.

27 Gueorguieva R, Mallinckrodt C, Krystal JH. Trajectories of depression severity in clinical trials of duloxetine: insights into antidepressant and placebo responses. Arch Gen Psychiatry. 2011;68(12):1227-37.

28 Uher R, Muthen B, Souery D, Mors O, Jaracz J, Placentino A, et al. Trajectories of change in depression severity during treatment with antidepressants. Psychol Med. 2010;40(8):1367-77. 


\section{SUPPLEMENTARY FILES}

\section{Supplementary table 1.}

Baseline demographic and clinical characteristics of the active treatment and the placebo treated group. ${ }^{\mathrm{a}}$

\begin{tabular}{l|l|l}
\hline Variable & $\begin{array}{l}\text { Treatment group } \\
(\mathbf{N = 6 1 )}\end{array}$ & $\begin{array}{l}\text { Placebo group } \\
(\mathbf{N = 3 2})\end{array}$ \\
\hline Age (years) & $64.2(10.0)$ & $61.4(10.0)$ \\
\hline Male (\%) & $62 \%$ & $59 \%$ \\
\hline Years since PD diagnosis & $5.3(4.1)$ & $5.5(3.9)$ \\
\hline UPDRS total score & $42.6(17.5)$ & $41.3(16.4)$ \\
\hline Major depression $(\%)$ & $59 \%$ & $56 \%$ \\
\hline HAM-D total score & $17.1(4.3)$ & $17.3(3.8)$ \\
\hline MADRS total score & $20.1(7.5)$ & $20.2(6.2)$ \\
\hline BDI-II total score & $16.7(8.3)$ & $17.8(7.8)$ \\
\hline UPDRS section 3 score & $27.3(11.1)$ & $25.8(11.9)$ \\
\hline MMSE total score & $28.9(1.5)$ & $28.6(3.9)$ \\
\hline
\end{tabular}

Abbreviations: HAM-D, Hamilton Depression Rating Scale; MADRS, Montgomery-Asberg Depression Rating Scale; BDI-II, Beck Depression Inventory II; UPDRS, Unified Parkinson's Disease Rating Scale; MMSE, Mini Mental State Examination.

${ }^{a}$ Values are presented as mean (standard deviation) unless otherwise indicated.

\section{Supplementary table 2.}

Mean z-scores and $p$ value for the comparison between the active treatment (venlafaxine and paroxetine) and the placebo treated group in the affective, somatic and cognitive domain.

\begin{tabular}{|c|c|c|c|c|c|c|c|}
\hline \multirow{2}{*}{\multicolumn{2}{|c|}{$\begin{array}{l}\text { Domain } \\
0\end{array}$}} & \multicolumn{6}{|l|}{ Week } \\
\hline & & 2 & 4 & 6 & 8 & 12 & \\
\hline \multirow{3}{*}{ Affective } & Z-score placebo & 0.22 & -0.624 & -0.756 & -0.981 & -1.114 & -0.865 \\
\hline & Z-score treatment & -0.13 & -0.708 & -1.212 & -1.406 & -1.575 & -1.581 \\
\hline & $p$ & 0.85 & 0.69 & 0.02 & 0.03 & 0.02 & 0.00 \\
\hline \multirow{3}{*}{ Somatic } & Z-score placebo & 0.071 & -0.392 & -0.477 & -0.495 & -0.673 & -0.427 \\
\hline & Z-score treatment & -0.036 & -0.393 & -0.644 & -0.841 & -0.905 & -0.951 \\
\hline & $p$ & 0.55 & 0.99 & 0.33 & 0.04 & 0.10 & 0.00 \\
\hline \multirow{3}{*}{ Cognitive } & Z-score placebo & 0.025 & -0.629 & -0.702 & -0.883 & -0.822 & -0.764 \\
\hline & Z-score treatment & -0.014 & -0.618 & -0.927 & -1.088 & -1.324 & -1.28 \\
\hline & $p$ & 0.82 & 0.95 & 0.16 & 0.16 & 0.00 & 0.00 \\
\hline
\end{tabular}

$P<.05$ are shown in bold. 


\section{Supplementary table 3.}

Mean z-scores comparison between the placebo group $(n=32)$, paroxetine group $(n=33)$ and venlafaxine group $(n=28)$.

\section{Affective domain:}

\begin{tabular}{l|l|l|l}
\hline Week & Placebo & Paroxetine & Venlafaxine \\
\hline 0 & .022 & .105 & -.151 \\
\hline 2 & -.624 & -.631 & -.798 \\
\hline 4 & -.756 & $-1.246^{*}$ & $-1.173^{*}$ \\
\hline 6 & -.981 & -1.372 & $-1.446^{*}$ \\
\hline 8 & -1.145 & $-1.639^{*}$ & $-1.499^{*}$ \\
\hline 12 & -.865 & $-1.687^{*}$ & $-1.455^{*}$ \\
\hline
\end{tabular}

* $\mathrm{p}<.05$ compared to placebo

\section{Somatic domain:}

\begin{tabular}{l|l|l|l}
\hline Week & Placebo & Paroxetine & Venlafaxine \\
\hline 0 & .071 & .073 & -.165 \\
\hline 2 & -.391 & -.341 & -.454 \\
\hline 4 & -.477 & -.629 & -.661 \\
\hline 6 & -.495 & -.798 & $-.891^{*}$ \\
\hline 8 & -.673 & -.941 & -.863 \\
\hline 12 & -.427 & $-.999^{*}$ & $-.894^{*}$ \\
\hline
\end{tabular}

${ }^{*} \mathrm{p}<.05$ compared to placebo

\section{Cognitive domain:}

\begin{tabular}{l|l|l|l}
\hline Week & Placebo & Paroxetine & Venlafaxine \\
\hline 0 & .025 & .047 & -.086 \\
\hline 2 & -.629 & -.519 & -.735 \\
\hline 4 & -.702 & -.849 & -1.019 \\
\hline 6 & -.883 & -1.079 & -1.099 \\
\hline 8 & -.822 & $-1.300^{*}$ & $-1.352^{*}$ \\
\hline 12 & -.764 & $-1.358^{*}$ & $-1.188^{*}$ \\
\hline
\end{tabular}

${ }^{*} \mathrm{p}<.05$ compared to placebo 



\section{Chapter 6}

Unraveling the Relationship between Motor Symptoms, Affective States and Contextual Factors in Parkinson's Disease: A Feasibility Study of the Experience Sampling Method 


\section{ABSTRACT}

\section{Background:}

In Parkinson's disease (PD), the complex relationship between motor symptoms, affective states, and contextual factors remains to be elucidated. The Experience Sampling Method provides (ESM) a novel approach to this issue. Using a mobile device with a special purpose application (app), motor symptoms, affective states and contextual factors are assessed repeatedly at random moments in the flow of daily life, yielding an intensive time series of symptoms and experience. The aim of this study was to study the feasibility of this method.

\section{Method:}

We studied the feasibility of a five-day period of ESM in PD and its ability to objectify diurnal fluctuations in motor symptom severity and their relation with affect and contextual factors in five PD patients with motor fluctuations.

\section{Results:}

Participants achieved a high compliance, with $84 \%$ of assessment moments completed without disturbance of daily activities. The utility of the device was rated 8 on a 10 -point scale. We were able to capture extensive diurnal fluctuations that were not revealed by routine clinical assessment. In addition, we were able to detect clinically relevant associations between motor symptoms, emotional fluctuations and contextual factors at an intra-individual level.

\section{Conclusions:}

ESM represents a viable and novel approach to elucidate relationships between motor symptoms, affective states and contextual factors at the level of individual subjects. ESM holds promise for clinical practice and scientific research. 


\section{INTRODUCTION}

Parkinson disease is a complex neurodegenerative disease with both motor and nonmotor symptoms. In time, most patients with Parkinson's disease (PD) eventually develop motor fluctuations such as "wearing-off" and "on-off" fluctuations. It has been estimated that two thirds of these patients also experience mood fluctuations $(1,2)$ and that these fluctuations are often more disabling and distressing to patients than motor symptoms (3). Moreover, it is increasingly recognized that personal circumstances and contextual factors may also impact the severity of motor symptoms as well as the well-being of PD patients. However, the relationship between affect, motor fluctuations and their social context remains to be elucidated (4). Traditional research methods are unlikely to provide sufficiently detailed and personal information to provide insight into the relationship between these variables. Assessing subjects several times a day during their normal daily activities, which is possible with the Experience Sampling Method (ESM), may not only provide information about the frequency and severity of emotions or motor fluctuations, but also provide valuable information on situational and behavioural moderators driving these fluctuations (5-8).

The ESM approach is gaining terrain in the study of psychopathology, $(5,6,9,10)$ and is previously used among others, in studies on depression (11), asthma (12), irritable bowel syndrome (13) and migraine (14). To date, this approach had not yet been used in a PD population. The well known, but complex relation between the severity of motor symptoms in $\mathrm{PD}$ with affect and contextual factors, varying during the course of the disease, represents a particularly good target for ESM. The method assesses symptoms, contextual factors and other variables several times a day at random intervals in the subject's natural environment $(5,6)$. The primary aim of this study was to assess the feasibility of ESM in PD. In addition, we present an overview of the utility of ESM in 5 PD patients with motor fluctuations for detecting intra-individual associations between motor fluctuations, affective states and contextual factors.

\section{METHODS}

\section{Participants}

This study was part of a clinical initiative to assess the feasibility of ESM for routine outcome monitoring in a psychiatric outpatient population (9). The parent study was exempt from ethical approval since it concerns routine clinical follow-up measurements. For our pilot study five consecutive PD patients with motor fluctuations from the multidisciplinary movement disorder clinic were asked to participate in this initiative to assess the feasibility of the ESM method to detect intra-individual fluctuations. PD was diagnosed according to the Queens Square Brain Bank criteria (15). Subjects with 
known cognitive impairment, operationalized as an MMSE < 24, were excluded given anticipated difficulties in working with the mobile ESM application (PsyMate device). All approached subjects gave written informed consent. The parent study was approved by the Institutional Review Board of Maastricht University Medical Center.

\section{The Experience Sampling Method (ESM)}

ESM is based on multiple repeated (within-subject) mini-measurements of experience (motor symptoms, anxiety, affect, wellbeing, motivation, stress) and context (medication use, stressors, situations, activities) at unselected semi-random moments in daily life. Within-subject data provide subjects and health professionals with the opportunity to follow intra-individual changes in relation to in-the-moment daily life situations and experiences. As it assesses the occurrence of motor symptoms, mental states and contexts in the flow of daily life, ESM Is a validated, structured diary technique to assess subjects in their daily living environment $(5,16)$. ESM is able to follow the impact of motor and mental states, as well as their context, on each other over time.

\section{Measures}

The PsyMate device used in this study (17) was an iPod touch with a special ESM app installed. The device is programmed to generate 10 beeps per day at semi-random moments in 90-minutes time blocks between 7:30 and 22.30, for 5 consecutive days (total of 50 measurement points). At each beep, the PsyMate presents a number of questions on the experience of motor symptoms, affective states and contextual factors, which are recorded through a touch screen (Fig 1, screenshot question). First, subjects were asked if they felt in their "on" or "off" state, the latter being a state where in their opinion the dopaminergic medication was not working anymore (due to the short halftime of levodopa preparations). For example, when just before the next medication gift the subject experienced more motor- (return of parkinsonism), sensory- or autonomic symptoms, they answered they were in an "off" state. On the contrary, when subjects experienced few complaints during dopaminergic treatment, they answered "on". We included 5 Parkinson-specific questions, rating the symptoms 'tremor', 'rigidity', 'problems with walking', 'balance problems' and 'dyskinesia'. These questions were selected from the Unified Parkinson Disease Rating Scale (UPDRS), which is a commonly used scale in PD (18). Since this was a pilot study we only included general motor symptoms and not more specific motor symptoms such as freezing, which is only present in a small proportion of PD patients. All of the included motor symptoms are strongly correlated with quality of life (19). To assess affect state we used a constructed composite score for positive affect (PA) and negative affect (NA) (11), in line with previous studies $(20,21)$. PA comprised the weighted average of scores on the affect adjectives: 'happy', 'satisfied', 'relaxed' and 'feeling well' and for NA: 'insecure', 'lonely', 'anxious', 'irritated', 'guilty', 'suspicious' and 'threatened'. As contextual factors, the whereabouts, presence of others, 
and activities of the subject were registered, as well as how comfortable the subject felt in these circumstances. All PD symptoms and affect adjectives were rated by subjects on a 7 -point Likert scale ranging from $1=$ 'not at all' to 7 = 'very'. A complete overview of the questions is given in supplementary S1 table A. The questions were the same for each measurement point. In addition, once in the morning and once in the evening, subjects had to fill in additional 'morning' and 'evening' questionnaires (S1 table B). The application uploaded the responses in an anonymized central database, from which they were analyzed. The data collection method can be considered ecologically valid measures of the subject's circumstances and affective fluctuations in the flow of daily life $(5,6,22)$.

\section{Figure 1.}

Screenshot of the question "Ik voel me opgewekt" ("I feel cheerful") on a 7 point Likert scale. A score of 1 indicates "niet" ("not at all"), a score of 4 "matig" ("moderate") and a score of 7 "Zeer" ("Very much so").

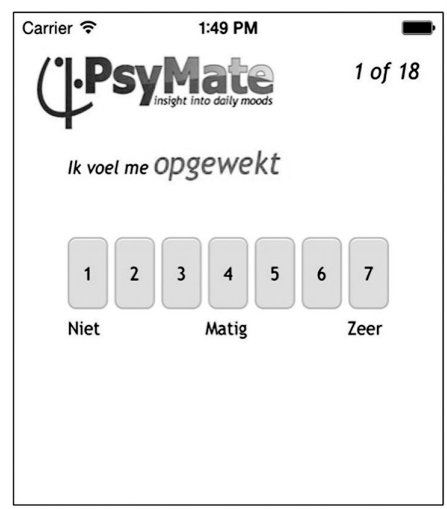

\section{Assessment}

Baseline demographic and disease-related characteristics were collected during a visit at the outpatient clinic (MPGB). In addition, the following scales were applied: the Hoehn and Yahr stage (23), the UPDRS to quantify motor symptoms, the Mini-Mental State Examination (MMSE) to assess global cognitive function (24), the Beck Depression Inventory II (BDI-II) to assess depressive symptoms (25), the Parkinson Anxiety Scale (PAS) (26) to assess anxiety symptoms and the Parkinson Disease Questionnaire-8 (PDQ-8) (27) to assess quality of life. During the assessment subjects received oral information on how to interpret the question about the "on" or "off" state. On the same day, information about the PsyMate as well as a demonstration was given in person (VAM). Subjects were given the option to either download and use the PsyMate on their own smartphone (iOS or Android), or to use an iPod touch provided by Maastricht University Medical Centre for the duration of the study. During the following five con- 
secutive days the PsyMate generated a total of 50 semi-random measurement points, 10 per day. At day two, subjects were called to check whether everything was clear and functioning correctly. At any time during the study period, subjects could ask for help by calling one of the investigators (VAM). After five days, they returned the device and the data were collected in an anonymized central database. Two weeks later, the subjects were interviewed by telephone about their experiences with the device (see S1 table C for evaluation questions).

\section{Statistical analysis}

Before running the analysis, missing items due to technical issues of the device were excluded from the data set. First, descriptive statistics were calculated for all PD symptom variables, as well as PA and NA. Since all variables were not normally distributed (kurtosis values ranging from 2.9 to 28.7), correlations were computed with Spearman's rho. Strength of the correlation was defined as $r<0.3$ very small, $r=0.3-0.5$ small, $r=0.5-0.7$ moderate and $r>0.7$ strong. Additionally, effect sizes were calculated by calculating Cohen's $d$, e.g. a 1 point change on the scale has an effect size of $1 /$ standard deviation of the variable. Strength of the effect size was defined as medium $d=0.3-0.6$ and large $d>0.6$. Analyses were done using the statistical software program STATA (version 13.1 for Mac).

\section{RESULTS}

Table 1 shows baseline characteristics of the 5 subjects. The mean age was $60.4 \mathrm{yr}$ (SD 6.1). All subjects had a Hoehn and Yahr stage of 2-2.5, which indicates bilateral or midline involvement of the disease, without impairment of balance or a recovery on the pull test. The mean UPDRS III score was 22 (SD 6.2). On the PAS, subject 1 and 4 scored above the cut-off point of 13/14 indicating clinically relevant anxiety. Subject 4 also scored above the cut off score of $14 / 15$ on the BDI-II, which fits with a mild depression. Quality of life of the subjects was relatively good with a maximum score of 13 out of 32, with higher scores indicating a lesser quality of life.

\section{Compliance}

A mean total of $84 \%$ (range 76-96\%) of all 50 measurement points were completed correctly. Previous research has shown that ESM data validity is compromised if less than one third of beeps yield data (5). All subjects in met this requirement. Subject 2 and 3 both missed three beeps because they did not hear the sound of the alarm and subject 4 went swimming several times and missed four beeps when she was in the water. Unfortunately, when transferring data from the device of subject 1, data of fifteen measurement points were lost due to connection malfunction. The exact cause of this malfunction remains unclear. There was no significant difference in terms of compliance between the three subjects using their own smartphone and the two using an Ipod (89\% vs 83\%). 


\section{User friendliness, evaluation and feedback}

All subjects found the information about the PsyMate device clear and concise. None of them said they changed their daily behaviour. This occasionally led to a missed assessment point when they were showering, swimming, riding a bike or driving a car. Three subjects used their own smartphone and two used an iPod. These two were not inconvenienced by having to carry the iPod device with them. Beep assessments never took more than 5 minutes, with a mean completion time between 2 and 3 minutes. The mean utility score that the subjects gave the device was 8 on a 10-point scale. Some subjects suggested also including questions about exercise, since in their own experience this also influences their affect. Three subjects mentioned that repetitive assessments tended to get boring. However, studying the relationship between affect and motor fluctuations and contextual factors was considered very meaningful by all subjects and they all would participate in future ESM studies.

\section{Ability to detect diurnal fluctuations in motor symptom severity at an individual level.}

Fig 2 shows the overall motor symptom severity and the real-time diurnal fluctuations in motor symptom severity of subject 4. Cohen's $d$ for tremor was .75 and 1.28 for PA, with indicates a large, meaningful effect size of a 1 point change on the Likert scale. Similar patterns were found in all subjects. These figures show that ESM is sensitive enough to capture clinically relevant diurnal fluctuations of motor symptom severity.

\section{Ability to detect intra-individual relationships between motor symptoms, affect and contextual factors in 5 PD subjects with motor fluctuations}

First, since subjects with mood fluctuations are more likely to have higher scores on psychiatric rating scales [28], we expected that subjects 1 and 4, which had the highest scores on the anxiety and depression rating scales, would also have the strongest correlation between motor symptoms, affect and possibly contextual factors. This was especially true for the severity of the tremor; both subject 1 and 4 had a moderate negative correlation between positive affect and the severity of the tremor $(r=-0.5, p<.01)$. For subject 1 , Cohen's $d$ for tremor was .57 and 2.63 for PA, indicating a large effect size for a 1-point change on the Likert scale. See Figs 3 and 4 for an example of the fluctuations of tremor and affect during the day. In Fig 3, one can see that the severity of the tremor fluctuates heavy, but the positive affect line shows only minor changes. This is most likely because the PA is a weighted average of 4 affect adjectives and when looking closer at the data it turned out that mainly the variable "satisfied" had a correlation with tremor $(r=-0.6$, $p<.01)$. In subject 4 , feeling relaxed $(r=-0.6, p<.01)$, satisfied $(r=-0.6, p<.01)$ and feeling happy $(r=-0.4, p<.01)$ all had a negative correlation with tremor severity, visible as a more fluctuating PA pattern in the diagram. On the contrary, subject 5 had the lowest scores on the rating scales and we were unable to find a significant correlation between affect and any of the motor or contextual factors. 
Chapter 6

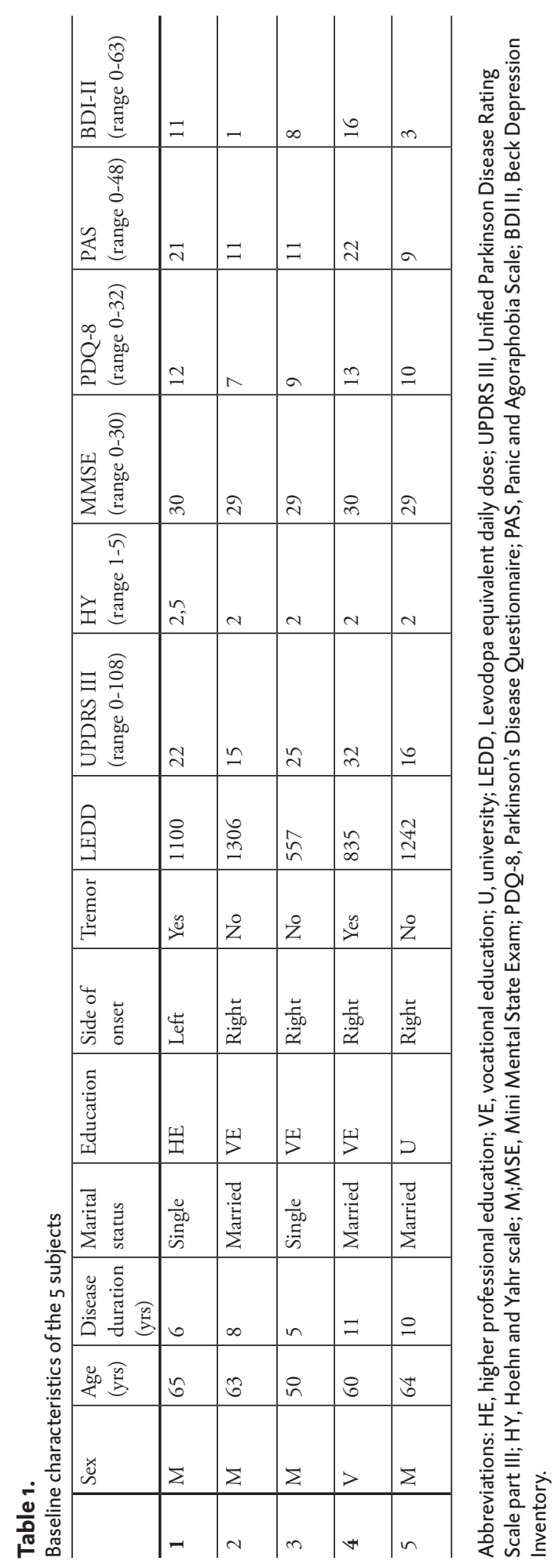

104 
Figure $2 a$ and $\mathbf{2 b}$.

Cross-sectional overall daily assessment (Fig 2a) versus real-time measurements (Fig $2 \mathrm{~b}$ ) of motor symptoms in subject 4 .

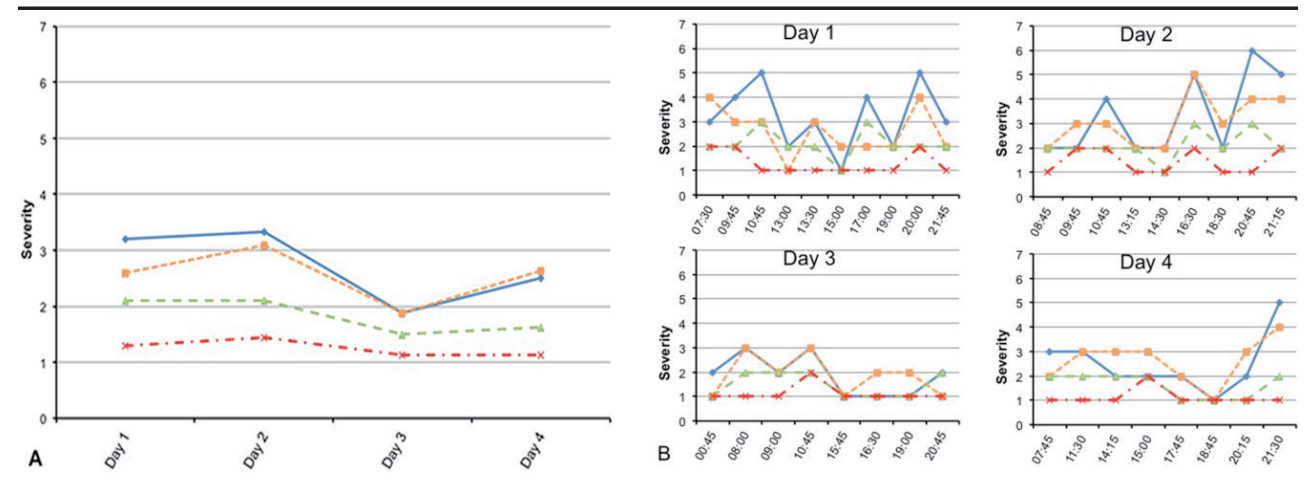

Legend: Y-axis: item score ( $1=$ not all, 7 = very much); X-axis: time. Blue solid line: Tremor; Orange line: Dyskinesia; Red line: Trouble Walking; Green line: Rigidity.

\section{Figure 3.}

Example of real time assessment of tremor and positive affect in subject 1.

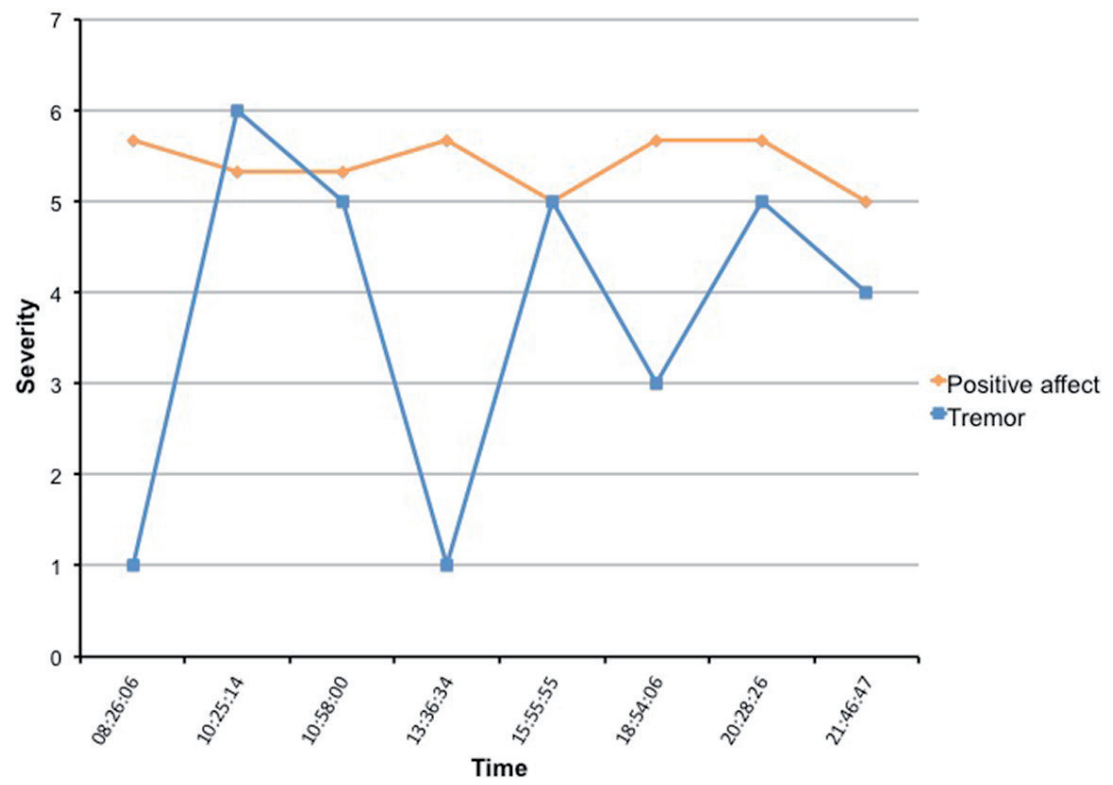


Figure 4.

Example of real time assessment of tremor and positive affect in subject 4 .

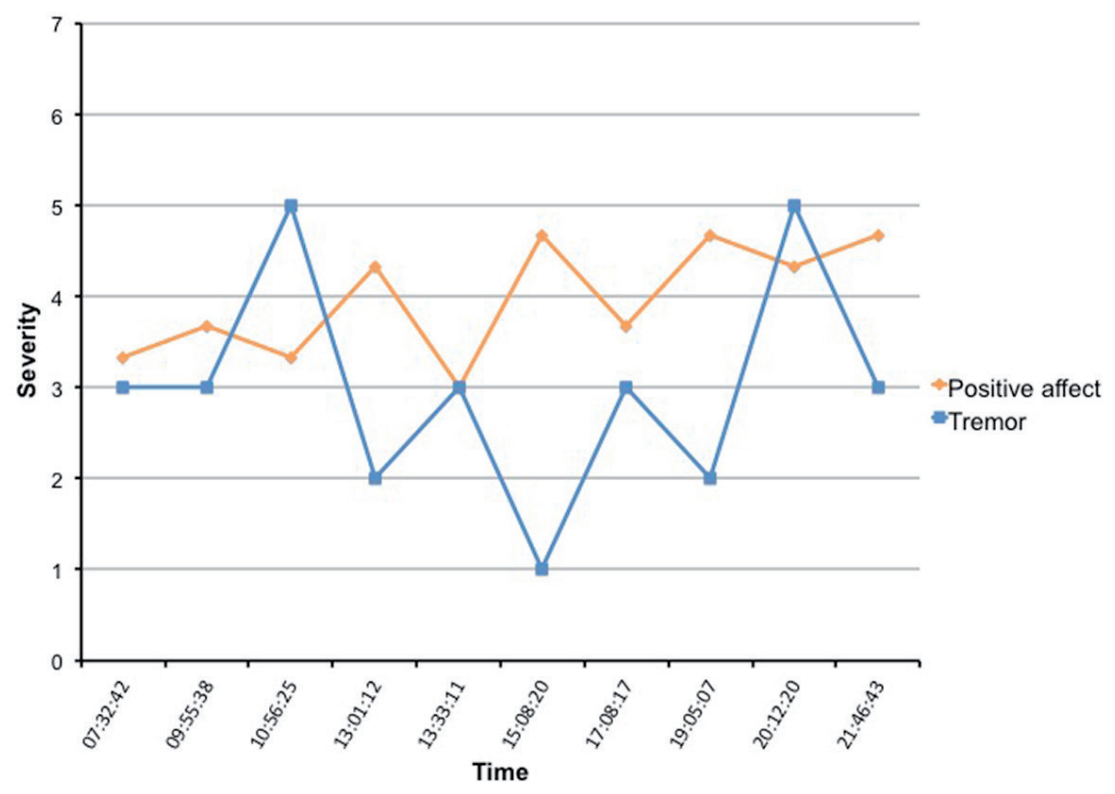

Second, we evaluated the influence of context on the severity of motor symptoms. Again, in subject 1 , the effect was most impressive. Fig 5 shows that all motor symptoms were more severe when he was not at home but in public. In the other subjects it was difficult to find a correlation between contextual factors and symptom severity, mainly because the measurement point were not evenly distributed, e.g. most of the measurements were taken at home, or in company with their spouses with only a few measurements taken in the opposite situation which makes a statistical comparison difficult. 


\section{Figure 5.}

Clustered column diagram of motor symptom severity in subject 1.

Legend: $Y$-axis: item score ( $1=$ not all, 7 = very much); X-axis: motor symptoms.

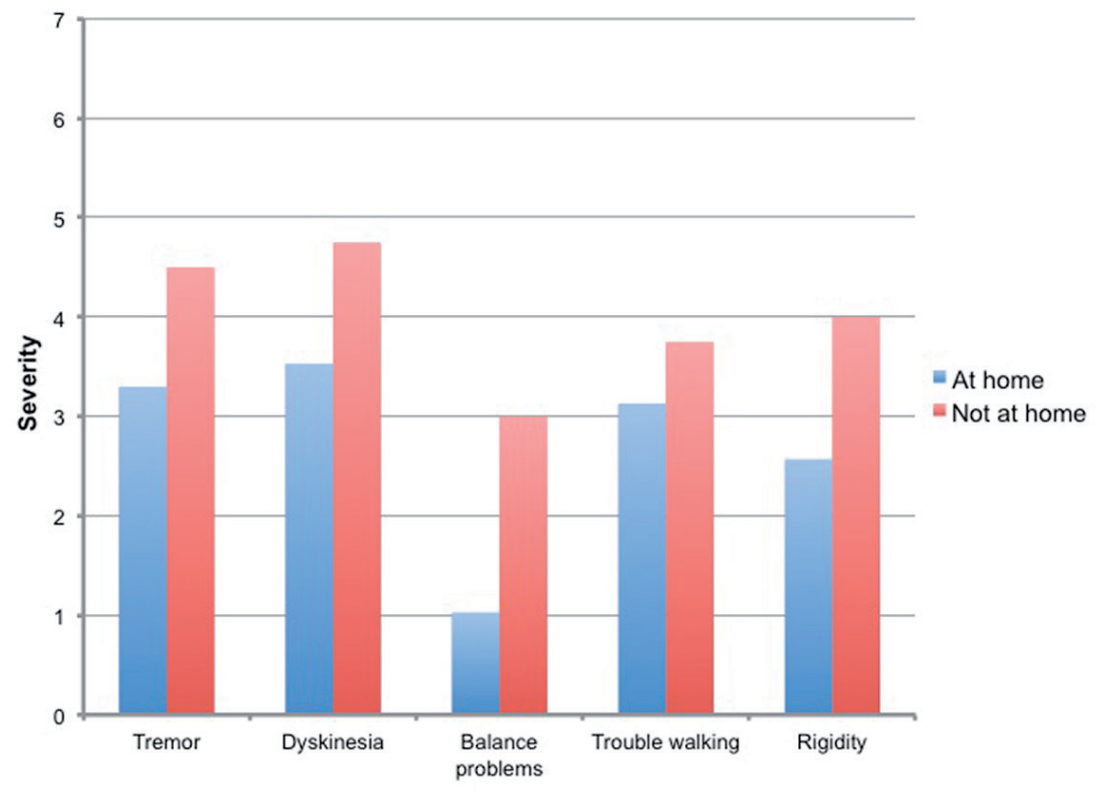

Third, to test whether individual motor symptoms were logically correlated, e.g. improved rigidity will normally lead to impaired balance or walking difficulties, we calculated these correlations in subject 3, who had a moderate score on the UPDRS III. We found a strong correlation between rigidity and the severity of walking difficulties $(r=0.8, p<.01)$. Balance problems were moderate correlated with dyskinesia $(r=0.6$, $p<.01)$ and also strongly correlated with walking difficulties $(r=0.8, p<.01)$. For subject 3 Cohen's $d$ for balance problems was 1.90 , for walking difficulties 1.26 and 3.51 for dyskinesia. Similar correlation coefficients were found in the other subjects, which indicated that their symptoms were logically scored.

Last, we tried to detect effects of dopaminergic treatment on the motor symptoms or affect fluctuations. However, in this pilot application subjects were not asked to mark at what exact time they took their medication, so we were only able to visible link their prescription time with the severity of their symptoms. For example, according to her prescription time subject 4 took levodopa medication at 7 and 11 o'clock in the morning, three o'clock in the afternoon and 7 and ten o'clock in the evening. Looking at her severity of the tremor (Fig 4), it seems that the tremor was worse just before she took her 
medication (point 3, 10:56) and less severe just after her medication (point 6, 15:08). Since the tremor severity and positive affect were correlated, this was also true for her affective state, having a more positive affect just after the medication gift. However, we realize this is not very accurate, since actual medication times can differ notoriously from prescription times.

\section{DISCUSSION}

This pilot study shows that ESM is a viable and promising method for evaluating affect and motor fluctuations in relation to contextual factors in PD. Subjects achieved a high compliance rate without disturbance of normal daily activities. The average rating of the utility of the device was an 8 on a 10-point scale. Subjects were confident that ESM had the potential of revealing meaningful information of factors associated with fluctuations in motor symptom severity. ESM proved to be sensitive enough to capture extensive diurnal fluctuations in motor symptom severity, affective states and contextual factors.

The advantage of ESM is that assessments take place in the flow of daily life, in the natural environment of the subject. This is important since contextual factors play an important role in motor symptom severity, affect and behavior $(29,30)$. By assessing subjects during normal activities in their natural environments, ESM avoids some of the methodological problems commonly encountered in research, which has implications for treatment. First, it reduces recall bias. Current assessments in clinical settings often rely on retrospective questionnaires and this possible leads to several sources of recall bias. It has been shown in depressed subjects that there is a high discrepancy between retrospective ratings and actual experiences (31). Another advantage is that by using an electronic device, investigators can be confident that the ratings were actually completed at the time specified by the research design, which one cannot be sure of when using repeated paper questionnaires. This avoids the problem of "back-filling" the diaries when subjects neglect to make ratings at the scheduled time. A clinical advantage of the ESM approach is that multiple repeated assessments within each subject, forming an intensive time series of symptoms, context and experience, increases the power of the data to such an extent that analysis of single subject time series becomes possible. This enables the recognition of highly individual patterns of reactivity to contextual factors, and may facilitate the prediction of 'off'-periods and other important transitions (32). Person-specific patterns may be fed back to the subject to enhance insight into factors associated with symptom severity and facilitate self-management. Behavioural insight may enhance feelings of mastery over the symptoms, and facilitate coping or adjustment of activities. Providing feedback may also lead to an increased sense of involvement in treatment, better adherence and better treatment outcome, as was previously reported in other subject populations, such as subjects with depression, 
migraine and asthma (33-35).

The monitoring of treatment progress is also a promising clinical application. ESM may reveal relatively small treatment effects by avoiding clouding due to recall bias when using retrospective self-report measures (36). This would allow for more targeted and individualized pharmacotherapy. A practical advantage is that ESM software is freeware and can be downloaded for free as an app on smart phones or iPods.

A possible limitation of ESM used in our study is that it needs a certain level of motor function to use the telephone device but also a sufficient cognitive level to understand the information and learn to use the PsyMate program. For this reason, the use of ESM is limited to a selected population with sufficient cognitive and motor function, which in future studies could lead to selection and lack of generalizability. However, in most PD studies a certain level of cognitive function is already required. Second, the presence of motor fluctuations was based on self-reports, i.e. were not observer-rated, which may differ objective ratings of fluctuations. Previous studies on motor and mood fluctuations reported a discrepancy between self-reported and physician-documented motor fluctuations, which could be due to "over reporting" of fluctuations by subjects but also by the tendency of neurologists to continue to view subjects who have developed motor fluctuations as "fluctuators", regardless of how well controlled their symptoms are at a given time (28). Such overestimation of fluctuations could be a problem, especially when treatment modifications are made due to ESM results. To further objectify the motor fluctuations additional use of an accelerometer is a possible solution, a method that is currently finding its way in studies of movement and gait disorders in PD (37, 38). With respect to the overestimation of emotional fluctuations, previous research has shown that self-reports are an useful source of data when dealing with immediate experiences such as affective states $(16,39)$. In our study it seems that the self-reports on emotional items are plausible representations of reality. However, this needs to be validated further. Last, our study was part of a larger study on ESM in a psychiatric population. Further studies are needed to validate our preliminary findings on the ability of ESM to detect meaningful intra-individual relationships. These future studies should implement an ESM questionnaire optimized for PD patients, e.g. more questions about motor symptoms and a more precise medication time queue which enables researches to better detect medication influences. In addition, PD patients with different stages of the disease should be included, to extend our findings in subjects who are more disabled. However, taken all these limitations into account, we think that ESM is a feasible method in PD and holds promises for future scientific and clinical implications. 


\section{CONCLUSION}

ESM may be a viable and useful method in PD. Subjects reached a high compliance rate and were able to rate multiple symptoms simultaneously in a brief period of time, without disturbance of daily activities. The study shows that ESM technology is sensitive enough to capture extensive diurnal fluctuations of motor symptom severity, affective states and contextual factors in individual subjects. Therefore ESM could be a useful tool for fine grained analyses of how these variables impact each other in the flow of daily life in individual subjects, and how these patterns may be altered as a function of treatment. Detailed feedback to the subject may enhance insight and facilitate self-management, shared decision making and compliance. 


\section{REFERENCES}

1. Nissenbaum H, Quinn NP, Brown RG, Toone B, Gotham AM, Marsden CD. Mood swings associated with the 'on-off phenomenon in Parkinson's disease. Psychol Med. 1987;17(4):899-904.

2. Richard IH, Justus AW, Kurlan R. Relationship between mood and motor fluctuations in Parkinson's disease. J Neuropsychiatry Clin Neurosci. 2001;13(1):35-41.

3. Cantello R, Gilli M, Riccio A, Bergamasco B. Mood changes associated with "end-ofdose deterioration" in Parkinson's disease: a controlled study. J Neurol Neurosurg Psychiatry. 1986;49(10):1182-90.

4. Leentjens AF, Dujardin K, Marsh L, Martinez-Martin P, Richard IH, Starkstein SE. Anxiety and motor fluctuations in Parkinson's disease: a cross-sectional observational study. Parkinsonism Relat Disord. 2012;18(10):1084-8.

5. Delespaul P. Assessing Schizophrenia in Daily Life. The Experience Sampling Method. Delespaul P, editor. Maastricht: Maastricht University Press; 1995.

6. Myin-Germeys I, Oorschot M, Collip D, Lataster J, Delespaul P, van Os J. Experience sampling research in psychopathology: opening the black box of daily life. Psychol Med. 2009;39(9):1533-47.

7. Sotgiu I, Rusconi ML. Investigating emotions in Parkinson's disease: what we know and what we still don't know. Front Psychol. 2013;4:336.

8. Walz LC, Nauta MH, Aan Het Rot M. Experience sampling and ecological momentary assessment for studying the daily lives of patients with anxiety disorders: a systematic review. J Anxiety Disord.
2014;28(8):925-37.

9. van Os J, Delespaul P, Barge D, Bakker RP. Testing an mHealth momentary assessment Routine Outcome Monitoring application: a focus on restoration of daily life positive mood states. PLoS One. 2014;9(12):e115254.

10. van Os J, Delespaul P, Wigman J, Myin-Germeys I, Wichers M. Beyond DSM and ICD: introducing "precision diagnosis" for psychiatry using momentary assessment technology. World Psychiatry. 2013;12(2):113-7.

11. Hartmann JA, Wichers M, Menne-Lothmann C, Kramer I, Viechtbauer W, Peeters F, et al. Experience sampling-based personalized feedback and positive affect: a randomized controlled trial in depressed patients. PLoS One. 2015;10(6):e0128095.

12. Dunton GF, Liao Y, Intille S, Huh J, Leventhal A. Momentary assessment of contextual influences on affective response during physical activity. Health Psychol. 2015;34(12):1145-53.

13. Mujagic Z, Leue C, Vork L, Lousberg R, Jonkers DM, Keszthelyi D, et al. The Experience Sampling Method--a new digital tool for momentary symptom assessment in IBS: an exploratory study. Neurogastroenterol Motil. 2015;27(9):1295-302.

14. Houtveen JH, Sorbi MJ. Prodromal functioning of migraine patients relative to their interictal state--an ecological momentary assessment study. PLoS One. 2013;8(8):e72827.

15. de Rijk MC, Rocca WA, Anderson DW, Melcon MO, Breteler MM, Maraganore DM. A population perspective on diagnos- 
tic criteria for Parkinson's disease. Neurology. 1997;48(5):1277-81.

16. Csikszentmihalyi M, Larson R. Validity and reliability of the Experience-Sampling Method. J Nerv Ment Dis. 1987;175(9):52636.

17. http://www.psymate.eu.

18. Fahn S, Elton RL. Members of the UPDRS Committee. Unified Parkinson's Disease Rating Scale. In: Fahn S, Marsden CD, Goldstein M, Calne DB, editors. Recent Developments in Parkinson's Disease. Florham Park, NJ: MacMillan Health Care; 1987. p. 153-63.

19. Rahman S, Griffin HJ, Quinn NP, Jahanshahi M. Quality of life in Parkinson's disease: the relative importance of the symptoms. Mov Disord. 2008;23(10):1428-34.

20. Jacobs N, van Os J, Derom C, Thiery E, Delespaul P, Wichers M. Neuroticism explained? From a non-informative vulnerability marker to informative person-context interactions in the realm of daily life. $\mathrm{Br} \mathrm{J}$ Clin Psychol. 2011;50(1):19-32.

21. Wichers MC, Barge-Schaapveld DQ, Nicolson NA, Peeters F, de Vries M, Mengelers $\mathrm{R}$, et al. Reduced stress-sensitivity or increased reward experience: the psychological mechanism of response to antidepressant medication. Neuropsychopharmacology. 2009;34(4):923-31.

22. Wichers M, Simons CJ, Kramer IM, Hartmann JA, Lothmann C, Myin-Germeys I, et al. Momentary assessment technology as a tool to help patients with depression help themselves. Acta Psychiatr Scand. 2011;124(4):262-72.

23. Hoehn MM, Yahr MD. Parkinsonism: onset, progression and mortality. Neurology. 1967;17(5):427-42.
24. Folstein MF, Folstein SE, McHugh PR. "Mini-mental state". A practical method for grading the cognitive state of patients for the clinician. J Psychiatr Res. 1975;12(3):189-98.

25. Beck AT, Steer RA, Ball R, Ranieri W. Comparison of Beck Depression Inventories -IA and -II in psychiatric outpatients. J Pers Assess. 1996;67(3):588-97.

26. Leentjens AF, Dujardin K, Pontone GM, Starkstein SE, Weintraub D, Martinez-Martin P. The Parkinson Anxiety Scale (PAS): Development and validation of a new anxiety scale. Mov Disord. 2014;29(8):1035-43.

27. Jenkinson C, Fitzpatrick R, Peto V, Greenhall R, Hyman N. The Parkinson's Disease Questionnaire (PDQ-39): development and validation of a Parkinson's disease summary index score. Age Ageing. 1997;26(5):353-7.

28. Richard IH, Frank S, McDermott MP, Wang H, Justus AW, LaDonna KA, et al. The ups and downs of Parkinson disease: a prospective study of mood and anxiety fluctuations. Cogn Behav Neurol. 2004;17(4):201-7.

29. Hufford MR, Shiffman S, Paty J, Stone AA. Ecological momentary assessment: Real-world, real-time measurement of subject experience. In: Fahrenberg J, Myrtek M, editors. Progress in ambulatory assessment: Computer-assisted pscyhological and psychophysiological methods in monitoring and field studies. Seattle, WA: Hogrefe \& Huber; 2001. p. 69-92.

30. Peeters F, Berkhof J, Delespaul P, Rottenberg J, Nicolson NA. Diurnal mood variation in major depressive disorder. Emotion. 2006;6(3):383-91. 
31. Kizilbash AH, Vanderploeg RD, Curtiss G. The effects of depression and anxiety on memory performance. Arch Clin Neuropsychol. 2002;17(1):57-67.

32. van de Leemput IA, Wichers M, Cramer AO, Borsboom D, Tuerlinckx F, Kuppens $\mathrm{P}$, et al. Critical slowing down as early warning for the onset and termination of depression. Proc Natl Acad Sci U S A. 2014;111(1):87-92.

33. Kramer I, Simons CJ, Hartmann JA, Menne-Lothmann C, Viechtbauer W, Peeters F, et al. A therapeutic application of the experience sampling method in the treatment of depression: a randomized controlled trial. World Psychiatry. 2014;13(1):68-77.

34. Mulvaney SA, Ho YX, Cala CM, Chen Q, Nian H, Patterson BL, et al. Assessing adolescent asthma symptoms and adherence using mobile phones. J Med Internet Res. 2013;15(7):e141.

35. Odawara M, Hashizume M, Yoshiuchi K, Tsuboi K. Real-Time Assessment of the Effect of Biofeedback Therapy with Migraine: A Pilot Study. Int J Behav Med. 2015.

36. Barge-Schaapveld DQ, Nicolson NA. Effects of antidepressant treatment on the quality of daily life: an experience sampling study. J Clin Psychiatry. 2002;63(6):47785.

37. Benka Wallen $M$, Franzen E, Nero $H$, Hagstromer M. Levels and Patterns of Physical Activity and Sedentary Behavior in Elderly Individuals With Mild to Moderate Parkinson Disease. Phys Ther. 2015.

38. Louter M, Maetzler W, Prinzen J, van Lummel RC, Hobert M, Arends JB, et al. Accelerometer-based quantitative analysis of axial nocturnal movements differentiates patients with Parkinson's di- sease, but not high-risk individuals, from controls. J Neurol Neurosurg Psychiatry. 2015;86(1):32-7.

39. de Vries M. The Experience of Psychopathology: Investigating Mental Disorders in their Natural Settings. Cambridge: Cambridge University Press; 2006. 


\section{SUPPLEMENTARY FILES}

S1 table A.

Experience Sampling Methods protocol, question per beep.

\begin{tabular}{|c|c|c|c|}
\hline Domain & Item & Description & Score \\
\hline \multirow[t]{13}{*}{ Mood } & 1 & I feel happy & $1-7(1=$ not, $4=$ moderate, $7=$ very $)$ \\
\hline & 2 & I feel insecure & $1-7$ \\
\hline & 3 & I feel relaxed & $1-7$ \\
\hline & 4 & I feel irritated & $1-7$ \\
\hline & 5 & I feel satisfied & $1-7$ \\
\hline & 6 & I feel lonely & $1-7$ \\
\hline & 7 & I feel afraid & $1-7$ \\
\hline & 8 & I feel down & $1-7$ \\
\hline & 9 & I feel guilty & $1-7$ \\
\hline & 10 & I rack my brain & $1-7$ \\
\hline & 11 & I feel suspicious & $1-7$ \\
\hline & 12 & I feel threatened & $1-7$ \\
\hline & 13 & Currently I am: & $1=$ "on", $0=$ "off" \\
\hline \multirow[t]{7}{*}{ Parkinson } & 14 & I experience tremor & $1-7$ \\
\hline & 15 & I experience rigidity & $1-7$ \\
\hline & 16 & Walking is difficult & $1-7$ \\
\hline & 17 & I experience balance problems & $1-7$ \\
\hline & 18 & I experience dyskinesia & $1-7$ \\
\hline & 19 & Personal complaints: & Open question \\
\hline & 20 & In general, I feel well & $1-7$ \\
\hline \multirow[t]{5}{*}{ Context } & 21 & Currently I am: & $\begin{array}{l}\text { Resting/working/housework/hygiene/ } \\
\text { eating,drinking/relaxing/conversating/other }\end{array}$ \\
\hline & 22 & I rather do something else & $1-7$ \\
\hline & 23 & Where am I? & Home/work/ friends place/public place/on the go \\
\hline & 24 & With who am I? & Partner/family/friends/collegues/nobody \\
\hline & 25 & I find this pleasant & $1-7$ \\
\hline \multirow[t]{6}{*}{ Somatic } & 26 & I am hungry & $1-7$ \\
\hline & 27 & Since the last beep I used: & $\begin{array}{l}\text { Nothing/caffeine/nicotine/alcohol/medication/cannabis/ } \\
\text { food/other }\end{array}$ \\
\hline & 28 & I am tired & $1-7$ \\
\hline & 29 & I am not feeling well & $1-7$ \\
\hline & 30 & I have pain & $1-7$ \\
\hline & 31 & I experience: & $\begin{array}{l}\text { Headache/abdominal pain/breathing difficulties/muscle } \\
\text { ache/ obstipation/tinnitus/dizziness/ dyspnea/ palpita- } \\
\text { tions/incontinence }\end{array}$ \\
\hline \multirow[t]{6}{*}{ Events } & 32 & $\begin{array}{l}\text { The most important event since } \\
\text { the last beep was: }\end{array}$ & Open question \\
\hline & $33 a$ & The event was: & $-3=$ very displeasing, $0=$ neutral, $3=$ very pleasant \\
\hline & $33 \mathrm{~b}$ & The event was: & $-3=$ not important, $0=$ neutral, $3=$ very important \\
\hline & $33 c$ & The event was under my control & $1-7$ \\
\hline & $33 \mathrm{~d}$ & I expected this event & $1-7$ \\
\hline & 34 & This beep was unpleasant & $1-7$ \\
\hline
\end{tabular}




\section{S1Table B.}

Additional questions once in the evening and once in the morning.

\begin{tabular}{l|l}
\hline Item & \multicolumn{2}{l}{ Scale } \\
\hline EVENING & \multicolumn{2}{l}{} \\
\hline In general, I felt well today & $1-7(1=$ not, 4=moderate, $7=$ very $)$ \\
\hline In general, I felt tired today & $1-7$ \\
\hline In general, I felt tense today & $1-7$ \\
\hline In general, I puzzled over a lot today & $1-7$ \\
\hline Today, I experienced Parkinson symptoms & $1-7$ \\
\hline Today, I experienced headache & $1-7$ \\
\hline Today, I experienced stomachache & $1-7$ \\
\hline Today, I had difficulties breathing & $1-7$ \\
\hline Today, I had muscle pain & $1-7$ \\
\hline Today, I experienced obstipation & $1-7$ \\
\hline Today, I experienced tinnitus & $1-7$ \\
\hline Today, I experienced palpitations & $1-7$ \\
\hline I was dizzy today & $1-7$ \\
\hline I had dyspnea today & $1-7$ \\
\hline I experienced micturition problems & $1-7$ \\
\hline Filling in these questions influenced my mood & $1-7$ \\
\hline Without PsyMate, I would have done different things today & $1-7$ \\
\hline
\end{tabular}

\section{MORNING}

\begin{tabular}{l|l}
\hline How long did it take to fell asleep yesterday? & $\begin{array}{l}0-5 \mathrm{~min} / 5-15 \mathrm{~min} / 15-30 \mathrm{~min} / 30-45 \mathrm{~min} / 45 \mathrm{~min}-1 \mathrm{~h} / \\
1-2 \mathrm{~h} / 2-4 \mathrm{~h} />4 \mathrm{~h}\end{array}$ \\
\hline How many times did I wake up last night? & $0->5 \mathrm{times}$ \\
\hline How long was I awake this morning, before I got up? & $\begin{array}{l}0-5 \mathrm{~min} / 5-15 \mathrm{~min} / 15-30 \mathrm{~min} / 30-45 \mathrm{~min} / 45 \mathrm{~min}-1 \mathrm{~h} / \\
1-2 \mathrm{~h} / 2-4 \mathrm{~h} />4 \mathrm{~h}\end{array}$ \\
\hline I slept well & $1-7$ \\
\hline I feel fit & $1-7$ \\
\hline
\end{tabular}




\section{S1 Table C.}

Evaluation questions asked during telephone interview.

1. Was the goal of our study clear to you?

2. Was the information about the study clear and sufficient for you?

3. Were all the question clear? If not, which questions were not clear?

4. Did you change your daily behavior during the study period? If so, why?

5. Did you bother caring around the PsyMate device (or cell phone) all day long?

6. Did you miss any measurement points? If so, how many and why (for example: I did not hear the beep/ forgotten/embarrassment)?

7. Did you fill in the questions by yourself or with your partner?

8. Please give an overall score for the utility of the device and program (0-10)?

9. How long did it take to fill in one measurement point $(0-1 \mathrm{~min}, 1-2 \mathrm{~min}, 2-5 \mathrm{~min},>5 \mathrm{~min})$ ?

10. Do you have any suggestions or comments to improve the study design? 



\section{Chapter 7}

GENERAL DISCUSSION 
The main aim of this thesis was to investigate conceptual and clinical aspects of anxiety and depression in Parkinson's disease, alongside testing the feasibility of a new method to further unravel the complexity of these non-motor symptoms in the future. In the first part of this chapter methodological issues of our studies are assessed. In the second part, the implication of our findings on the concept and classification of anxiety and depression in $\mathrm{PD}$ are discussed and some recommendations for future research are given.

\section{METHODOLOGICAL CONSIDERATIONS}

\subsection{Study populations}

Two out of five studies presented in this thesis involved patients from a cross-sectional multicenter study on anxiety disorders in PD conducted in 2008 and 2009 (Chapter 3 and 4) (1). Patients were recruited from consecutive referrals to movement disorder clinics, neurology clinics and psychiatry clinics of six centers in the United States, Europe and Australia. One study (Chapter 5) involved data from the Study of Antidepressants in PD (SAD-PD) (2), a study on the efficacy of treatment with venlafaxine or paroxetine over placebo treatment in depressed PD patients. It involved 20 centers in the United States, Canada and Puerto Rico from 2005 through 2009. The pilot study testing the feasibility of the Experience Sampling Method (ESM) was part of a larger study in a psychiatric population and enrolled 5 consecutive PD patients from the multidisciplinary movement disorder clinic of Maastricht University Medical Center (Chapter 6). Of the patients studied in chapter 3 and 4, 61\% were male with a mean age of 64.8 years and disease duration of 8.3 years. Mean UPDRS motor score was 26.4 points. These characteristics are comparable to the patients included in chapter 5, in which $61 \%$ were male, the mean age was 63.2 years and the mean UPDRS motor score was 28.8. Disease duration was shorter, with a mean of 5.4 years. In our pilot study, four out of five participants were male; the mean age was 60.4 years and the mean disease duration 8 years. The UPDRS III motor score was 22 points. Overall, patients included in our studies had a mean Hoehn and Yahr rating of 2-2.5, indicating bilateral or midline involvement of the disease without impairment of balance or a recovery on the pull test. Comparing study characteristics to other large studies in the field $(3,4)$, we see that demographic and disease related characteristics are comparable. Therefore, we think that our results are generalizable to a population that clinicians encounter in outpatient clinics. Although most studies were multicenter studies, no Asian or African centers participated. As shown in Chapter 1, anxiety is more common in western developed countries (5), which could implicate that our findings are not generalizable to Asian or African countries. Second, since most patients were recruited from movement disorder clinics, a possible influence of recruitment bias cannot be ruled out. Tertiary centers may encounter more complex patients with a higher prevalence of anxiety or depression. 


\subsection{Diagnostics and rating scales}

In all studies, the diagnosis of idiopathic PD was made based on the clinical Queen Square Brain Bank criteria (6). Patients with neurodegenerative disorders other than PD and patients who had undergone DBS were excluded. In chapter 2 and 3 anxiety disorders were classified according to DSM-IV criteria, currently the most used classification system for anxiety disorders (7). However, due to high comorbidity rates its validity in the general population is questioned (8-10) and since we found that up to one third of PD patients diagnosed with anxiety also experienced multiple anxiety disorders, it appears that the construct validity of the current DSM classification is also questionable in PD patients (Chapter 2). On the contrary, diagnosing depressive disorders in PD with DSM-IV criteria seems appropriate in PD (11), although the National Institute of Neurological Disorders and Stroke (NINDS) (12) suggest some minor changes. These include 1) Assessment based on an "inclusive" approach, rather than the "etiologic" approach recommended by DSM, 2) Elimination of the DSM exclusion criterion "due to the effects of a general medical condition", 3) a modification of the anhedonia/loss of interest criterion to distinguish from primary apathy and 4) conduction of evaluations with awareness of whether the mood disturbance is related to motor fluctuations. Establishing true prevalence and severity of anxiety and depression in PD remains a diagnostic challenge because of the symptomatic overlap between the somatic features and the neuropsychiatric features of PD. Since, valid depression scales are important for adequate recognition and subsequent treatment, we assessed in chapter 4 the factor structure of the most commonly used measure of depressive symptoms in PD: The Hamilton Depression Rating Scale (HAMD). It appears that, although other clinometric properties of the scale are satisfactory, the factor structure is not. This makes it appropriate as a screening and evaluating tool, but not for studying specific symptom domains based on factorial structure in PD. Therefore, in chapter 5 we based our symptom domains on face validity instead of factor structure. The symptoms of the HAMD, Montgomery-Asberg Depression Rating Scale (MADRS) and the Beck Depression Inventory II (BDI-II) were combined and as such we believe that the symptom overlap of these scales strengthened the differentiation between affective, cognitive and somatic domains. With respect to the anxiety rating scales, it is well known that most anxiety scales are inappropriate to diagnose anxiety disorders in PD $(13,14)$. Some scales, such as the Beck Anxiety Inventory (BAI) focus mainly on symptoms of panic disorder while the Hamilton Anxiety Rating Scale (HARS) predominantly consists of items assessing generalized anxiety. In addition, the positive predictive values of most scales are suggested to be low in PD and consequently may contribute to a poor diagnostic accuracy (14). Preferably we would have used the recently developed and validated Parkinson Anxiety Scale for our model of anxiety in PD (Chapter 3), which better discriminates between episodic and persistent anxiety (15). However, the scale was not yet available 
during the study period. In our current model, the high correlation of the HAMD and the HARS may have introduced the problem of collinarity. However, the fact that only an acceptable model fit was reached after including the HAMD variable and a model of depression showed a good fit without including the HARS variable, suggests differential explanatory values. Last, including items from the PAS into the ESM application (Chapter 6) could be useful to further unravel the association between motor symptoms and affective states.

\subsection{Statistical approaches}

In chapter 2 we conducted a systematic review of anxiety disorders in PD following PRISMA guidelines (16). We calculated a weighted point prevalence of the different anxiety disorders and clinically relevant anxiety symptoms assessed by rating scales. For creating a model of anxiety (Chapter 3 ) we performed structural equation modeling (SEM). This method aims to identify the most parsimonious model that accounts for a substantial part of the variance in the total anxiety score. A limitation of this method is that parameters selected to be included in the analyses are based on availability. Therefore some variables, such as personality, marital status or coping style were not included in our analysis. Including a wider range of variables would lead to a more complete psychosomatic overview of all factors associated with anxiety in PD. In chapter 4 a principal component analysis was conducted on the HAMD. Subsequently, since the factor structure was unsatisfactory, we grouped items together into an affective, somatic or cognitive domain based on face validity to unravel trajectories of recovery in depressed PD patients (Chapter 5). In order to increase the stability of the domains and the likelihood of identifying different trajectories we included different depression scales. We examined domain differences using a repeated measures analysis of variance (rm-ANOVA). Preferably we would have used growth mixture modeling (GMM) to identify different treatment effects in different trajectory classes on an individual basis, but GMM requires much larger sample sizes than were available in the SAD-PD database. In chapter 6 we assessed the feasibility of the Experience Sampling Method (ESM) in 5 PD patients with motor fluctuations. In addition, correlations between motor symptoms, contextual factors and affective states were calculated. Since our primary aim was feasibility of the method and only two participants exhibited high scores on the anxiety and depression rating scales statistical analysis was limited. Further studies are needed to validate our preliminary findings on the ability of ESM to detect meaningful intra-individual relationships and the way these could be used on routine pharmacological treatment. 


\section{THE CONCEPT OF ANXIETY AND DEPRESSION IN PD}

\subsection{Risk factor, prodromal symptom or psychological reaction?}

A plausible explanation for the high prevalence of anxiety and depression in PD is that they are a psychological reaction to the impairments associated with disease progression. Invalidating and unpredictable motor symptoms lead to a perceived lack of control or embarrassment and in people with insufficient coping mechanism this eventually leads to anxiety or depression. On the contrary, several mainly register based studies showed that PD patients are at greater risk of developing anxiety and depressive disorders already before the diagnosis of $\mathrm{PD}$ is made (17-23). These studies suggest that anxiety and depression are a "pre-motor" manifestation of PD, related to neurobiological changes. Others have postulated a premorbid anxious personality as a risk factor for PD, which together with a high prevalence of anxiety disorders and depression among family members of PD patients suggests a genetic predisposition $(24,25)$. However, no consensus about the attribution of genetic polymorphisms to anxiety and PD currently exists. Furthermore, anxiety and depression are more common in PD when compared to other illnesses suggesting a cause that is unique to PD $(26,27)$. Symptom overlap between depression, anxiety and Parkinson's disease could point to a similar neurobiological basis. Everything taken together there appears to be a "late onset" anxiety or depression, which is related to a psychological reaction on the burden of the disease. This "late onset" type is most likely situational, related to off periods and specific ADL activities, which we also found in our anxiety model (Chapter 3). Although not thorough studied yet, insufficient coping mechanisms and psychological factors such as fear of falls, future dependency and burdening of others may further elevate the (pre-existing) risk for anxiety. This pre-existing risk or vulnerability for anxiety or depression is most likely due to "early onset" neurobiological changes in dopaminergic as well as serotonergic and noradrenergic neurotransmitter systems $(28,29)$. The question whether these neurobiological changes are a general risk factor for developing PD or if they are a prodromal symptom, e.g. part of PD symptomatology such as anosmia, remains a conundrum. In chapter 3 we proposed a model of anxiety in PD in which we showed than non-PD specific factors, such as a previous history of depression, are stronger markers for anxiety in PD than PD-specific risk factors such as motor fluctuations. The same was found in a model of depression in PD (30). Confirmation of these findings in longitudinal studies would support the hypothesis that patients with a specific constellation of general risk factors for anxiety or depression could also predispose them to PD, which more point to a risk factor than a prodromal stage of the disease.

\subsection{Current classification of depression and anxiety in PD}

The majority of studies investigating depression and anxiety disorders in PD use the DSM classification (7). Depressive disorders include major depressive disorder, dyst- 
hymic disorders and bipolar disorders. An extensive review found a prevalence of $17 \%$ major depressive disorders and $13 \%$ minor depression in PD (31). Given the relevance of depression in $\mathrm{PD}$, valid diagnostic criteria are necessary. A study that assessed the validity of diagnostic DSM criteria for depression in PD concluded that DSM criteria are valid in PD for diagnosing major depression in clinical practice and research $(11,12)$.

Anxiety is categorized into generalized anxiety disorder (GAD), panic disorder, agoraphobia, obsessive-compulsive disorder (OCD), posttraumatic stress disorder (PTSS), social or specific phobia and anxiety not otherwise specified (NOS). Some have questioned the validity of these criteria in anxious PD patients (1). First, our review on the prevalence of anxiety disorders in PD showed that approximately one third of patients diagnosed with anxiety experienced multiple anxiety disorders. It is plausible that this is an artifact of the current classification system instead of a representation of true comorbidity of multiple distinguishable disorders (1). Second, a significant proportion (Chapter 1,13.3\%) of patients have anxiety disturbances that do not meet the criteria for any specific anxiety disorder and are classified as anxiety NOS. Third, there is a high co-occurrence of depression and anxiety in $\operatorname{PD}(26,27,32,33)$, which is not accounted for in the current classification system. As well as the high prevalence of anxiety NOS and the multiple anxiety disorders could explain the high variation of prevalence rates we found in our review. For example, some researchers used hierarchical DSM criteria and ruled out GAD if another current anxiety disorder was diagnosed, leading to a lower prevalence of specific anxiety disorders.

\subsection{Towards a new classification of anxiety in PD}

Taken the abovementioned considerations together, there is reason to question the construct validity of the current DSM classification for anxiety syndromes in PD patients. To this end, a new classification is proposed using a data driven approach and latent class analysis. Starkstein et al. identified two subgroups of anxiety in a sample of 342 PD patients (34). The first group was termed "episodic anxiety" which included symptoms of panic disorder, agoraphobia and social phobia. The second group, "persistent anxiety" included the essential symptoms of GAD. Intriguing, persistent anxiety was always associated with high probabilities for essential symptoms of major depression, whereas episodic anxiety was not. Other studies dividing episodic from persistent anxiety also found a strong association between depression and persistent anxiety (e.g. GAD) in PD $(1,33)$ and in the general population $(8)$. Starkstein proposed a classification into three classes: "episodic anxiety without depression", "persistent anxiety with depression", and "both persistent and episodic anxiety with depression". This is in concordance with our model of anxiety in which depression is the most important marker and also with a latent class analysis in 513 PD patients done by Brown et al. He found an "anxiety alone", "anxiety with depression" and "depression without significant anxiety"- group 
(35). Since he used rating scales to assess anxiety and depression instead of DSM criteria, no subdivision in episodic or persistent anxiety could be made. However, both studies suggest a different nosology in PD from the anxiety syndromes described in the DSM, with also a role of comorbid depression.

\subsection{Motor and non-motor subtypes in Parkinson's disease}

Up until the nineties of the last century, Parkinson's disease was considered a single entity, but during the past 2-3 decades the clinical heterogeneity has been recognized and several sub-classifications based on clinical features have been proposed (36-38). Some divided patients in benign or malignant, but one of the earliest and most used classifications categorized PD in two subtypes: a tremor dominant type (TD) and one with postural instability and gait difficulty (PIGD), also called the akinetic/rigid type (AR) (39). In the past years several others identified PD phenotypes using a data driven approach with latent class analysis. This technique assesses the symptom profile of individual patients and produces classes of patients as suggested by their respective pattern of symptoms. Individual patients can only belong to one class (34). In general, four subtypes were identified: 1) old age at onset and rapid disease progression, 2) tremor-dominant phenotype, 3) young onset PD with slow progression and 4) postural instability and gait difficulties (40). As one can see, some subtypes are related with rapid disease progression, whereas others are associated with relatively slow disease progression and lower mortality rates $(41,42)$, which raises the possibility that these subtypes also differ in pathogenesis. Indeed, e.g. dopamine levels stay near normal in the ventral internal globus pallidum in tremor dominant patients compared to the non-tremor dominant subtype and Alzheimer pathology seem to be more prevalent in the subgroup with rapid disease progression $(43,44)$. The non-tremor dominant group has significant higher grading of cortical Lewy bodies and Braak stages than other subgroups $(44,45)$. In addition, different brain activity patterns between akinetic/rigid and tremor dominant subtypes are found, with more involvement of the cerebellum in the tremor dominant group and more mesolimbic and amygdala involvement in the akinetic/rigid subgroup (46-48). As one can see, most research on dividing PD into subtypes has focused on motor symptoms: patient groups with or without tremor, akinetic or rigid patients, patients with postural instability or gait difficulties. However, evidence is emerging that non-motor features are also important for defining subtypes (49-52).

\subsection{Anxiety and depression in the Parkinson spectrum: a subtype?}

Although, firm evidence is not yet available it is possible that there is a subtype of Parkinson's disease characterized by a high prevalence of both anxiety and depression (Chapter 2). Both are, among other non-motor symptoms, associated with the AR/ PIGD motor subtype of PD $(4,53,54)$ leading to a constellation of motor symptoms including axial rigidity, postural instability and gait difficulties together with anxiety 
and depression as the predominant non-motor features: an "Anxiety and depression" subtype. This is supported by our earlier mentioned new classification and the fact that persistent anxiety is strongly associated with depression, leading to the possibility of a single psychiatric syndrome instead of two different entities (34). In addition, in our model of anxiety (Chapter 3) depression was far most the strongest marker for anxiety. Since anxiety and depression are found consistently more frequent in non-tremor dominant subtypes in comparison with the tremor dominant type, it is suggested that the non motor features with axial rigidity reflects deficits in multiple non-dopaminergic transmitter systems, including the cholinergic, noradrenergic and serotonergic systems. This in contrast to a subtype with pronounced motor complications, which might reflect predominant involvement of the dopaminergic system (51). The fact that PIGD/ AR symptoms and non-motor symptoms generally respond poorly to dopaminergic therapy supports this view (49).

Pathological studies also provide evidence for a ramification of non-motor features in different subtypes (55-58). For example, Braak et al. suggested a six-stage system to indicate a predictable sequence of lesions with ascending progression from medullary and olfactory nuclei to the cortex, in which the first two presymptomatic stages being related to incidental Lewy body disease, stage 3 and 4 with motor symptoms and the last two cortical stages with cognitive impairment (56). However, growing evidence exists that up to $40 \%$ does not follow the proposed caudal-rostral patterns of $\alpha$-synuclein pathology (59). In addition, classic Braak stages do not correlate with severity of parkinsonism or Hoehn and Yahr stages (44). Most studies indicate that the neurodegenerative process begins in the brainstem nuclei or the olfactory bulb (60). Progression of neurodegenerative disease is than mediated via seeding of misfolded proteins, including $\alpha$-synuclein and tau, which lead to neurodegeneration (61). Differences in seeding pathways and involved proteins could be an explanation of the differences in phenotypes. Recently it is shown that different $\alpha$-synuclein strains seem to cause distinct phenotypes, which may explain some of the heterogeneity of the disease (62). It is suggested that a variable neuropathological spread is initiated through the olfactory bulb and then spread to 1) the limbic system, leading to depression, anxiety, fatigue or pain, or 2) spreading to the brainstem which lead to predominantly sleep and autonomic problems or 3) predominantly spread to the cortex leading to a more cognitive subtype with apathy, dementia and frequent falls $(49,50,55,58)$. It is likely that with advancing disease, more overlap between different subtypes occur. Some postulated that patients can switch during the course of the disease from a tremor dominant type to a non-tremor dominant type (63), but others have shown different courses of the distinct subtypes (42).

In line with this concept, depression and persistent anxiety could reflect a predominant involvement of multiple transmitter systems in the brainstem and the limbic system 
(Figure 1). However, not all depressed or anxious patients have the AR/PIGD motor subtype, what makes it unlikely that every anxious or depressed PD patients fits the proposed anxiety and depression subgroup. Also, patients with depression without anxiety, or anxiety without depression have probably a different underlying etiology. Although speculative, it is possible that isolated anxiety is especially episodic and linked to predominantly dopaminergic deficits, e.g. motor fluctuations like we found in our model (1, 33 ), and appears in already predisposed patients (Figure 2). This could be a genetic vulnerability or patients with already other risk factors lowering the threshold for acquiring an anxiety disorder. This is supported by the fact that non-disease specific risk factors seem to be more important than PD specific risk factors in both anxiety and depression (Chapter 2). The same could be the case for isolated depression, with general risk factors already lowering the threshold. However, this concept needs further validation and it is clear that subtypes may overlap (50).

\section{Figure 1.}

Different subtypes in Parkinson's disease, incorporating motor and non-motor symptoms. The "persistent anxiety and depression subtype" involves multiple neurotransmitter systems. Figure partly adapted from Sauerbier et al. (50).

Tremor dominant subtype
Akinetic / rigidity subtype

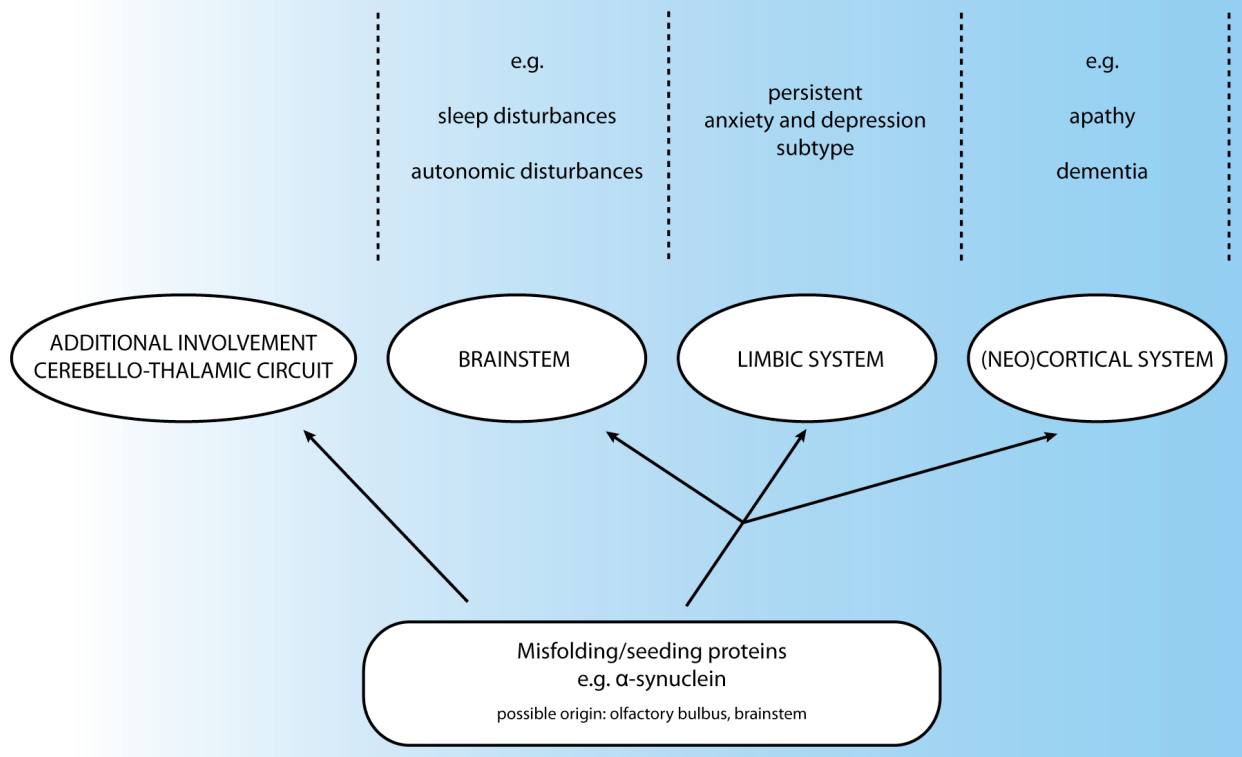


Figure 2.

Isolated depression or episodic anxiety in predisposed individuals. They predominantly have a late onset and are mainly related to dopaminergic deficits.

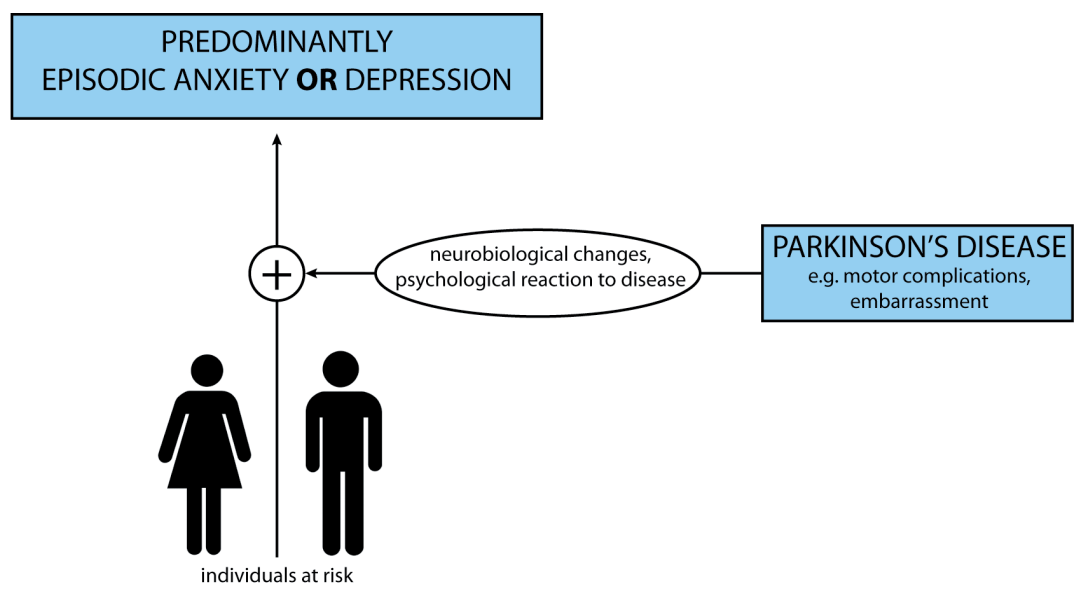

GENETIC PREDISPOSITION AND GENERAL RISK FACTORS

e.g. female sex, stressful life events, insufficient coping mechanisms

\subsection{Implications of the new concept}

The concept of a distinct etiology of persistent anxiety with depression versus isolated depression or anxiety mainly related to psychological factors and motor complications, could explain some of the controversies found in past research on motor and non-motor features in PD. For example, several risk factors for anxiety have been proposed but denied by others. Female gender is associated with anxiety in several studies $(1,4)$, but not in others $(33,64)$ and disease severity is associated with anxiety in some $(64,65)$, but not all studies $(4,27)$. As outlined above, it might be possible that the anxiety and depression subtype reflects a more widespread disease, which is likely associated with disease severity. On the other hand, isolated depression or anxiety could be the result of a psychological reaction in predisposed patients, which is only partly dependent of disease severity. For example, according to the new concept, it is more likely to find a significant influence of disease severity in studies with mainly patients with persistent anxiety and depression, in contrast to studies with mainly patients with isolated depression or anxiety.

As we showed in chapter 5 , a sufficient study period is important to rule out placebo responses in treatment trials. However, the proposed concept could also explain some of the disappointing results in treatment trials for depression in PD (66). Treatment 
both targeting the dopaminergic system (pramipexole (67)) and the serotonergic and/ or noradrenergic system (venlafaxine and paroxetine (2)) seem to have an effect in some patients but not in others. Sample size was not large enough to identify subject characteristics, but it would be interesting to see if dopaminergic treatment was especially effective in depressed patients with predominantly motor complications and late onset anxiety instead of patients with more non-motor symptoms or AR/PIGD motor symptoms. The fact that patients with high anxiety scores seem to respond less to paroxetine and venlafaxine treatment (68) support the concept of involvement of multiple neurotransmitters, requiring more intensive treatment. Further evidence of different optimal treatment choices in specific PD subtypes is provided by Katz et al., who also found some differential effects of deep brain stimulation target on motor subtypes in Parkinson's disease (69).

\subsection{Clinical implications and future prospective}

We think that it is clinically relevant to include non-motor symptoms alongside motor symptoms when subtyping PD. Further understanding of neuropathological heterogeneity in the PD spectrum will aid in unraveling this complex disease. It is likely that different biological underpinnings will need different treatment strategies. Therefore, it is warranted that future trials divide patients in subgroups based on motor and non-motor features to identify different trajectories. However, since non-motor subtypes can change throughout the course of the disease and subtypes may overlap, large multicenter studies will be necessary with a longitudinal design. Another problem is that latent class analysis, currently the most used technique to define subtypes, is dependent on the number of included variables. Some studies only used 8 non-motor symptoms, whereas others used up to 33 variables $(34,35)$. In addition, some used symptoms from rating scales, where others used DSM criteria. To this end, it is important to examine an extensive array of non-motor features with their context and relation with motor symptoms to create a comprehensive overview of patients' symptoms. The method we examined in Chapter 6, the Experience Sampling Method (ESM) could be a valuable tool. ESM creates fine grain analyses of both motor and non-motor features and gives information on how these variables impact each other in the flow of daily life on an individual basis. In our study, ESM provided with a good feasibility a widespread overview of patients' motor symptoms, contextual factors and affective states. Only with a comprehensive overview of both non-motor symptoms and motor symptoms detailed subtyping is possible, and given its possibilities, ESM could become an important method creating this overview in future studies.

\subsection{CONCLUSIONS}

Anxiety and depression are both frequent in PD. Episodic anxiety with a "late onset" is most likely predominantly related to psychological factors in combination with motor 
fluctuations whereas an "early onset" may reflect a neurobiological involvement leading to a more persistent state of anxiety. The current classification system of anxiety in PD, mainly based on DSM criteria does not seem to reflect true clinical phenotypes. A division in:

- "Episodic anxiety without depression"

- "Persistent anxiety with depression"

- "Both persistent and episodic anxiety with depression"

fits in the proposed new concept of an "anxiety and depression" subtype in the PD spectrum. Although further studies are warranted, evidence exists that the clinical heterogeneity of PD is based on different neuropathological processes. Therefore, subtype-directed treatment strategies are needed in a clinically heterogeneous condition as PD. Focused treatment on specific non-motor- and motor subtypes based on individual symptoms, will ultimately aid in optimizing quality of life for PD patients and further increase our understanding of the complex PD spectrum. 


\section{REFERENCES}

1. Leentjens AF, Dujardin K, Marsh L, Martinez-Martin P, Richard IH, Starkstein SE. Symptomatology and markers of anxiety disorders in Parkinson's disease: a cross-sectional study. Mov Disord. 2011;26(3):48492.

2. Richard IH, McDermott MP, Kurlan R, Lyness JM, Como PG, Pearson N, et al. A randomized, double-blind, placebo-controlled trial of antidepressants in Parkinson disease. Neurology. 2012;78(16):1229-36.

3. Barone P, Antonini A, Colosimo C, Marconi R, Morgante L, Avarello TP, et al. The PRIAMO study: A multicenter assessment of nonmotor symptoms and their impact on quality of life in Parkinson's disease. Mov Disord. 2009;24(11):1641-9.

4. Negre-Pages L, Grandjean H, Lapeyre-Mestre M, Montastruc JL, Fourrier A, Lepine JP, et al. Anxious and depressive symptoms in Parkinson's disease: the French cross-sectionnal DoPaMiP study. Mov Disord. 2010;25(2):157-66.

5. Kessler RC, Aguilar-Gaxiola S, Alonso J, Chatterji S, Lee S, Ormel J, et al. The global burden of mental disorders: an update from the WHO World Mental Health (WMH) surveys. Epidemiol Psichiatr Soc. 2009;18(1):23-33.

6. de Rijk MC, Rocca WA, Anderson DW, Melcon MO, Breteler MM, Maraganore DM. A population perspective on diagnostic criteria for Parkinson's disease. Neurology. 1997;48(5):1277-81.

7. Diagnostic and Statistical Manusal of Mental Disorders. Association AP, editor. Washington, DC: American Psychiatric Association; 1994.
8. Brawman-Mintzer O, Lydiard RB, Emmanuel N, Payeur R, Johnson M, Roberts J, et al. Psychiatric comorbidity in patients with generalized anxiety disorder. Am J Psychiatry. 1993;150(8):1216-8.

9. Kessler RC, McGonagle KA, Zhao S, Nelson CB, Hughes M, Eshleman S, et al. Lifetime and 12-month prevalence of DSM-III-R psychiatric disorders in the United States. Results from the National Comorbidity Survey. Arch Gen Psychiatry. 1994;51(1):8-19.

10. Wittchen HU, Zhao S, Kessler RC, Eaton WW. DSM-III-R generalized anxiety disorder in the National Comorbidity Survey. Arch Gen Psychiatry. 1994;51(5):35564.

11. Starkstein S, Dragovic M, Jorge R, Brockman S, Merello M, Robinson RG, et al. Diagnostic criteria for depression in Parkinson's disease: a study of symptom patterns using latent class analysis. Mov Disord. 2011;26(12):2239-45.

12. Marsh L, McDonald WM, Cummings J, Ravina B, Depression NNWGo, Parkinson's D. Provisional diagnostic criteria for depression in Parkinson's disease: report of an NINDS/NIMH Work Group. Mov Disord. 2006;21(2):148-58.

13. Dissanayaka NN, Torbey E, Pachana NA. Anxiety rating scales in Parkinson's disease: a critical review updating recent literature. Int Psychogeriatr. 2015;27(11):1777-84.

14. Leentjens AF, Dujardin K, Marsh L, Martinez-Martin P, Richard IH, Starkstein SE, et al. Anxiety rating scales in Parkinson's disease: critique and recommendations. Mov Disord. 2008;23(14):2015-25. 
15. Leentjens AF, Dujardin K, Pontone GM, Starkstein SE, Weintraub D, Martinez-Martin P. The Parkinson Anxiety Scale (PAS): development and validation of a new anxiety scale. Mov Disord. 2014;29(8):1035-43.

16. Moher D, Liberati A, Tetzlaff J, Altman DG, Group P. Preferred reporting items for systematic reviews and meta-analyses: the PRISMA statement. BMJ. 2009;339:b2535.

17. Ishihara L, Brayne C. A systematic review of depression and mental illness preceding Parkinson's disease. Acta Neurol Scand. 2006;113(4):211-20.

18. Leentjens AF, Van den Akker M, Metsemakers JF, Lousberg R, Verhey FR. Higher incidence of depression preceding the onset of Parkinson's disease: a register study. Mov Disord. 2003;18(4):414-8.

19. Schuurman AG, van den Akker M, Ensinck KT, Metsemakers JF, Knottnerus JA, Leentjens AF, et al. Increased risk of Parkinson's disease after depression: a retrospective cohort study. Neurology. 2002;58(10):15014.

20. Gustafsson H, Nordstrom A, Nordstrom P. Depression and subsequent risk of Parkinson disease: A nationwide cohort study. Neurology. 2015;84(24):2422-9.

21. Shen CC, Tsai SJ, Perng CL, Kuo BI, Yang AC. Risk of Parkinson disease after depression: a nationwide population-based study. Neurology. 2013;81(17):1538-44.

22. Shiba M, Bower JH, Maraganore DM, McDonnell SK, Peterson BJ, Ahlskog JE, et al. Anxiety disorders and depressive disorders preceding Parkinson's disease: a case-control study. Mov Disord. 2000;15(4):669-77.

23. Weisskopf MG, Chen H, Schwarzschild
MA, Kawachi I, Ascherio A. Prospective study of phobic anxiety and risk of Parkinson's disease. Mov Disord. 2003;18(6):64651.

24. Arabia G, Grossardt BR, Geda YE, Carlin JM, Bower JH, Ahlskog JE, et al. Increased risk of depressive and anxiety disorders in relatives of patients with Parkinson disease. Arch Gen Psychiatry. 2007;64(12):138592.

25. Bower JH, Grossardt BR, Maraganore DM, Ahlskog JE, Colligan RC, Geda YE, et al. Anxious personality predicts an increased risk of Parkinson's disease. Mov Disord. 2010;25(13):2105-13.

26. Henderson R, Kurlan R, Kersun JM, Como P. Preliminary examination of the comorbidity of anxiety and depression in Parkinson's disease. J Neuropsychiatry Clin Neurosci. 1992;4(3):257-64.

27. Menza MA, Robertson-Hoffman DE, Bonapace AS. Parkinson's disease and anxiety: comorbidity with depression. Biol Psychiatry. 1993;34(7):465-70.

28. Espay AJ, LeWitt PA, Kaufmann H. Norepinephrine deficiency in Parkinson's disease: the case for noradrenergic enhancement. Mov Disord. 2014;29(14):1710-9.

29. Kano O, Ikeda K, Cridebring D, Takazawa T, Yoshii Y, Iwasaki Y. Neurobiology of depression and anxiety in Parkinson's disease. Parkinsons Dis. 2011;2011:143547.

30. Leentjens AF, Moonen AJ, Dujardin K, Marsh L, Martinez-Martin P, Richard IH, et al. Modeling depression in Parkinson disease: disease-specific and nonspecific risk factors. Neurology. 2013;81(12):1036-43.

31. Reijnders JS, Ehrt U, Weber WE, Aarsland $\mathrm{D}$, Leentjens AF. A systematic review of prevalence studies of depression in Parkinson's disease. Mov Disord. 2008;23(2):183-9; 
quiz 313.

32. Nuti A, Ceravolo R, Piccinni A, Dell'Agnello G, Bellini G, Gambaccini G, et al. Psychiatric comorbidity in a population of Parkinson's disease patients. Eur J Neurol. 2004;11(5):315-20.

33. Pontone GM, Williams JR, Anderson KE, Chase G, Goldstein SA, Grill S, et al. Prevalence of anxiety disorders and anxiety subtypes in patients with Parkinson's disease. Mov Disord. 2009;24(9):1333-8.

34. Starkstein SE, Dragovic M, Dujardin K, Marsh L, Martinez-Martin P, Pontone GM, et al. Anxiety has specific syndromal profiles in Parkinson disease: a data-driven approach. Am J Geriatr Psychiatry. 2014;22(12):1410-7.

35. Brown RG, Landau S, Hindle JV, Playfer J, Samuel M, Wilson KC, et al. Depression and anxiety related subtypes in Parkinson's disease. J Neurol Neurosurg Psychiatry. 2011;82(7):803-9.

36. Lewis SJ, Foltynie T, Blackwell AD, Robbins TW, Owen AM, Barker RA. Heterogeneity of Parkinson's disease in the early clinical stages using a data driven approach. J Neurol Neurosurg Psychiatry. 2005;76(3):343-8.

37. Lees AJ, Katzenschlager R, Head J, Ben-Shlomo Y. Ten-year follow-up of three different initial treatments in de-novo PD: a randomized trial. Neurology. 2001;57(9):1687-94.

38. Paulus W, Jellinger K. The neuropathologic basis of different clinical subgroups of Parkinson's disease. J Neuropathol Exp Neurol. 1991;50(6):743-55.

39. Jankovic J, McDermott M, Carter J, Gauthier S, Goetz C, Golbe L, et al. Variable expression of Parkinson's disease: a base-line analysis of the DATATOP cohort.
The Parkinson Study Group. Neurology. 1990;40(10):1529-34.

40. van Rooden SM, Heiser WJ, Kok JN, Verbaan D, van Hilten JJ, Marinus J. The identification of Parkinson's disease subtypes using cluster analysis: a systematic review. Mov Disord. 2010;25(8):969-78.

41. de Lau LM, Verbaan D, van Rooden SM, Marinus J, van Hilten JJ. Relation of clinical subtypes in Parkinson's disease with survival. Mov Disord. 2014;29(1):150-1.

42. Rajput AH, Voll A, Rajput ML, Robinson CA, Rajput A. Course in Parkinson disease subtypes: A 39-year clinicopathologic study. Neurology. 2009;73(3):206-12.

43. Rajput AH, Sitte HH, Rajput A, Fenton ME, Pifl C, Hornykiewicz O. Globus pallidus dopamine and Parkinson motor subtypes: clinical and brain biochemical correlation. Neurology. 2008;70(16 Pt 2):1403-10.

44. van de Berg WD, Hepp DH, Dijkstra AA, Rozemuller JA, Berendse HW, Foncke E. Patterns of alpha-synuclein pathology in incidental cases and clinical subtypes of Parkinson's disease. Parkinsonism Relat Disord. 2012;18 Suppl 1:S28-30.

45. Selikhova M, Williams DR, Kempster PA, Holton JL, Revesz T, Lees AJ. A clinico-pathological study of subtypes in Parkinson's disease. Brain. 2009;132(Pt 11):2947-57.

46. Bergman H, Deuschl G. Pathophysiology of Parkinson's disease: from clinical neurology to basic neuroscience and back. Mov Disord. 2002;17 Suppl 3:S28-40.

47. Duval C, Daneault JF, Hutchison WD, Sadikot AF. A brain network model explaining tremor in Parkinson's disease. Neurobiol Dis. 2016;85:49-59.

48. Zhang J, Wei L, Hu X, Xie B, Zhang Y, Wu GR, et al. Akinetic-rigid and tre- 
mor-dominant Parkinson's disease patients show different patterns of intrinsic brain activity. Parkinsonism Relat Disord. 2015;21(1):23-30.

49. Marras C, Chaudhuri KR. Nonmotor features of Parkinson's disease subtypes. Mov Disord. 2016.

50. Sauerbier A, Jenner P, Todorova A, Chaudhuri KR. Non motor subtypes and Parkinson's disease. Parkinsonism Relat Disord. 2016;22 Suppl 1:S41-6.

51. van Rooden SM, Colas F, Martinez-Martin P, Visser M, Verbaan D, Marinus J, et al. Clinical subtypes of Parkinson's disease. Mov Disord. 2011;26(1):51-8.

52. Reijnders JS, Ehrt U, Lousberg R, Aarsland $\mathrm{D}$, Leentjens AF. The association between motor subtypes and psychopathology in Parkinson's disease. Parkinsonism Relat Disord. 2009;15(5):379-82.

53. Burn DJ, Landau S, Hindle JV, Samuel M, Wilson KC, Hurt CS, et al. Parkinson's disease motor subtypes and mood. Mov Disord. 2012;27(3):379-86.

54. Starkstein SE, Petracca G, Chemerinski E, Teson A, Sabe L, Merello M, et al. Depression in classic versus akinetic-rigid Parkinson's disease. Mov Disord. 1998;13(1):29-33.

55. Beach TG, Adler CH, Lue L, Sue LI, Bachalakuri J, Henry-Watson J, et al. Unified staging system for Lewy body disorders: correlation with nigrostriatal degeneration, cognitive impairment and motor dysfunction. Acta Neuropathol. 2009;117(6):61334.

56. Braak H, Del Tredici K, Rub U, de Vos RA, Jansen Steur EN, Braak E. Staging of brain pathology related to sporadic Parkinson's disease. Neurobiol Aging. 2003;24(2):197211.
57. Halliday G, Lees A, Stern M. Milestones in Parkinson's disease--clinical and pathologic features. Mov Disord. 2011;26(6):101521.

58. Jellinger KA. Neuropathology of sporadic Parkinson's disease: evaluation and changes of concepts. Mov Disord. 2012;27(1):830.

59. Kalaitzakis ME, Graeber MB, Gentleman SM, Pearce RK. The dorsal motor nucleus of the vagus is not an obligatory trigger site of Parkinson's disease: a critical analysis of alpha-synuclein staging. Neuropathol Appl Neurobiol. 2008;34(3):284-95.

60. Del Tredici K, Rub U, De Vos RA, Bohl JR, Braak H. Where does parkinson disease pathology begin in the brain? J Neuropathol Exp Neurol. 2002;61(5):413-26.

61. Walker LC, Diamond MI, Duff KE, Hyman BT. Mechanisms of protein seeding in neurodegenerative diseases. JAMA Neurol. 2013;70(3):304-10.

62. Peelaerts W, Bousset L, Van der Perren A, Moskalyuk A, Pulizzi R, Giugliano M, et al. alpha-Synuclein strains cause distinct synucleinopathies after local and systemic administration. Nature. 2015;522(7556):340-4.

63. Von Coelln FR, Barr E, Gruber-Baldini A, Reich S, Armstrong MJ, Shulman L. Motor Subtypes of Parkinson Disease Are Unstable Over Time. Neurology. 2015;84(14):Supplement S48.002.

64. Kulisevsky J, Pagonabarraga J, Pascual-Sedano B, Garcia-Sanchez C, Gironell A, Trapecio Group S. Prevalence and correlates of neuropsychiatric symptoms in Parkinson's disease without dementia. Mov Disord. 2008;23(13):1889-96.

65. Khedr EM, El Fetoh NA, Khalifa H, Ahmed MA, El Beh KM. Prevalence of non 
motor features in a cohort of Parkinson's disease patients. Clin Neurol Neurosurg. 2013;115(6):673-7.

66. Troeung L, Egan SJ, Gasson N. A meta-analysis of randomised placebo-controlled treatment trials for depression and anxiety in Parkinson's disease. PLoS One. 2013;8(11):e79510.

67. Barone P, Poewe W, Albrecht S, Debieuvre C, Massey D, Rascol O, et al. Pramipexole for the treatment of depressive symptoms in patients with Parkinson's disease: a randomised, double-blind, placebo-controlled trial. Lancet Neurol. 2010;9(6):573-80.

68. Moonen AJ, Wijers A, Leentjens AF, Christine CW, Factor SA, Juncos J, et al. Severity of depression and anxiety are predictors of response to antidepressant treatment in Parkinson's disease. Parkinsonism Relat Disord. 2014;20(6):644-6.

69. Katz M, Luciano MS, Carlson K, Luo P, Marks WJ, Jr., Larson PS, et al. Differential effects of deep brain stimulation target on motor subtypes in Parkinson's disease. Ann Neurol. 2015;77(4):710-9. 

Summary 
Parkinson's disease (PD) is the second most common neurodegenerative disease, after Alzheimer's disease. The four cardinal motor features upon which the diagnosis of PD is based, include bradykinesia, muscle rigidity, resting tremor and postural instability. However, PD also encompasses a wide range of non-motor symptoms including neuropsychiatric disturbances such as depression and anxiety. These neuropsychiatric disturbances are the most frequent non-motor symptoms and occur in up to $67 \%$ of PD patients. They have a detrimental influence on patient's quality of life, contributing to motor symptom severity, motor complications, gait difficulties, cognitive impairment, poor self-perceived health status and even increased mortality. This thesis aimed to investigate conceptual and clinical aspects of anxiety and depression in $\mathrm{PD}$, as well as to test the feasibility of a novel method to further unravel the complexity of these non-motor symptoms in the future.

Chapter $\mathbf{1}$ is a general introduction into the theme and aims of this thesis. It provides a general background of PD with an emphasis on the non-motor symptoms anxiety and depression.

Chapter 2 is a systematic review on the prevalence of anxiety disorders in PD, defined by DSM criteria and clinically relevant anxiety symptoms assessed by an anxiety rating scale. The average point prevalence of anxiety disorders in PD was 31\%. Generalized anxiety disorder was the most frequent disorder, present in $14 \%$ of patients, followed by social phobia (13.8\%), anxiety not otherwise specified (NOS) $13.3 \%$ ) and specific phobia (13.0\%). Thirty-one percent of patients fulfilled criteria for current multiple anxiety disorders and, based on anxiety rating scale cutoff scores, clinically significant anxiety symptoms were present in a weighted average of $25.7 \%$. The review confirms that anxiety, although often unrecognized, is very common and occurs at a higher average prevalence than depressive disorders in PD (17\%). This underlines the importance for proper identification.

In Chapter 3 we used structural equation modeling (SEM), a methodology for representing, estimating, and testing a network of relationships between variables. Doing so, we explored the relative contribution of $\mathrm{PD}$-specific factors (such as more severe motor symptoms or motor complications) and nonspecific markers (such as history of anxiety or female sex) in a model for anxiety in PD. We found that the PD-specific markers were the presence of motor fluctuations and disease-related decline in activities of daily living. Nonspecific markers were a previous history of depression and the severity of the depressive symptoms scored on the Hamilton Depression Rating Scale. Nonspecific markers had a greater influence in the model than PD-specific markers of anxiety. Moreover, a post hoc analysis showed that the effects of the following variables on anxiety were fully mediated via depression: sex, family history of depression, previous history of 
anxiety, cognitive status, difficulties in non-disease-specific activities of daily living and severity of motor signs. Depression was the most prominent marker for anxiety, where PD-specific markers appeared to be more situational, e.g. related to 'off periods and disease-specific disturbances of activities of daily living.

In Chapter 4 we investigated the factor structure of the Hamilton Depression Rating Scale (HAMD) to explore its multidimensionality in patients with Parkinson's disease. We conducted a principal component analysis of the 17-item HAMD on data of 341 PD patients. The factorial validity of the HAMD was unsatisfactory due to varying items per factor, low inter-item correlations within each components and a high percentage of non-redundant residuals and low communality. This analysis shows that based on factorial structure the HAMD is not appropriate for defining specific symptom domains of depression for further study.

Since there has been limited research into the domain specific magnitude or relative timing of treatment response in patients with PD, we studied the differential responses to antidepressant treatment with venlafaxine or paroxetine in affective, somatic and cognitive domains of depression in Chapter 5. We found that all symptom domains improved during the 12-week study period, although there was a significant placebo effect in the first two weeks. Compared to placebo, the affective symptoms significantly improved during treatment as early as week 4 , followed by the somatic symptoms of depression in week 6 and cognitive symptoms in week 8. These findings could guide patient counseling and increase patient compliance by informing about the expected treatment responses. In addition, it underlines the importance of a sufficient long study period in future studies since there was a substantial placebo effect.

In Chapter 6 we investigated the feasibility of a novel method to unravel the complex relationship between motor symptoms, affective states and contextual factors in PD. For example, motor symptoms may be more severe when patients are in a public place and not at home (contextual factor), with subsequently more anxiety feelings (affective state). The method, known as the Experience Sampling Method (ESM), uses a mobile device with a special purpose application to assess motor symptoms, affective states and contextual factors repeatedly at random moments in the flow of daily life. Participants achieved a high compliance (84\%) and they rated the utility of the device an 8 on a 10 -point scale. We were able to capture extensive diurnal fluctuations that were not revealed by routine clinical assessments. In addition, we detected clinically relevant associations between motor symptoms, emotional fluctuations and contextual factors at an intra-individual level. In conclusion, we found that ESM represents a viable and novel approach to elucidate relationships between motor symptoms, affective states and contextual factors at the level of individual subjects. 
Chapter 7 summarizes and discusses the main findings of this thesis. The first part assesses methodological issues of the conducted studies and in the second part the implication of our findings and recommendations for future research are given on the concept and classification of anxiety and depression in PD. The current classification system of anxiety in PD mainly based on DSM criteria does not seem to reflect true clinical phenotypes. A new concept of an "anxiety and depression" subtype is proposed. Focused research and treatment on specific non-motor or motor subtypes based on individual symptoms, will ultimately aid in optimizing quality of life for PD patients and further increase our understanding of the complex PD spectrum. 



\section{Nederlandse Samenvatting}


De ziekte van Parkinson is, na de ziekte van Alzheimer, de meest voorkomende neurodegeneratieve aandoening. De ziekte wordt gediagnosticeerd op basis van vier motorische hoofdsymptomen, te weten bradykinesie (traagheid van bewegen), rigiditeit (stijfheid), rusttremor en houdingsinstabiliteit. Echter, de ziekte van Parkinson kenmerkt zich ook door een verscheidenheid aan niet-motorische klachten, waaronder neuropsychiatrische klachten zoals depressie en angst. Deze neuropsychiatrische klachten zijn de meest voorkomende niet-motorische klachten en aanwezig bij 67\% van de patiënten. Ze hebben een grote invloed op de kwaliteit van leven van de patiënt en dragen onder andere bij aan de ernst van de motorische symptomen, motorische complicaties, loopproblemen, cognitieve problemen en zelfs tot een hogere mortaliteit. In dit proefschrift worden conceptuele en klinische aspecten van angst en depressie bij de ziekte van Parkinson onderzocht en beschreven. Daarnaast wordt een nieuwe methode onderzocht die gebruikt kan worden om motorische en niet-motorische klachten beter in kaart te brengen.

In Hoofdstuk 1 wordt een algemeen overzicht gegeven over de ziekte van Parkinson met een nadruk op de niet-motorische symptomen angst en depressie.

In Hoofdstuk 2 worden de bevindingen van een systematisch literatuuroverzicht over de prevalentie van angst en angststoornissen bij de ziekte van Parkinson weergegeven. Gebaseerd op de DSM-criteria was de gemiddelde puntprevalentie van angststoornissen bij patiënten met de ziekte van Parkinson 31\%. Het meest frequent was de gegeneraliseerde angststoornis die bij $14 \%$ van de patiënten aanwezig was, gevolgd door de sociale fobie (13.8\%), de angststoornis niet-anderszins-omschreven (13.3\%) en de specifieke fobie (13.0\%). Eenendertig procent van de patiënten voldeed aan de criteria voor multipele angststoornissen. Wanneer er gekeken werd naar scores op angstschalen, bleek dat $25.7 \%$ van de patiënten klinisch significante angstklachten hadden. Dit overzicht bevestigt dat angst, alhoewel vaak niet herkend, veel voorkomend is bij de ziekte van Parkinson en het benadrukt het belang van adequate herkenning.

In Hoofdstuk 3 onderzochten we middels structural equation modeling (SEM), een statistische methode waarmee verbanden tussen variabelen in een bepaald netwerk worden onderzocht, de invloed van PD-specifieke factoren (zoals de ernst van de motorische symptomen of motorische complicaties) en niet-specifieke factoren (zoals vrouwelijk geslacht of een angststoornis in de voorgeschiedenis) op angstklachten. We vonden dat de aanwezigheid van motorische fluctuaties en de ziekte gerelateerde beperkingen in het dagelijks functioneren PD-specifieke markers waren voor het ontwikkelen van angstklachten. Niet-specifieke markers waren een eerder doorgemaakte depressie en de ernst van de huidige depressieve symptomen. De niet-specifieke markers hadden een grotere invloed in het angstmodel dan de PD-specifieke factoren. Daarenboven toonde een post hoc analyse aan dat het effect op angst van de volgende variabelen geheel geme- 
dieerd werd via de depressie variabele: geslacht, depressieve stoornis bij een familielid, een angststoornis in de voorgeschiedenis, cognitief functioneren, niet-ziekte gerelateerde beperkingen in het dagelijks functioneren en de ernst van de motorische klachten. Geconcludeerd kan worden dat depressie de meest belangrijke risicofactor is voor het ontwikkelen van angstklachten. PD-specifieke risicofactoren lijken met name in bepaalde situaties van invloed op de angstklachten, bijvoorbeeld tijdens off-perioden of bij ziekte specifieke beperkingen in het dagelijks functioneren.

In Hoofdstuk 4 onderzochten we de factorstructuur van de Hamilton Depression Rating Scale (HAMD), de meest gebruikte depressieschaal bij patiënten met de ziekte van Parkinson. Bij het onderzoeken van een factorstructuur probeert men voor een groot aantal geobserveerde variabelen (in dit geval de vragen van de HAMD) een kleiner aantal achterliggende variabelen te identificeren met gemeenschappelijke kenmerken (de factoren). Dit zorgt niet alleen voor datareductie maar ook voor meer inzicht in de structuur van de data in een bepaalde populatie. Zo kan er gekeken worden of er bepaalde symptoomdomeinen te identificeren zijn, bijv. een affectief domein waarin alle affectieve symptomen gegroepeerd worden. We verrichtten een principale componentenanalyse over de 17 items van de HAMD bij 341 parkinsonpatiënten en vonden dat de factoriële validiteit onvoldoende was vanwege wisselende items per factorcomponent, een lage inter-item correlatie tussen de componenten en een hoog percentage aan non-redundant residuals en een lage communaliteit. Onze analyse toont aan dat de HAMD niet geschikt is voor het onderzoeken van specifieke symptoomdomeinen van depressie bij de ziekte van Parkinson.

Er is weinig bekend over symptoom specifieke effecten van antidepressiva bij depressieve parkinsonpatiënten, alsmede de timing van het behandelingseffect. In Hoofdstuk 5 onderzochten we de effecten van de antidepressiva venlafaxine en paroxetine op de affectieve, somatische en cognitieve symptoomdomeinen van depressie. We concludeerden dat symptomen in alle domeinen verbeterden gedurende de 12 weken durende studieperiode, echter er was een significant placebo-effect gedurende de eerste twee weken. Vergeleken met de placebogroep, verbeterde de affectieve symptomen significant vanaf week 4, gevolgd door de somatische symptomen van depressie in week 6 en de cognitieve symptomen in week 8 . Onze bevindingen kunnen helpen bij het counselen van parkinsonpatiënten tijdens de start van behandeling met een antidepressivum. Uitleg over de verwachte respons verhoogt de compliantie. Daarnaast onderstreept deze studie het belang van een voldoende lange studieperiode gezien het substantiële placebo-effect.

In Hoofdstuk $\mathbf{6}$ onderzochten we de geschiktheid van een nieuwe methode om de complexe relatie tussen motorische symptomen, affectieve symptomen en contextuele factoren bij de ziekte van Parkinson te ontrafelen. Bij deze methode, de Experience Sampling 
Method (ESM), wordt via een mobiele applicatie de ernst van de motorische symptomen, affectieve symptomen en aan- of afwezigheid van contextuele factoren frequent en willekeurig gedurende de dag gescoord, tijdens de dagelijkse bezigheden van de patienten. Er werd een hoge compliantie (84\%) gehaald en de deelnemers scoorden bij de gebruiksvriendelijkheid van de applicatie een 8 op een schaal van 10. Door de multipele meetpunten per dag was het mogelijk om fluctuaties gedurende de dag te monitoren, iets wat niet mogelijk is bij de huidige dagelijkse meetmomenten. Daarnaast lukte het om klinisch relevante associaties tussen motorische symptomen, emotionele fluctuaties en contextuele factoren te detecteren op een intra-individueel niveau. Concluderend vonden we dat de ESM methode een geschikte methode lijkt om in de toekomst de complexe relatie tussen motorische symptomen, affectieve symptomen en contextuele factoren te ontrafelen op een individueel niveau.

In Hoofdstuk 7 worden de belangrijkste bevindingen van dit proefschrift bediscussieerd. Het eerste gedeelte gaat dieper in op de methodologische aspecten van dit proefschrift, het tweede gedeelte bevat een beschouwing over de implicatie van onze bevindingen op het concept en de classificatie van angst en depressie bij de ziekte van Parkinson. Het huidige classificatiesysteem van angststoornissen bij de ziekte van Parkinson, gebaseerd op DSM criteria, is ontoereikend. Een nieuw concept dat rekening houdt met de verschillende klinische fenotypes, zoals bijvoorbeeld een "angst- en depressie" subtype lijkt geïndiceerd. Behandelingen en toekomstige onderzoeken zouden zich moeten richten op zowel motorische als niet-motorische subtypes. Dit leidt tot een meer geïndividualiseerde aanpak en hopelijk tot een verbetering van de kwaliteit van leven van parkinsonpatiënten. 



\section{Knowledge Valorisation}


'Valorisation is the process of creating value from knowledge, by making this knowledge available and suitable for economic and social exploitation and to translate this knowledge into products, services, processes and new business.' (1). With other words, it is a way in which one can express the importance of research by translating it into social, economic and financial value.

\section{Economic and financial valorisation of this thesis}

According to the Dutch Ministry of Health, Wellbeing and Sports, approximately 29000 patients suffered from parkinsonism, mostly Parkinson's disease, in 2011 (2). This was based on registration by general practitioners, but it is estimated that the true prevalence is 2-2.5 times higher (3). In the next decades the median age of the population will rise, the number of PD patients will further increase and as such its burden on health care services and costs (2). In the Netherlands, health care costs in 2011 for patients with parkinsonism was estimated to be 267 million euro. This encompasses $0.3 \%$ of Dutch total health care costs and $5.1 \%$ of health care costs related to diseases of the central nervous system (4). The progressive and long-term nature of PD puts a substantial financial burden on patients, spouses and healthcare providers. Next to direct costs such as drug costs, in- and outpatients care costs and ancillary treatment, indirect costs also impacts financial burden (5). The latter includes costs due to lost productivity and early retirement. In general, disease severity, motor impairment and motor complications appear to have a higher impact on illness costs than non-motor symptoms (NMS) (6). However, impairment of patients' quality of life (QoL) leads to elevation of both direct and indirect costs (7). This thesis aids in our understanding of both anxiety and depression, which are both known to have a high impact on QoL of PD patients (8, 9). It may be expected that by increasing awareness and recognition with subsequently proper treatment, total healthcare costs will eventually decrease.

\section{Social valorization of this thesis}

Health related quality of life (HRQoL) is "the perception and evaluation by patients themselves of the impact caused on their life by the disease and its consequences", and is crucial in defining his/her wellbeing (10). It is well known that PD has a high impact on quality of life (11). HRQoL is not only affected by motor symptoms, but there is increasing evidence that the occurrence of various non-motor symptoms (NMS) also play an important role in HRQoL perception of PD patients $(12,13)$. In addition, a recent study showed that despite having progressive motor impairment, non-motor symptoms provided a better prediction of the change of HRQoL over time than motor symptoms (14). Among the NMS with the highest impact on HRQoL are depression, anxiety, urinary disturbances, pain, fatigue and sleep problems (15-17). Especially depression is one of the most significant determinants of HRQoL, although some found that anxiety is even more so $(8,9)$. Next to the effect of anxiety and depression on the 
patient themselves, it also has a high impact on caregivers. They experience distress and problems on physical, mental and socioeconomic aspects of their lives (18). For example, a PD patients' depression seems to be strongly correlated with the presence of depressive symptoms in the caregiver (19). Emotional strain of caregivers even contributes to mortality (20) and in PD it leads to higher patient institutionalization with subsequently higher health care costs (21). Especially neuropsychiatric symptoms, such as anxiety and depression, are identified as predictors of caregiver burden (18, 22-24). Increasing the awareness of the high prevalence of anxiety in PD (Chapter 2) and trying to identify markers (Chapter 3) hopefully lead to earlier treatment. In addition, incorporating new diagnostic and monitoring tools (Chapter 6), improving rating scales of depression (Chapter 4) and informing depressed PD patients about the expected treatment response (Chapter 5) will likely improve identification and treatment compliance. Improved recognition, reporting and management of anxiety and depression positively affect the HRQoL of patients with PD and their caregivers.

\section{Products and processes}

The application we studied in chapter 6, the Experience Sampling Method seems to be a viable and useful method to study influences of motor symptoms, affective states and contextual factors in PD patients. The ESM software is freeware and can be downloaded for free as an app on smartphones or iPods. By implementing this method in daily practice, it enables the recognition of highly individual patters and aids in unraveling intra-individual relations between motor and non-motor symptoms. These person-specific patters may be fed back to the subject to enhance insight into factors associated with symptom severity and even more importantly facilitate self-management. Behavioral insight may enhance feelings of mastery over the symptoms and facilitate coping or adjustment of activities. Second, ESM can be used to monitor the treatment progress and drug side effects, revealing relatively small treatment effects by avoiding clouding due to recall bias when using retrospective self-report measures. Last, ESM captures subjective experiences of PD patients, which can differ from more objective tools like the UPDRS scale. However, self-reports may be a more useful source of data when dealing with immediate experiences such as affective states. In addition, combining ESM with an accelerometer will give both objective and subjective measures, providing an extensive overview of symptom patterns on an individual base. As mentioned in the discussion (Chapter 7), this is needed for optimizing treatment strategies in a heterogeneous illness such as PD.

\section{Conclusion}

This thesis can help neurologists, psychiatrists, psychologists, general practitioners and PD patients and their spouses in their understanding of anxiety and depression in PD. Highlighting the high prevalence of anxiety in PD hopefully increase its awareness. The 
markers identified in our model can aid in recognizing anxiety and specialists should search for clinically relevant anxiety in depressed PD patients. With testing depression rating scales and studying treatment responses in depressed PD patients we hopefully help to optimize recognition and treatment compliance. Treatment strategies must focus on individual patients and ESM seem to be a feasible tool to monitor and study PD symptoms and treatment responses. When this is accomplished, HRQoL of PD patients and their spouses will increase and health related costs will likely decline. 


\section{REFERENCES}

1. Maastricht University. Maastricht Valorisation Center [cited 2016 March 25th]. Available from: http://www.maastrichtuniversity.nl/web/Main/AboutUM/OurProfile/MVC.htm.

2. Post B, Poos MJJC. Hoe vaak komt de ziekte van Parkinson voor, hoeveel mensen sterven eraan en neemt dit toe of af? Bilthoven: RIVM; 2013. Available from: http://www. nationaalkompas.nl/gezondheid-en-ziekte/ziekten-en-aandoeningen/zenuwstelsel-en-zintuigen/ziekte-van-parkinson/omvang/.

3. Maas IAM, Gijsen R, Lobbezoo IE, Poos MJJC. Volksgezondheid Toekomst Verkenning 1997. I De gezondheidstoestand: een actualisering. Maarssen: Elsevier/De Tijdstroom; 1997.

4. Poos MJJC, Bijenhof AM, Slobbe LCJ. Ziekte van Parkinson: Hoeveel zorg gebruiken patiënten en wat zijn de kosten? In: Volksgezondheid Toekomst Verkenning, Nationaal Kompas Volksgezondheid. Bilthoven: RIVM; 2014 [cited 2016 March 25th]. Available from: http://www.nationaalkompas.nl/gezondheid-en-ziekte/ziekten-en-aandoeningen/zenuwstelsel-en-zintuigen/ziekte-van-parkinson/zorgkosten/.

5. Spottke AE, Reuter M, Machat O, Bornschein B, von Campenhausen S, Berger K, et al. Cost of illness and its predictors for Parkinson's disease in Germany. Pharmacoeconomics. 2005;23(8):817-36.

6. Cubo E, Martinez Martin P, Gonzalez M, Frades B, miembros del grupo E. [Impact of motor and non-motor symptoms on the direct costs of Parkinson's disease]. Neurologia. 2009;24(1):15-23.
7. Martinez-Martin P, Rodriguez-Blazquez C, Paz S, Forjaz MJ, Frades-Payo B, Cubo E, et al. Parkinson Symptoms and Health Related Quality of Life as Predictors of Costs: A Longitudinal Observational Study with Linear Mixed Model Analysis. PLoS One. 2015;10(12):e0145310.

8. Quelhas R, Costa M. Anxiety, depression, and quality of life in Parkinson's disease. J Neuropsychiatry Clin Neurosci. 2009;21(4):413-9.

9. Yamanishi T, Tachibana $H$, Oguru $M$, Matsui K, Toda K, Okuda B, et al. Anxiety and depression in patients with Parkinson's disease. Intern Med. 2013;52(5):539-45.

10. Martinez-Martin P. An introduction to the concept of "quality of life in Parkinson's disease". J Neurol. 1998;245 Suppl 1:S2-6.

11. Muslimovic D, Post B, Speelman JD, Schmand B, de Haan RJ, Group CS. Determinants of disability and quality of life in mild to moderate Parkinson disease. Neurology. 2008;70(23):2241-7.

12. Barone P, Antonini A, Colosimo C, Marconi R, Morgante L, Avarello TP, et al. The PRIAMO study: A multicenter assessment of nonmotor symptoms and their impact on quality of life in Parkinson's disease. Mov Disord. 2009;24(11):1641-9.

13. Santos-Garcia D, de la Fuente-Fernandez R. Impact of non-motor symptoms on health-related and perceived quality of life in Parkinson's disease. J Neurol Sci. 2013;332(1-2):136-40.

14. Prakash KM, Nadkarni NV, Lye WK, Yong $\mathrm{MH}$, Tan EK. The impact of non-motor symptoms on the quality of life of Parkinson's disease patients: a longitudinal study. 
Eur J Neurol. 2016.

15. Carod-Artal FJ, Vargas AP, Martinez-Martin P. Determinants of quality of life in Brazilian patients with Parkinson's disease. Mov Disord. 2007;22(10):1408-15.

16. Gallagher DA, Lees AJ, Schrag A. What are the most important nonmotor symptoms in patients with Parkinson's disease and are we missing them? Mov Disord. 2010;25(15):2493-500.

17. Martinez-Martin P, Rodriguez-Blazquez C, Kurtis MM, Chaudhuri KR, Group NV. The impact of non-motor symptoms on health-related quality of life of patients with Parkinson's disease. Mov Disord. 2011;26(3):399-406.

18. Martinez-Martin P, Benito-Leon J, Alonso F, Catalan MJ, Pondal M, Zamarbide I, et al. Quality of life of caregivers in Parkinson's disease. Qual Life Res. 2005;14(2):463-72.

19. Meara J, Mitchelmore E, Hobson P. Use of the GDS-15 geriatric depression scale as a screening instrument for depressive symptomatology in patients with Parkinson's disease and their carers in the community. Age Ageing. 1999;28(1):35-8.

20. Schulz R, Beach SR. Caregiving as a risk factor for mortality: the Caregiver Health Effects Study. JAMA. 1999;282(23):22159 .

21. Abendroth M, Lutz BJ, Young ME. Family caregivers' decision process to institutionalize persons with Parkinson's disease: a grounded theory study. Int J Nurs Stud. 2012;49(4):445-54.

22. D'Amelio M, Terruso V, Palmeri B, Di Benedetto N, Famoso G, Cottone P, et al. Predictors of caregiver burden in partners of patients with Parkinson's disease. Neurol Sci. 2009;30(2):171-4.

23. Martinez-Martin P, Rodriguez-Blazquez
C, Forjaz MJ. Quality of life and burden in caregivers for patients with Parkinson's disease: concepts, assessment and related factors. Expert Rev Pharmacoecon Outcomes Res. 2012;12(2):221-30.

24. Schrag A, Hovris A, Morley D, Quinn N, Jahanshahi M. Caregiver-burden in parkinson's disease is closely associated with psychiatric symptoms, falls, and disability. Parkinsonism Relat Disord. 2006;12(1):3541. 



\section{Additional Files}




\section{LIST OF PUBLICATIONS}

Broen MPG, Narayen NE, Kuijf ML, Dissanayaka NNW, Leentjens AFG. Prevalence of anxiety in Parkinson's disease: a systematic review and meta-analysis. Mov Disord. 2016 Aug;31(8):1125-33.

Broen MP, Marsman VA, Kuijf ML, Van Oostenbrugge RJ, van Os J, Leentjens AF. Unraveling the Relationship between Motor Symptoms, Affective States and Contextual Factors in Parkinson's Disease: A Feasibility Study of the Experience Sampling Method. PLoS One. 2016 Mar 10;11(3):e0151195.

Broen MPG, Leentjens AFG, Köhler S, Kuijf ML, McDonald WM, Richard IH. Trajectories of recovery in depressed Parkinson's disease patients treated with paroxetine or venlafaxine. Parkinsonism Relat Disord. 2016 Feb;23:80-5.

Broen MP, Köhler S, Moonen AJ, Kuijf ML, Dujardin K, Marsh L, Richard IH, Starkstein SE, Martinez-Martin P, Leentjens AF. Modeling anxiety in Parkinson's disease. Mov Disord. 2016 Mar;31(3):310-6.

Broen MPG, Moonen AJH, Kuijf ML, Dujardin K, Marsh L, Richard IH, Starkstein SE, Martinez-Martin P, Leentjens AFG. Factor analysis of the Hamilton Depression Rating Scale in Parkinson's disease. Parkinsonism Relat Disord. 2015 Feb;21(2):142-6.

Broen MPG, Kuiper M, Weijs B, Lenderink T, Schreuder A. Neurologische complicaties van Staphylococcus Aureus endocarditis. Tijdschr Neurol Neurochir 2015 Dec;116(4):180-6.

Broen M, Schreuder A. A frog in the throat (NeuroImage). Neurology. 2015 Jan 27;84(4):433.

Broen MPG, Draak T, Riedl RG, Weber WE. Diffuse large B-cell lymphoma of the cauda equina. BMJ Case Rep. 2014 Nov 3;2014.

Broen M, Haeren R, Hoff E, Temel Y, Schijns O. Hemiballism-hemidystonia after parietal lobe tumour resection. Clin Neurol Neurosurg. 2014 Oct;125:148-50.

Gerlach OH, Broen MP, Weber WE. Motor outcomes during hospitalization in Parkinson's disease patients: a prospective study. Parkinsonism Relat Disord. 2013 Aug;19(8):737-41. 
Gerlach OH, Broen MP, van Domburg PH, Vermeij AJ, Weber WE. Deterioration of Parkinson's disease during hospitalization: survey of 684 patients. BMC Neurol. 2012 Mar 8;12:13.

Broen MP, Braaksma MM, Patijn J, Weber WE. Prevalence of pain in Parkinson's disease: a systematic review using the modified QUADAS tool. Mov Disord. 2012;27:4804 .

Broen MPG, Duits A, Visser-Vandewalle V, Temel Y, Winogrodzka A. Impulse control and related disorders in Parkinson's disease patients treated with bilateral subthalamic nucleus stimulation: a review. Parkinsonism Relat Disord. 2011;17: 413-417. 


\section{DANKWOORD/ ACKNOWLEDGMENTS}

Een proefschrift kan niet tot een goed einde worden gebracht zonder de hulp en steun van patiënten, collega's, vrienden en dierbaren. Oprechte dank aan iedereen die heeft bijgedragen aan de totstandkoming van dit proefschrift. Enkele personen wil ik echter in het bijzonder bedanken.

Geachte professor van Oostenbrugge, beste Robert. Hartelijk bedankt voor het vertrouwen en je ondersteuning gedurende het doorlopen van dit promotietraject én mijn opleiding. Het is bijzonder om te zien hoe jouw overzicht en visie er uiteindelijk voor zorgen dat alles op zijn plaats valt. Je stimuleert mensen om zich te blijven ontwikkelen en geeft tevens voldoende vrijheid om nieuwe vaardigheden te ontplooien. Hiervoor ben ik je zeer dankbaar.

Geachte Dr. Leentjens, beste Albert. Jouw inspiratie en wetenschappelijke kennis zijn bewonderingswaardig. Je bent de drijvende kracht geweest achter dit project. Ik kan mij de eerste keer dat we samen zaten nog goed herinneren. Je zat vol met goede vraagstukken en overviel mij met de mogelijkheden. $\mathrm{Nu}$, enkele jaren later kijk ik terug op een zeer prettige samenwerking, waarbij ik heel veel van je heb geleerd. Hopelijk kunnen we onze samenwerking in de toekomst voortzetten.

Geachte Dr. Kuijf, beste Mark. Ik ben blij dat jij mijn copromotor bent. Tijdens onze tweemaandelijkse gesprekken over mijn thesis kwam niet alleen mijn voortgang ter sprake, maar ook allerlei andere vraagstukken. Zo gaf je mij adviezen over mijn toekomstplannen, nam je me mee tijdens internationale congressen en leerde je mij de beginselen van de botuline behandeling. De wijze waarop jij wetenschappelijk onderzoek met kliniek combineert is een voorbeeld voor mij.

Ik wil de beoordelingscommissie bestaande uit Prof. Dr. F. Verhey, Prof. Dr. H. Berendse, Dr. P. van Domburg, Prof. Dr. F. Peeters en Dr. M. Vugt hartelijk danken voor hun tijd en kritische beoordeling van mijn thesis.

Geachte Drs. Oosterloo, beste Mayke. Een speciaal woord van dank voor jou is hier zeker op zijn plaats. Als mijn mentor heb je mij op een voortreffelijke manier door mijn opleiding en promotietraject geloodst. Op momenten dat het nodig was kon ik altijd bij je terecht en gaf je de juiste adviezen. Hartelijk dank daarvoor.

Tom en Jasper, ik vind het een eer dat ik met jullie aan mijn zijde dit proefschrift mag verdedigen. Jasper, je bent altijd een voorbeeld voor mij geweest, behoudens op sportief gebied. Door je kennis en gedrevenheid gaat je carrière als een speer. Ik hoop dat we ech- 
ter nog vaak de tijd vinden om te relativeren onder het genot van een (speciaal) biertje! Tom, ik herinner mij nog goed de eerste maanden samen in opleiding bij de neurologie op C5 links en rechts. Je bent een top arts, met bovendien veel humor, maar op zijn tijd ook een luisterend oor. Ik ben trots dat je vandaag naast me staat.

Assistenten van de neurologie Maastricht, jullie zijn een fantastische groep. Door jullie enthousiasme, maar zeker ook de nodige humor is er zowel tijdens als na werktijd een goede sfeer. Op de momenten dat het nodig is, zijn jullie er voor elkaar. Speciaal wil ik nog twee mensen uitlichten; Mark en Caroline. Dr. Janssen, beste Mark, naast dat je mij hier en daar wegwijs gemaakt hebt in het wetenschappelijk onderzoek hebben we al menig hotelkamer gedeeld tijdens congressen en cursussen. Zowel op werk- als op privé gebied kan ik altijd bij je terecht. Ik had je graag naast mij gehad vandaag, maar je weet: “je moet kiezen..". Caroline, samen begonnen aan de opleiding en samen een jaar lang op één kamer bij de KNF. Jouw aanstekelijk enthousiasme (stuiterbal) zorgde ervoor dat geen dag saai was, dank voor de leuke tijd. Charlotte, Kim en Martine dank voor alle leuke jaarcursussen, babyborrels en gewone borrels. We zullen voor altijd de "jonkies 2012" blijven. Verona, na 6 jaar geneeskunde komen we ons nu vaak tegen op de IC. Daarnaast kan ik voor lekker eten ook altijd bij jullie terecht. Ik hoop dat je humor er nog lang voor zorgt dat werkelijk alles te relativeren is. Dank.

Mijn vrienden van Linne en omstreken. Ik kan jullie niet genoeg bedanken voor de vele dagen, avonden en nachten die zorgden voor de nodige ontspanning en relativering. Door voldoende afleiding presteert men beter zeggen ze, dus ik hoop dat we ons de komende jaren nog heel vaak gaan zien!

Ik wil alle neurologen van het MUMC+ en Zuyderland Heerlen bedanken voor hun steun en bereidwilligheid tijdens mijn opleiding tot neuroloog. Tevens wil ik alle medeauteurs bedanken voor hun kritische beoordeling en de prettige samenwerking.

Michelle, soms lopen dingen niet zoals je verwacht. Ik ben je dankbaar voor alle steun, afleiding en begrip. Ik weet zeker dat je een mooie toekomst tegemoet gaat.

Beste Esther, Maarten en Inge dank voor de vele momenten van ontspanning maar ook voor de ondersteuning tijdens het volbrengen van mijn thesis. Ik kan altijd bij jullie aankloppen en dat waardeer ik zeer. Lieve ouders, zonder jullie wijze lessen en steun was ik nooit zover gekomen. Jullie hebben altijd de vrijheid gelaten om mijzelf te ontwikkelen en zo nodig hebben jullie mij ondersteund of aangestuurd. Op de momenten dat het nodig was kon ik altijd op jullie rekenen, jullie hebben geen idee hoe fijn ik dat vond. 
Ik hoop dat we nog vaak samenzijn op de manier hoe moeder het zou omschrijven: "full house".

Ook al staan we nog in het begin, het voelt heel goed. Dank voor alle ontspannende en leuke momenten, ik hoop dat er nog veel mogen volgen.. 


\section{CURRICULUM VITAE}

Martinus Petrus Gertrudis Broen was born on the 15th of April 1987 in Linne, The Netherlands. He graduated for secondary school, VWO, at the Stedelijk Lyceum Roermond in 2005. In the same year he started his medical training at the Faculty of Health, Medicine and Life Sciences at the Maastricht University. In 2009 he received the "Top $3 \%$ Award", a prize for the top 3\% students of Maastricht University. In 2011 he received his medical doctor degree and in January 2012 he started his specialist training in Neurology at the Maastricht University Medical Centre under the supervision of Prof. Dr. R. J. Van Oostenbrugge. He is currently in his fifth year of training. In 2014 he started his $\mathrm{PhD}$ investigating anxiety and depression in Parkinson's disease at the departments of Neurology and Psychiatry of the Maastricht University Medical Centre under the supervision of Dr. A.F.G. Leentjens, Dr. M.L. Kuijf and Prof. Dr. R. J. Van Oostenbrugge.

Martinus Petrus Gertrudis Broen werd op 15 april 1987 geboren te Linne (Nederland). In 2005 slaagde hij voor zijn VWO-diploma aan het Stedelijk Lyceum te Roermond. In datzelfde jaar startte hij met de studie geneeskunde aan de Faculty of Health, Medicine and Life Sciences van de Universiteit Maastricht. In 2009 ontving hij de "Top 3\% Award", een prijs voor de beste $3 \%$ studenten van de Universiteit van Maastricht. In 2011 behaalde hij zijn artsdiploma en in januari 2012 startte hij met de opleiding tot neuroloog aan het Maastricht Universitair Medisch Centrum (opleider: Prof. Dr. R. J. Van Oostenbrugge). Momenteel bevindt hij zich in het $5^{\mathrm{e}}$ jaar van zijn opleiding tot neuroloog. In 2014 begon hij aan de afdeling neurologie en afdeling psychiatrie van het Maastricht Universitair Medisch Centrum aan zijn promotieonderzoek naar angst en depressie bij de ziekte van Parkinson o.l.v. Dr. A.F.G. Leentjens, Dr. M.L. Kuijf en Prof. Dr. R. J. van Oostenbrugge. 
